\title{
LIGAÇÃO LAGOA-MAR, UMA NECESSIDADE
}

\author{
Paulo Cesar Colonna Rosman ${ }^{1}$ \\ ${ }^{1}$ Universidade Federal do Rio de Janeiro: COPPE/PENO - Área de Engenharia Costeira \& Oceanográfica \& Escola Politécnica - Departamento de \\ Recursos Hídricos e Meio Ambiente / Centro de Tecnologia-UFRJ - Ilha do Fundão, RJ. \\ E-mail: pccrosman@ufrj.br
}

\section{RESUMO}

O artigo apresenta uma discussão sobre a necessidade uma ligação hidráulica permanente da lagoa Rodrigo de Freitas com o mar. Também justifica a conveniência de mobilizar sedimentos na lagoa, recuperando espaços aquáticos perdidos por assoreamentos marginais e enchendo cavas anaeróbicas geradas por dragagens mal planejadas. Analisam-se quantitativamente os efeitos de se efetuar uma ligação permanente lagoa-mar através de dutos afogados. Simulações com modelos sugerem que tal ligação propiciará as condições ideais para melhorar qualidade de água da lagoa, bem com para aumentar as trocas de massas de águas e nutrientes com o mar. Os modelos mostram que os dutos afogados teriam capacidade de escoar águas de chuvas torrenciais sem inundações marginais, acabando com o continuado processo de assoreamento no Canal do Jardim de Alah e restaurando as características de sistema estuarino, com gradientes horizontais e verticais de salinidade.

Palavras-chave: lagoas costeiras; hidrodinâmica ambiental; modelagem de circulação hidrodinâmica; estabilidade de canais de maré.

\begin{abstract}
LAGOON-SEA CONNECTION, A NECESSITY. The article presents a discussion concerning the need of a permanent hydraulic connection between Rodrigo de Freitas Lagoon and the sea. It also justifies the convenience of sediment relocation within the lagoon, reclaiming aquatic spaces lost to near shore shoaling and filling anoxic potholes caused by badly planned dredging operations. It presents a quantitative assessment on the effects of a permanent lagoon-sea connection through drowned ducts. One sees that such a connection would provide the necessary conditions for good water quality in the lagoon, with proper renewal ratios of water and nutrients, in addition to ample biological exchanges with the sea. The system would have the capacity to discharge the outflow of torrential rains without overspills of marginal areas, stop the continuing shoaling processes within Jardim de Alah Canal and restore estuarine conditions to the lagoon, with horizontal and vertical saline gradients, favoring an ample biodiversity, typical of healthy estuarine systems.
\end{abstract}

Keywords: coastal lagoons; environmental hydrodynamics; hydrodynamic circulation modeling; water quality modeling; stability of tidal inlets.

\section{RESUMEN}

CONEXIÓN LAGUNA-MAR, UNA NECESIDAD. El artículo presenta una discusión sobre la necesidad de una conexión hidráulica permanente de la laguna Rodrigo de Freitas con el mar. También justifica la conveniencia de movilizar sedimentos en la laguna, recuperando espacios acuáticos perdidos por colmataciones marginales y llenando espacios anaeróbicos generados por dragados mal planeados. Se analizan cuantitativamente los efectos de efectuar una conexión permanente laguna-mar a través de ductos sumergidos. Simulaciones con modelos sugieren que tal conexión propiciaría las condiciones ideales para mejorar la calidad de agua de la laguna, y para aumentar los intercambios de masas de agua y nutrientes con el mar. Los modelos mostraron que los ductos tendrían capacidad de drenar aguas de lluvias torrenciales sin inundaciones 
marginales, acabando con el proceso continuo de colmatación en el Canal del Jardín de Alá y restaurando las características de un sistema estuarino, con gradientes horizontales y verticales de salinidad.

Palabras clave: lagunas costeras; hidrodinámica ambiental; modelamiento de circulación hidrodinámica; estabilidad de canales de marea.

\section{INTRODUÇÃO}

Este artigo tem um caráter técnico de avaliações de engenharia, por isso apresenta muitos dados e números, possibilitando ao leitor uma ideia quantitativa do que se pode esperar de uma ligação permanente entre a lagoa e o mar. Discute-se também, com enfoque quantitativo, a necessidade de remanejar sedimentos na lagoa para recuperação de espaços aquáticos perdidos por assoreamentos e preenchimento de cavas criadas por dragagens realizadas principalmente nos anos 70, para realização de aterros marginais. Texto e figuras deste artigo foram adaptados de Ros$\operatorname{man}(2009)$.

A proposição de uma ligação permanente entre a Lagoa Rodrigo de Freitas, LRF, e o mar objetiva sanar de modo definitivo quatro problemas:

1. Má qualidade de água em função dos excessivos estoques de nutrientes na LRF, que se acumulam pelo fato do sistema atual não exportar em taxas suficientes os nutrientes que recebe.

2. Alagamentos marginais decorrentes de obstruções do canal do Jardim de Alah em épocas de fortes chuvas.

3. Contínuo processo de assoreamento do Canal do Jardim de Alah, que acarreta em altos custos de manutenção de sua capacidade de extravasamento para garantia da macrodrenagem da bacia da LRF.

4. Perda das características estuarinas em função da estagnação e uniformização das águas da LRF, acarretando em biodiversidade reduzida e má qualidade ambiental.

Neste artigo, são apresentadas análises de hidrodinâmica ambiental para ligação da lagoa Rodrigo de Freitas ao mar através de dutos afogados. Os seguintes assuntos são discutidos em mais detalhes:

- Necessidade da ligação permanente entre a LRF e o mar.

- Caracterização hidrodinâmica da LRF antes e depois da ligação.
- Renovação das águas da LRF e salinidades esperadas.

- Necessidade de dragagem para recuperar espaços aquáticos perdidos por assoreamentos na faixa costeira e para encher cavas existentes na LRF, que funcionam como digestores anaeróbicos.

- Comparação entre opções de ligação por dutos afogados e de ligação por guia-correntes.

\section{SOBRE A NECESSIDADE DA LIGAÇÃO LAGOA-MAR}

Há quem pergunte se não seria suficiente apenas uma boa gestão ambiental da LRF, impedindo qualquer aporte de esgotos, para que os problemas de qualidade de água fossem sanados pela própria natureza. Infelizmente, a resposta é "não". As explicações sobre porque "não" poderiam se estender por páginas, o que segue é uma síntese da principal razão e justificativas adicionais.

Impedir o aporte de esgotos deve ser sempre buscado. Porém, ao se analisar os objetivos da ligação permanente proposta, fica evidente que impedir o aporte de esgotos na Lagoa Rodrigo de Freitas ajudaria a resolver apenas o primeiro dos problemas listados. Mesmo assim, como explicado a seguir com base no princípio da conservação, a ajuda pelo corte do aporte de esgotos seria insuficiente para que as águas da lagoa recuperassem a qualidade necessária para estar em boas condições sanitárias, visto que o estoque de nutrientes no sistema é muito grande e o ambiente continuaria apresentando características impactadas por décadas. Para esclarecer este ponto, convém lembrar o básico conceito de balanço de quantidade de uma propriedade, ex. quantidade de movimento, massa ou energia, em um volume de controle, que exprime o princípio da conservação em um sistema aberto:

"A taxa temporal de variação do estoque de uma propriedade em um volume de controle é igual à taxa de depósitos vindos de fora, menos a taxa de saques para fora, mais a taxa resultante dos processos de 
produção e consumo da propriedade no interior do volume." 1

Pelo princípio da conservação, se há estoque excessivo de nutrientes em um dado volume de controle, no nosso caso a Lagoa Rodrigo de Freitas, a única maneira de diminuí-lo é fazer com que o valor \{saques + consumo interno $\}$ seja maior que o valor \{depósitos + produção interna $\}$. Basicamente, os processos internos de produção e consumo se equilibram e, por isso, mais reciclam do que alteram o estoque existente. Por exemplo, no ciclo da vida ocorre consumo de nutrientes disponíveis na água quando há nascimento e crescimento de biomassa. Porém, a quase totalidade dos nutrientes consumidos é devolvida para a massa de água via excreção, morte e decomposição da biomassa. Portanto, considerando que os processos internos de produção e consumo mais reciclam que alteram o estoque de nutrientes, torna-se evidente que para reduzir o estoque de nutrientes, a taxa de saques tem que ser maior que a taxa de depósitos.

Em um corpo de água, níveis de nutrientes muito elevados não representam boas condições ambientais. Corpos de água com excesso de nutrientes são denominados eutrofizados e, dependendo da magnitude do excesso, chegam a estados hipertróficos. A LRF atual sofre um contínuo processo de eutrofização e pode-se dizer que apresenta aspectos de hipertrofia. Consequentemente, reduzir os estoques de nutrientes na LRF, levando-os a um patamar de equilíbrio muito abaixo do vigente, é indispensável para obtenção de um corpo de água ambientalmente mais equilibrado. Em outras palavras, a meta é promover condições para que a LRF deixe de ser hipertrófica e passe a ser meso ou oligotrófica. A questão então passa a ser: como atingir tal meta?

Um engano comum, cometido por algumas pessoas interessadas em questões ambientais, está em supor que os depósitos de origem antrópica sejam a principal causa dos problemas de qualidade de água em sistemas naturais muito eutrofizados, como lagoas e baías do Rio de Janeiro, e que tudo se resolva apenas minimizando os depósitos antrópicos. Tal suposição advém da não observância do princípio da conservação. Se há estoque excessivo, caso não haja saques suficientes, o fato de se minimizar os depósi-

${ }^{1} \mathrm{O}$ conceito aqui é expresso de modo textual para facilitar o entendimento de leitores não especializados. Para uma formulação matemática formal veja Rosman (1997). tos pode apenas diminuir a taxa de crescimento do estoque, sem diminuí-lo efetivamente. Não há como diminuir o estoque se não houver mais saques do que depósitos.

$\mathrm{O}$ modo de se promover condições para que um corpo de água hipertrófico torne-se oligotrófico varia de caso para caso, mas a resposta possível sempre está no princípio da conservação. Repetindo, para se reduzir o estoque de nutrientes, a taxa de saques tem que ser maior que a taxa de depósitos. Vejamos três casos no Rio de Janeiro:

1. Lagoa Rodrigo de Freitas: levando-se em conta obras e melhorias no sistema de drenagem urbana, redes de esgoto e elevatórias, além da construção de cinturão ao redor da lagoa para captura em tempo seco de escoamentos de redes pluviais, que ainda recebem ligações clandestinas de esgotos; além de outras intervenções pontuais desde os anos 70, é possível constatar que o que poderia ser feito para minimizar depósitos de origem antrópica, na prática, já foi feito. Entretanto, os maiores depósitos de nutrientes e cargas orgânicas na lagoa decorrem dos afluxos trazidos por chuvas fortes. Como a LRF é o ponto mais baixo da bacia hidrográfica e, como as águas fluem de partes mais altas para as partes mais baixas ${ }^{2}$, é natural que a LRF receba enormes afluxos carreando toda sorte de substâncias dissolvidas e arrastadas pelas chuvas de maior porte. Como a minimização dos depósitos já foi feita, a única forma de reduzir os estoques de nutrientes é criar mecanismos para aumentar os saques, ou a retirada de nutrientes. A forma de aumentar os saques ou esta retirada será discutida a seguir

2. Baía de Guanabara: o caso da BG é o exato oposto do caso da LRF. Na BG não há como aumentar a taxa de saques de nutrientes. Tais saques são realizados pelos afluxos e efluxos das marés. Não é possível incrementar a renovação de água, pois é inviável aumentar a boca da baía e é impossível aumentar as amplitudes das marés. Como aumentar os saques é impossível, no caso da BG, todas as ações devem estar focadas na minimização dos depósitos - e há muito a se fazer nesta questão.

3. Sistema lagunar de Jacarepaguá: neste caso há muito a se fazer tanto pelo lado da minimização dos

\footnotetext{
${ }^{2}$ A principal força motriz de escoamentos em condições naturais advém de gradientes de pressão. Em um dado sistema hídrico, águas em níveis mais elevados têm maior pressão que águas em níveis mais baixos, assim, a força gerada é oposta ao gradiente de pressão, impulsionando as águas de níveis mais elevados para níveis mais baixos.
} 
depósitos quanto pelo lado do aumento dos saques. Um estudo sobre tal sistema lagunar é apresentado por Moraes (2007).

\section{COMO AUMENTAR OS SAQUES DE NUTRIENTES NA LRF}

O estoque de nutrientes na LRF está dissolvido em suas águas, absorvido na biomassa existente e em depósitos orgânicos em decomposição no fundo. Como usual em corpos de água naturais, a maior parcela dos nutrientes está dissolvida na água e absorvida na biomassa planctônica, fitoplanctônica e zôoplanctônica. Pelo discutido anteriormente, com base no princípio da conservação, a única forma de se viabilizar saques efetivos de nutrientes na LRF está em promover trocas contínuas de água. Para isso, há que haver grandes afluxos de águas oligotróficas e efluxos das águas da LRF em volumes similares. Como os rios afluentes à LRF têm baixas vazões e nem sempre apresentam condições oligotróficas, a única fonte de águas oligotróficas em quantidades necessárias é o mar.

Nos últimos 100 anos, houve muitas propostas de mecanismos de bombeamento de água do mar para a LRF objetivando promover renovação de suas águas. Existem várias resenhas sobre as diversas propostas, inclusive um relatório oficial sobre o assunto emitido por uma comissão mista formada em 1995-1996 por técnicos do Governo do Estado e da Prefeitura do Rio de Janeiro. Tal comissão concluiu que o projeto desenvolvido pela COPPE/UFRJ em 1992, seria o mais adequado. A seguir são mencionadas apenas três das muitas propostas, por estarem diretamente ligadas ao contexto deste capítulo:

1. Propostas apresentadas em 11/1992 no relatório final do estudo intitulado "Solução Conjunta dos Problemas de Erosão na Praia de Ipanema Leblon e Qualidade de Água na Lagoa Rodrigo de Freitas - Relatório Final", desenvolvido na COPPE/ UFRJ, coordenado pelo Prof. Paulo Cesar Colonna Rosman, ref. Fundação Coppetec ET-170172, de 11/1992. Tal estudo recomendou quatro ações:

a. Ligação permanente da LRF com o mar através de canal estável. O canal seria obtido via ampliação do Canal do Jardim de Alah, em largura, profundidade e comprimento, com embocadura protegida por guia-correntes nas duas margens. b. Alteração na embocadura do Canal da Av. Visconde de Albuquerque com construção de guiacorrentes na margem esquerda.

c. Engordamento das praias de Ipanema e Leblon, de modo a restaurar o estoque de areia perdido, estimado em cerca de 1,5 milhões de metros cúbicos.

d. Dragagem dos trechos assoreados nas margens da LRF, com lançamento dos sedimentos em cavas existentes, objetivando recuperar espaços aquáticos perdidos, encher cavas e assegurar que o espelho de água da lagoa conectada ao mar não exporia bancos de sedimentos.

2. Propostas apresentadas em 12/2000 no relatório de conclusão do estudo intitulado "Lagoa Rodrigo de Freitas e Praias de Leblon, Ipanema e Arpoador: Solução Integrada de Reabilitação Ambiental", desenvolvido no LNEC - Laboratório Nacional de Engenharia Civil de Portugal, entre 1998 e 2000, feito para a Prefeitura da Cidade do Rio de Janeiro. As propostas apresentadas por especialistas do LNEC, basicamente, corroboraram e detalharam as propostas feitas no estudo desenvolvido na COPPE/UFRJ em 1992, com três alternativas de dimensionamento de larguras e profundidades para o Canal do Jardim de Alah, a saber:

a. Alternativa 1: canal tal como proposto pela COPPE/UFRJ em 1992;

b. Alternativa 2: manutenção do canal atual, entre o desemboque na lagoa e a seção antes da comporta existente. Desta seção até o desemboque no mar, a Alternativa 2 seria semelhante à Alternativa 1;

c. Alternativa 3: igual à Alternativa 2, mas com aprofundamento do Canal do Jardim de Alah dos atuais $0,70 \mathrm{~m}$ de profundidade média para $2,88 \mathrm{~m}$.

3. Proposta apresentada em 01/2001 no relatório intitulado "Aspectos de uma Alternativa em Dutos Afogados para a Embocadura do Canal do Jardim de Alah", pelo Prof. Paulo Cesar Colonna Rosman, ref. Fundação Coppetec PENO-467. O contrato PENO-467 foi firmado entre a Fundação Coppetec e a Fundação Rio-Águas da Prefeitura do Município do Rio de Janeiro, objetivando fornecer assessoria técnica à Fundação Rio-Águas no contexto de seu contrato com o LNEC, mencionado no item anterior. A proposição de dutos afogados foi feita em contraponto ao fato do LNEC ter apresentado três alternativas de mesma concepção, variando apenas 
as dimensões do canal. Os estudos apresentados neste artigo são diretamente relacionados a tal proposta.

Destaca-se que as três proposições acima são inter-relacionadas, e todas visam, além de melhorias na qualidade de água da LRF, os demais objetivos listados no início do artigo.

\section{USO DE MODELAGEM PARA SUPORTE DAS ANÁLISES}

Os modelos utilizados para suporte às análises discutidas neste capítulo fazem parte do $\mathrm{SisBaHiA}^{\circledR}$

- Sistema Base de Hidrodinâmica Ambiental. Amplos detalhes técnicos sobre o funcionamento do SisBaHiA ${ }^{\circledR}$ podem ser vistos através da Internet no site www.sisbahia.coppe.ufrj.br. Uma vez na página, o leitor interessado ao clicar no item "O que é?", encontra uma descrição geral do sistema, que inclui o subtítulo "Atributos do SisBaHiA ${ }^{\circledR}$ ", onde se discute a confiabilidade geral dos modelos. No mesmo site, clicando no item "Referência Técnica", baixa-se a documentação técnica, com todos os detalhes da formulação matemática e numérica dos modelos do sistema. Descreve-se brevemente como foi desenvolvida a modelagem.

\section{ÁREA MODELADA E DESENVOLVIMENTO DOS MODELOS}

Como mostra a Figura 1, a área modelada cobre todo o espelho de água da Lagoa Rodrigo de Freitas e a zona costeira adjacente. Desta forma são avaliados conjuntamente os efeitos de misturas de água do mar na lagoa e vice-versa. No mapa da figura vê-se a situação projetada, sem a embocadura do canal atual que divide as praias, e o delineamento dos quatros eixos dos dutos afogados que fariam a conexão permanente lagoa-mar.

A Figura 2 mostra detalhes da malha de discretização desenvolvida para modelagem digital da área de interesse. A batimetria vista pelo modelo e as características dos sedimentos de fundo fazem parte dos dados usados pelos modelos.

\section{SOBRE MODELOS DESENVOLVIDOS}

Foram desenvolvidos diversos modelos para análises de circulação hidrodinâmica relacionados a este estudo, três dos quais pertinentes a avaliações de ligação lagoa-mar por dutos afogados: lagoa-mar com 3 dutos de $3,05 \mathrm{~m}$ de diâmetro $\left(21,89 \mathrm{~m}^{2}\right)$; lagoamar com 4 dutos de $2,60 \mathrm{~m}$ de diâmetro $\left(21,24 \mathrm{~m}^{2}\right)$ e lagoa-mar com 9 dutos de $1,60 \mathrm{~m}$ de diâmetro $\left(18,09 \mathrm{~m}^{2}\right)$. Os números entre parêntesis representam a área hidráulica total do feixe de dutos. Os resultados obtidos para os três casos são semelhantes uma vez que as áreas hidráulicas de cada caso têm valores próximos. Por razões construtivas, a opção mais viável é a segunda, com ligação por 4 dutos e área hidráulica de $21,24 \mathrm{~m}^{2}$, e por isso será a mais discutida neste capitulo.

Para cada modelo de circulação hidrodinâmica foram desenvolvidos um modelo para avaliação das taxas de renovação das águas da LRF e um para avaliação de distribuições de salinidades de equilíbrio que resultarão. Os principais resultados obtidos e respectivas análises são discutidos mais à frente. Antes convém discutir um pouco a validade de resultados.

Para situações de diagnóstico, ex. quando se simula situações existentes, a confirmação usual de que os modelos representam os fenômenos que ocorrem na natureza é obtida através de um processo denominado calibração, no qual se compara, através de um processo interativo seguido de ajustes, valores medidos e valores computados. Entretanto, em condições de prognóstico, ex. simulações de situações hipotéticas, não é possível se dispor de dados medidos. Como explicado no capítulo 8 da Referência Técnica do sistema, Rosman (2011), os modelos do SisBaHiA ${ }^{\circledR}$ têm mecanismos de auto calibração que permitem obtenção de resultados confiáveis, mesmo sem dados disponíveis para calibração. Porém, deve-se enfatizar que a confiabilidade depende fortemente da validade dos dados de entrada. Tipicamente na utilização do SisBaHiA ${ }^{\circledR}$ observa-se que:

1. Coerências na modelagem digital do terreno, ou representação de valores de contornos e batimetria podem ser tão boas quanto se queira, dependendo apenas do refinamento da malha de representação, como ilustra a Figura 3. 
2. Coerências entre valores reais e valores computados de níveis de água são usualmente melhores que $90 \%$, podendo se aproximar de $100 \%$ com ajustes de calibração.

3. Coerências entre valores reais e valores computados de velocidade e direção de correntes são usualmente melhores que $70 \%$. Após calibração é comum ter-se coerências superiores a $90 \%$.

4. Coerências entre valores reais e valores medidos de concentração de contaminantes ou parâmetros de qualidade de água são semelhantes às verificadas para velocidade e direção de correntes. Como os modelos de transporte de contaminantes recebem como dados de entradas os resultados de níveis e correntes dos modelos hidrodinâmicos, a confiabilidade dos modelos de transporte é intrinsecamente função da qualidade dos resultados hidrodinâmicos.

Para atingir tais coerências é necessário atender às seguintes condições:

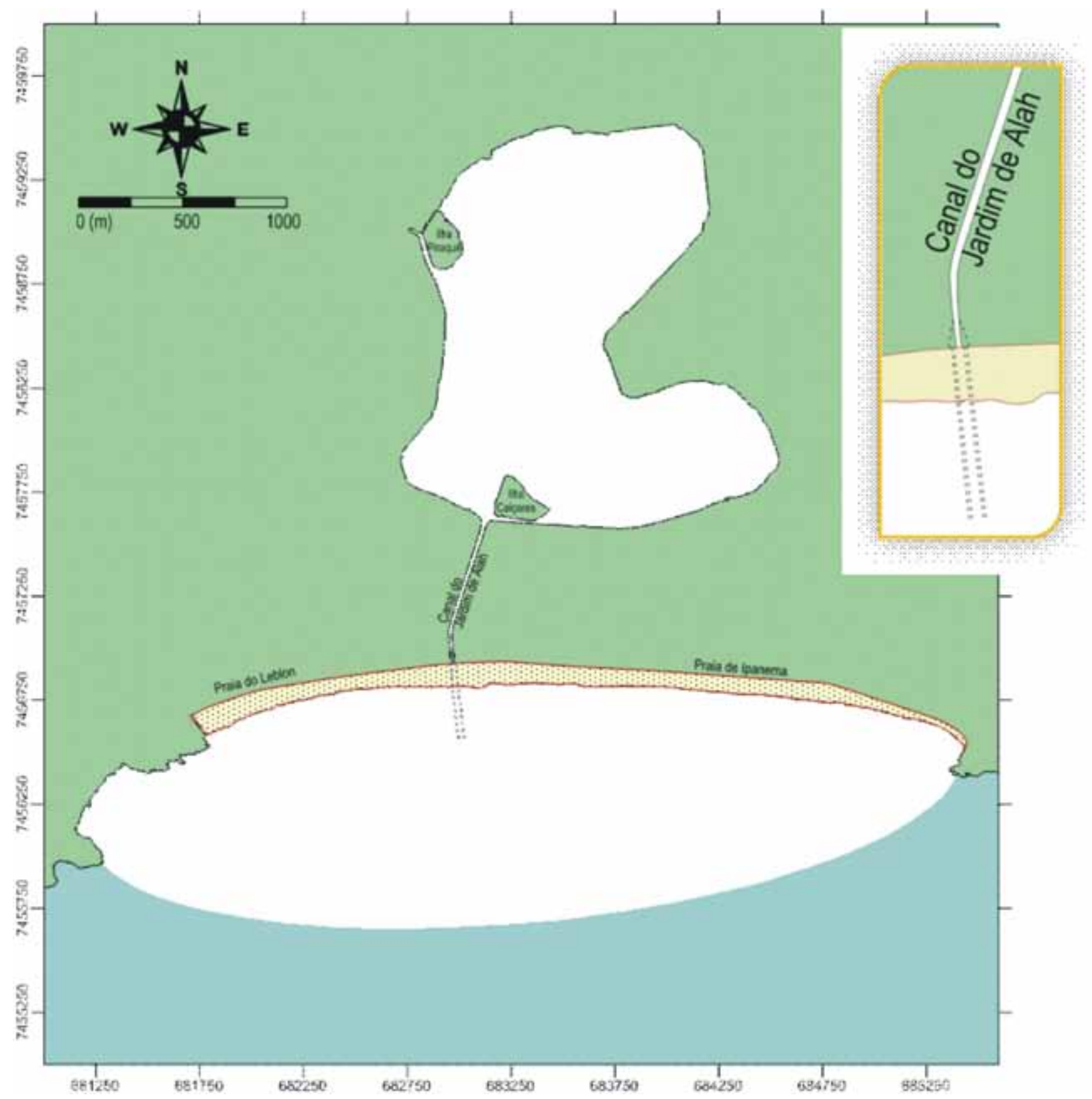

Figura 1. A área modelada é a região em branco que inclui a Lagoa Rodrigo de Freitas e a zona costeira com as praias do Leblon, Ipanema e Arpoador. No destaque à direita, nota-se a praia sem a embocadura do canal, e linhas pontilhadas representando eixos de dutos afogados, partindo de uma seção do Canal do Jardim de Alah junto da Avenida Vieira Souto. No total, são quatro dutos, dois de cada lado.

Figure 1. The modeled area is the white region that includes the Rodrigo de Freitas lagoon and the coastal zone with the beaches of Leblon, Ipanema, and Arpoador. In the inset on the right, one sees the beach without the tidal inlet mouth and dashed lines representing the axes of the drowned ducts, starting at a section of the Jardim de Alah Canal close to the Vieira Souto Avenue. In total, there are four ducts, two in each side. 
i. Garantir que a geometria do corpo de água implantada no sistema de modelos esteja correta e seja condizente com a existente na época de medição de níveis e correntes. Discrepâncias em dados de batimetria e contornos são frequentes causas de diferenças entre valores medidos e valores computados. ii. Garantir que os forçantes dos escoamentos, ex. níveis de maré, ventos e vazões fluviais, estejam corretamente disponibilizados no sistema de modelos, e sejam condizentes com os existentes na época de medição de níveis e correntes. Erros na especificação dos forçantes dos escoamentos são frequentes causas de diferenças entre valores medidos e valores computados.

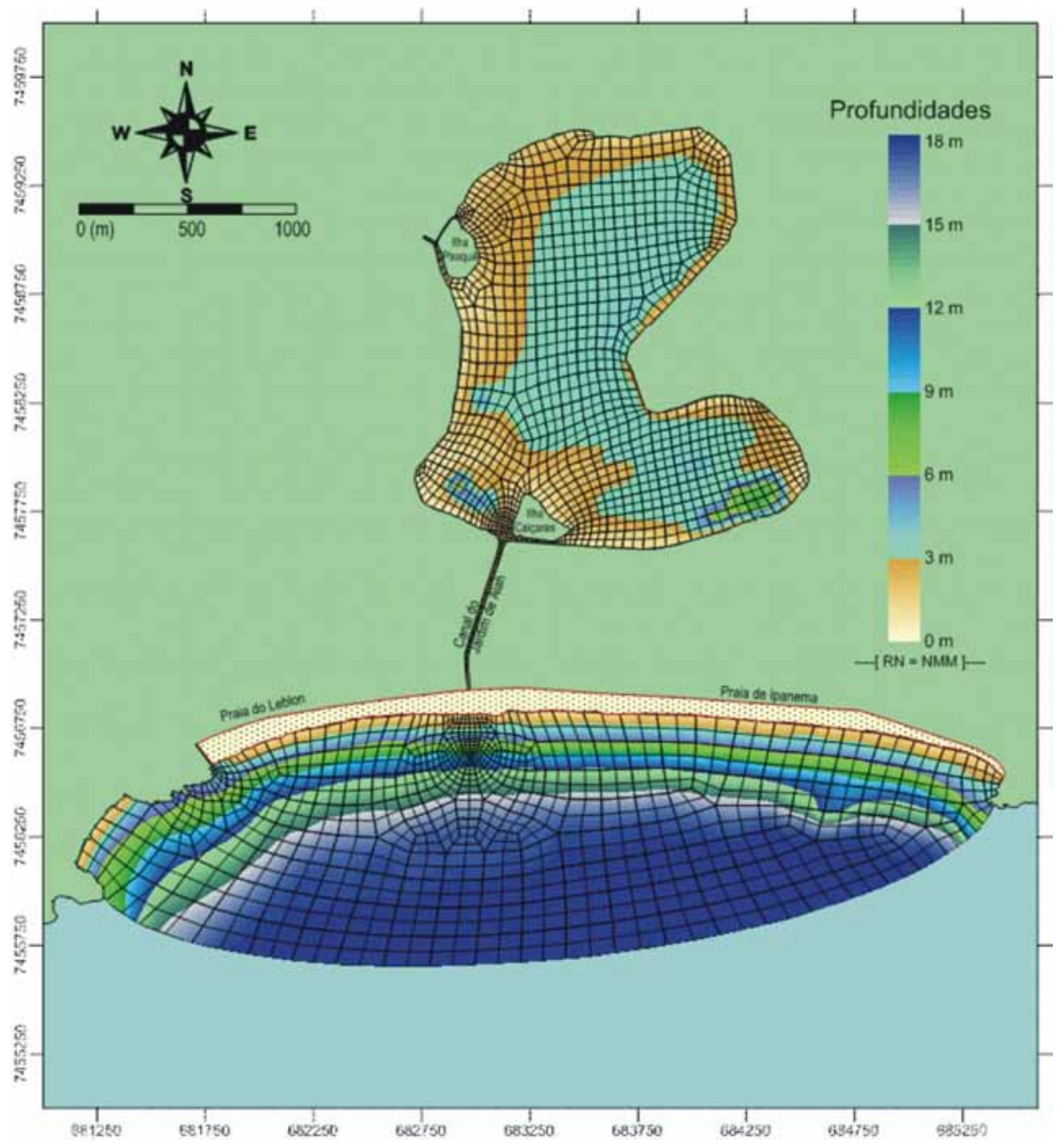

Figura 2. Mapa base da área de modelagem e vista superior da discretização tridimensional feita através de uma pilha de 21 malhas de elementos finitos biquadráticos, com um total de $621 \times 21=12642$ elementos. Cada malha tem 2655 nós, totalizando 55755 pontos de cálculo. Outros detalhes sobre a discretização do domínio estão no quadro inserido. No mapa acima, cada cruzamento de linhas de malha corresponde a um nó representando uma coluna de água contendo 21 pontos de cálculo distribuídos do fundo à superfície. A batimetria associada a esta malha está em maior destaque na Figura 3.

Figure 2. Base map of the modeling area and top view of the tridimensional discretization done through a pile of 21 biquadratic finite element meshes, with a total of $621 \times 21=12642$ elements. Each mesh has 2655 nodes, totalizing 55755 calculation points. Other details concerning the domain discretization are in the inserted box. On the map above, each mesh line crossing corresponds to a node representing a water column with 21 calculation points distributed from the bottom up to the water surface. The bathymetry associated with this mesh is in more details in Figure 3. 
iii. Garantir que as intensidades das fontes contaminantes e os parâmetros das reações cinéticas tenham sido corretamente fornecidos ao sistema de modelos, e sejam condizentes com os existentes na época de medição de concentrações. Erros na especificação de intensidades de fontes e parâmetros de reações cinéticas são frequentes causas de diferenças entre valores medidos e valores computados.

Os dados de entrada foram amplamente verificados e, portanto, podem ser esperadas coerências semelhantes às descritas acima nos resultados obtidos. Em resumo, a calibração de modelos de hidrodinâmica ambiental é um processo que deve obedecer à seguinte ordem:

Nível 1 - Calibração geométrica: aferir se a modelagem digital do terreno da área modelada, feita através da malha de discretização, representa adequadamente os contornos e a batimetria da região de interesse. Para isso, é necessário que haja dados recentes de levantamentos de campo.

Nível 2 - Calibração hidrodinâmica: aferir se os modelos hidrodinâmicos representam adequadamente a variação de níveis de água e correntes na região de interesse, para diferentes condições, ex. marés de sizígia e de quadratura, ventos e vazões. Para isso é necessário que, além da boa modelagem digital do terreno, haja informações corretas sobre os forçantes da circulação hidrodinâmica, tais como ventos, marés e vazões afluentes.

Nível 3 - Calibração de qualidade de água: aferir se os modelos de transporte de escalares, usando as correntes e níveis dos modelos hidrodinâmicos, são capazes de representar adequadamente as concentrações de parâmetros de qualidade de água ao longo do tempo. Para isso, é necessário que, além das correntes e níveis, haja informações corretas sobre fontes poluentes e sobre taxas de reação de parâmetros não conservativos, ex. OD, DBO e coliformes termotolerantes. Neste artigo, apenas aspectos de renovação de água e salinidade são analisados, portanto não há dúvidas quanto a reações cinéticas, pois os parâmetros envolvidos não sofrem reações.

Não é razoável querer obter uma boa calibração Nível 3, sem previamente obter uma boa calibração Nível 2, que por sua vez depende da calibração Nível 1.

\section{DADOS E CALIBRAÇÃO DOS MODELOS DESENVOLVIDOS}

Apresenta-se a seguir os dados utilizados no desenvolvimento dos diversos modelos.

Dados e calibração do modelo digital do terreno Nivel 1

Para realização de uma boa calibração geométrica, ou do modelo digital do terreno região de interesse, os seguintes dados foram utilizados:

- Contornos de margem: considera-se que, em geral, o contorno do domínio de modelagem é atual e preciso, pois foi extraído de levantamentos realizados em 2000 no âmbito do Projeto Coppetec PENO-467 contratado pela Prefeitura do Rio de Janeiro (Figura 36). Além de tais dados, foram utilizadas imagens georeferenciadas do Google Earth de 2008.

- Batimetria e tipo de material de fundo: considera-se que, em geral, as informações batimétricas e de caracterização do material de fundo do domínio de modelagem da área de interesse são atuais e precisas. Os dados utilizados foram extraídos de levantamentos realizados em 2000 no âmbito do Projeto Coppetec PENO-467 contratado pela Prefeitura do Rio de Janeiro (Figura 36).

- Foram utilizados ainda dados disponibilizados no EIA para o projeto "Solução Integrada de Reabilitação Ambiental da Lagoa Rodrigo de Freitas, Canal do Jardim de Alah e Praias do Arpoador, Ipanema e Leblon", feito em 2001, pela empresa Ambiental Engenharia e Consultoria Ltda. para a Prefeitura da Cidade do Rio de Janeiro.

Quanto aos sedimentos, segundo os dados disponíveis, os diversos compartimentos contêm os seguintes tipos de sedimentos:

- Região costeira em mar: areias com granulometria variando de fina a grossa, com predominância de areia média.

- Canal do Jardim de Alah e cercanias de sua embocadura na LRF: areias com granulometria variando de fina a média, com predominância de areia média.

- Lagoa Rodrigo de Freitas: como se pode ver na Figura 37, a maior parte dos fundos da LRF, especialmente em regiões com mais de $1 \mathrm{~m}$ de 
profundidade, contém elevado teor de lamas siltosas a $1 \mathrm{~m}$, contêm areias de granulometria fina a grossa, e argilosas com considerável teor de matéria orgânica. especialmente no entorno de pontos de deságue de Os trechos marginais, com profundidades inferiores redes de drenagem e rios afluentes.

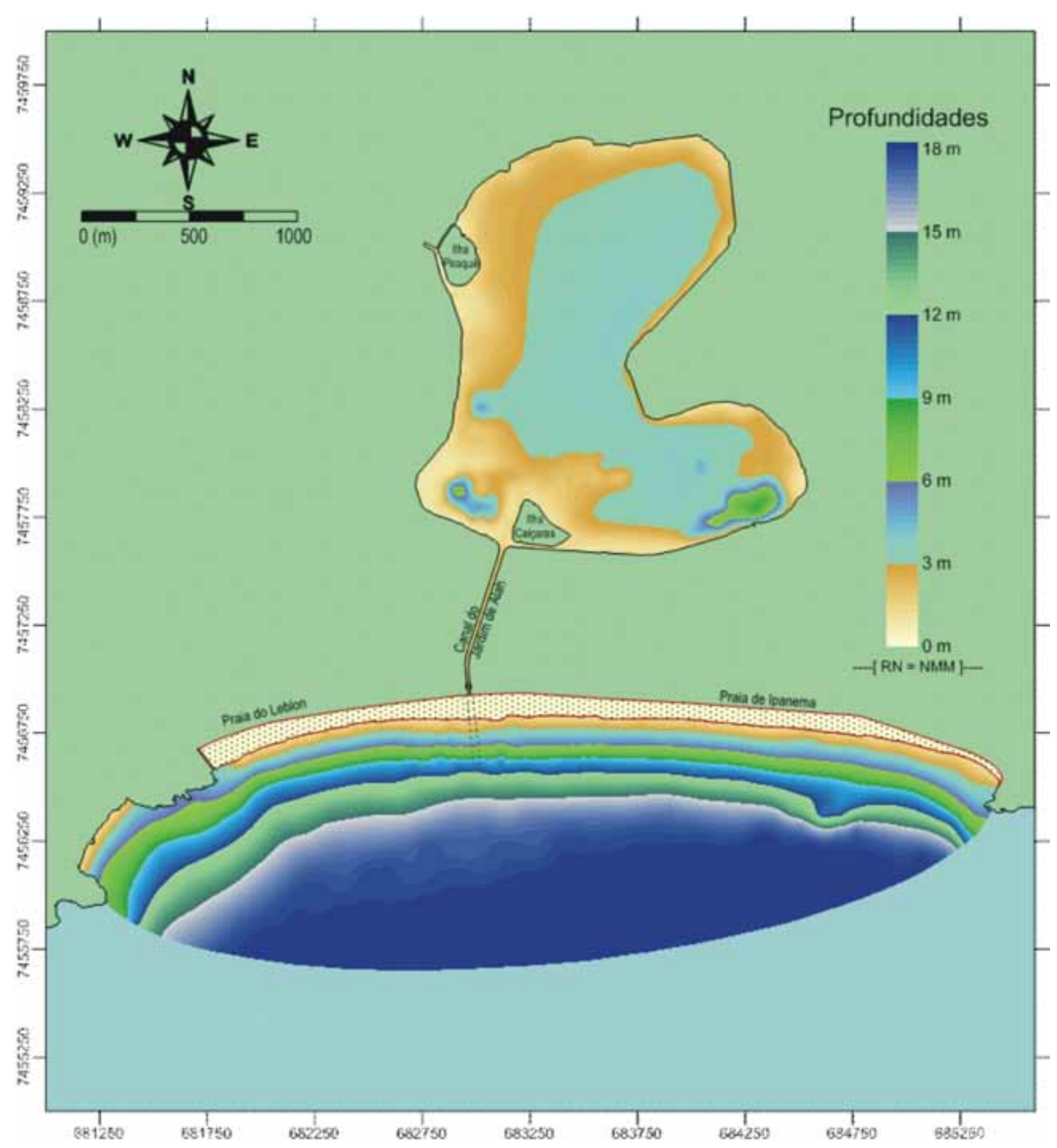

Figura 3. Mapa mostrando modelagem digital do terreno da região de interesse, com batimetria referida ao nível médio do mar, NMM, que corresponde à cota $-0,18 \mathrm{~m}$ do Datum Imbituba - IBGE.

Figure 3. Map showing the digital mapping of the terrain of the area of interest, with bathymetry referred to the mean sea level, NMM, that corresponds to level $-0.18 m$ of Datum Imbituba from IBGE. 


\section{Dados e calibração do modelo hidrodinâmico -}

Nivel 2

Considerando que o Nível 1 de calibração esteja efetivado, ex. há um bom modelo digital do terreno, a calibração hidrodinâmica Nível 2 é basicamente feita em 3 etapas: calibração de níveis de água; calibração de correntes médias na coluna de água e, se necessário; calibração de correntes 3D, ex. perfis de velocidade.

Para tanto são necessários dados referentes a medições de níveis, correntes, ventos e vazões fluviais. Idealmente, para uma ótima calibração e aferição de modelos hidrodinâmicos costeiros deve-se dispor de dados sinóticos, ex. ao longo de um mesmo período, com intervalo de medição de até 30 minutos durante no mínimo 15 dias, pelo menos para os dados de maré, ventos e correntes.

\section{Dados de maré e calibração de níveis de água}

No caso em estudo, utilizou-se ao longo da fronteira aberta dados de maré incluindo efeitos meteorológicos, como mostra a Figura 4. Na figura mostra-se a variação do nível médio diário do mar [NM diário-Mar] que reflete eventos meteorológicos de meso-escala que não estão relacionados a ventos locais. O nível médio estático do mar [NM - Mar (estático)] é calculado com base nas constantes harmônicas do local e equivale ao valor definido em tábuas de maré e cartas náuticas da região.

\section{Dados de maré com mudanças climáticas em 2100}

Há muita incerteza quanto a valores de elevação do nível médio do mar em 2100 devido a mudanças climáticas (Neves et al. 2007, Rosman et al. 2009). Para uma avaliação de efeitos de subida do nível médio do mar, adotou-se o registro de níveis de maré apresentado na Figura 4 somando uma sobreelevação no nível médio diário do mar de $0,5 \mathrm{~m}$. A maioria das estimativas de elevação do nível médio do mar para 2100 prevê valores abaixo de $0,5 \mathrm{~m}$.

\section{Dados de vazões fluviais}

A Tabela 1 apresenta os valores de vazão média dos afluentes que foram usadas nos modelos hidrodinâmicos.
Tabela 1. Vazões médias dos principais rios impostas aos modelos hidrodinâmicos

Table 1. Average discharges of the main rivers imposed in the hydrodynamic models

\begin{tabular}{lc}
\hline \multicolumn{1}{c}{ Rio Afluente } & Vazões Médias \\
\hline Macacos \& Cabeças (LRF) & $300,0 \ell / \mathrm{s}$ \\
Saída - Vasco (LRF) & $1,0 \ell / \mathrm{s}$ \\
Saída - Hípica (LRF) & $1,0 \ell / \mathrm{s}$ \\
Saída - Rebouças (LRF) & $20,0 \ell / \mathrm{s}$ \\
Visconde de Albuquerque (Mar) & $45,0 \ell / \mathrm{s}$ \\
\hline
\end{tabular}

\section{Condições de ligação permanente lagoa-mar}

Os modelos avaliados consideraram 3 casos de ligação lagoa-mar através de feixes de dutos afogado:

1. Feixe de 3 Dutos de $3,05 \mathrm{~m}$ de diâmetro, com as seguintes características:

a. Área hidráulica do feixe $=21,89 \mathrm{~m}^{2}$

b. Raio hidráulico do feixe $=0,76 \mathrm{~m}$

c. Altura da rugosidade equivalente $=0,03 \mathrm{~m}$, admitindo parede de PEAD lisa com ondulações e incrustações.

d. Perdas localizadas: 1,94 (canal-duto; dutomar e grades)

e. Comprimento do feixe $=360 \mathrm{~m}$

2. Feixe de 4 Dutos de $2,60 \mathrm{~m}$ de diâmetro, com as seguintes características:

a. Área hidráulica do feixe $=21,24 \mathrm{~m}^{2}$

b. Raio hidráulico do feixe $=0,65 \mathrm{~m}$

c. Altura da rugosidade equivalente $=0,02 \mathrm{~m}$, admitindo parede de concreto liso com incrustações.

d. Perdas localizadas: 1,94 (canal-duto; dutomar e grades)

e. Comprimento do feixe $=360 \mathrm{~m}$

3. Feixe de 9 Dutos de $1,60 \mathrm{~m}$ de diâmetro, com as seguintes características:

a. Área hidráulica do feixe $=18,09 \mathrm{~m}^{2}$

b. Raio hidráulico do feixe $=0,40 \mathrm{~m}$

c. Altura da rugosidade equivalente $=0,01 \mathrm{~m}$, admitindo parede de PEAD lisa com incrustações.

d. Perdas localizadas: 1,94 (canal-duto; dutomar e grades)

e. Comprimento do feixe $=360 \mathrm{~m}$

Por razões construtivas, a melhor opção é a do feixe de 4 dutos com diâmetro interno de 2,60m, discutida em mais detalhes a seguir. 


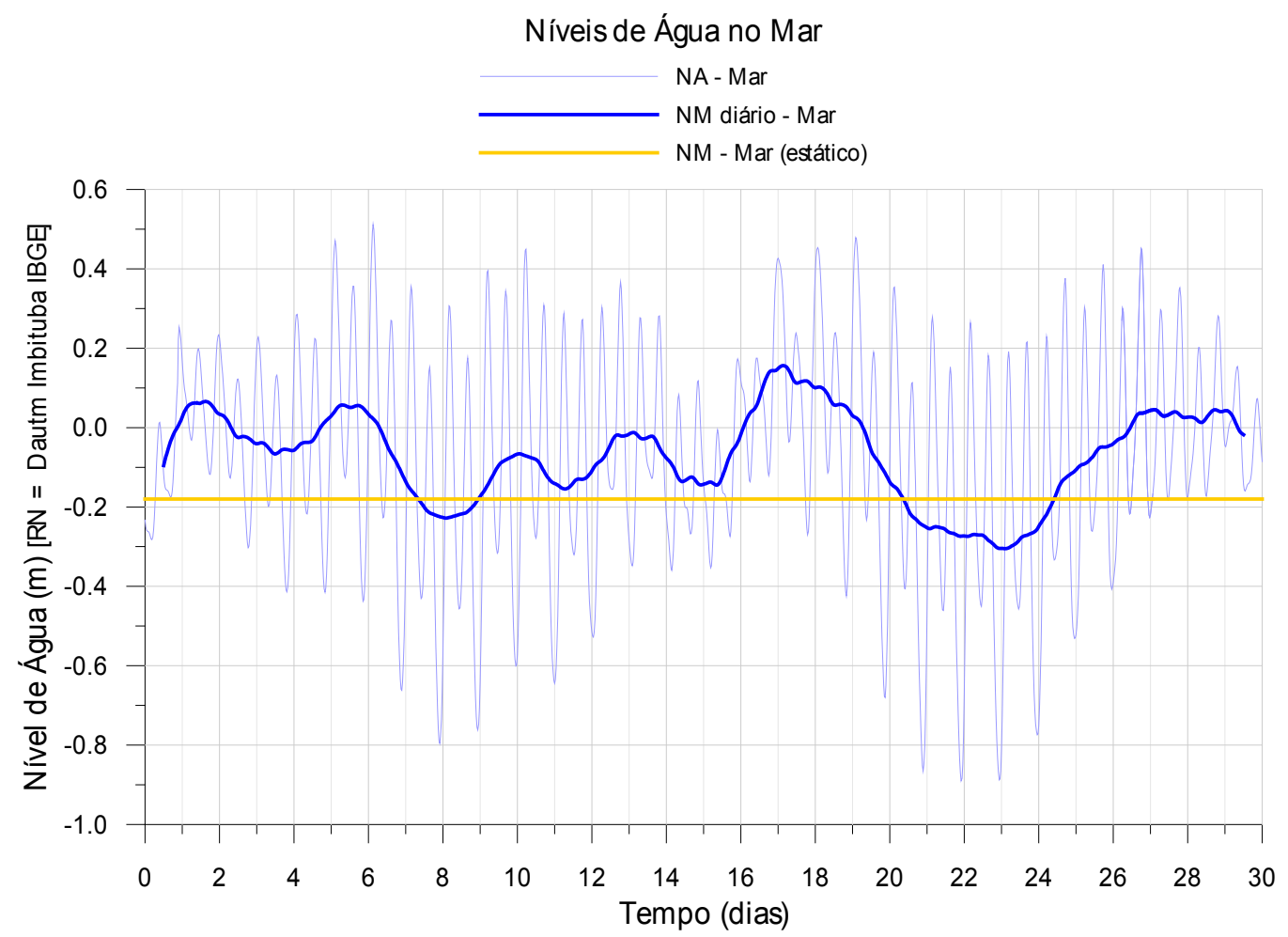

Figura 4. Níveis de água no mar prescritos na fronteira aberta dos modelos hidrodinâmicos. Os níveis adotados retratam variações típicas no local, incluindo marés de sizígia e quadratura e efeitos meteorológicos. O nível de referência é o zero do Datum Imbituba - IBGE.

Figure 4. Sea water levels prescribed as open boundary values for the hydrodynamic models. The adopted levels show typical local variations, including spring and neap tides, and meteorological effects. The reference level is the zero from the Datum Imbituba - IBGE.

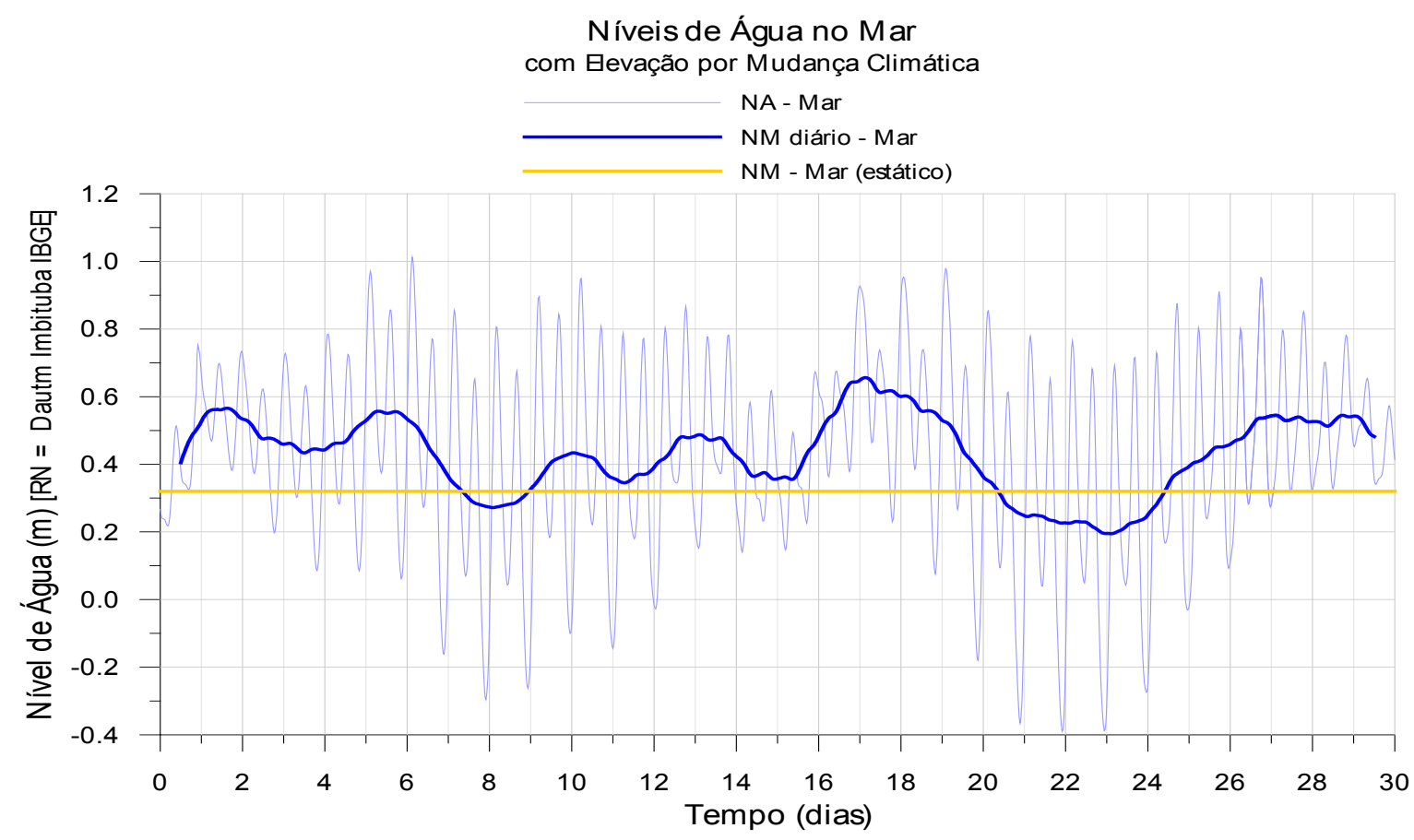

Figura 5. Níveis de água no mar prescritos na fronteira aberta dos modelos hidrodinâmicos, retratando possível condição em 2100 , com elevação de 0,5m no nível médio do mar devido a mudanças climáticas. O nível de referência é o zero do Datum Imbituba - IBGE.

Figure 5. Sea water levels prescribed as open boundary values for the hydrodynamic models, showing a condition in 2100 , with a mean sea level rise of $0.5 \mathrm{~m}$. The reference level is the zero from the Datum Imbituba-IBGE. 
Dados de vento

Os dados de vento utilizados estão apresentados na Figura 6. Os dados usados representam situação típica da região com regime de brisa, com uma entrada de frente fria entre os dias 20 e 23 do período de simulação. Foram usados dados de vento medidos na Baía de Guanabara por falta de dados consistentes medidos localmente.

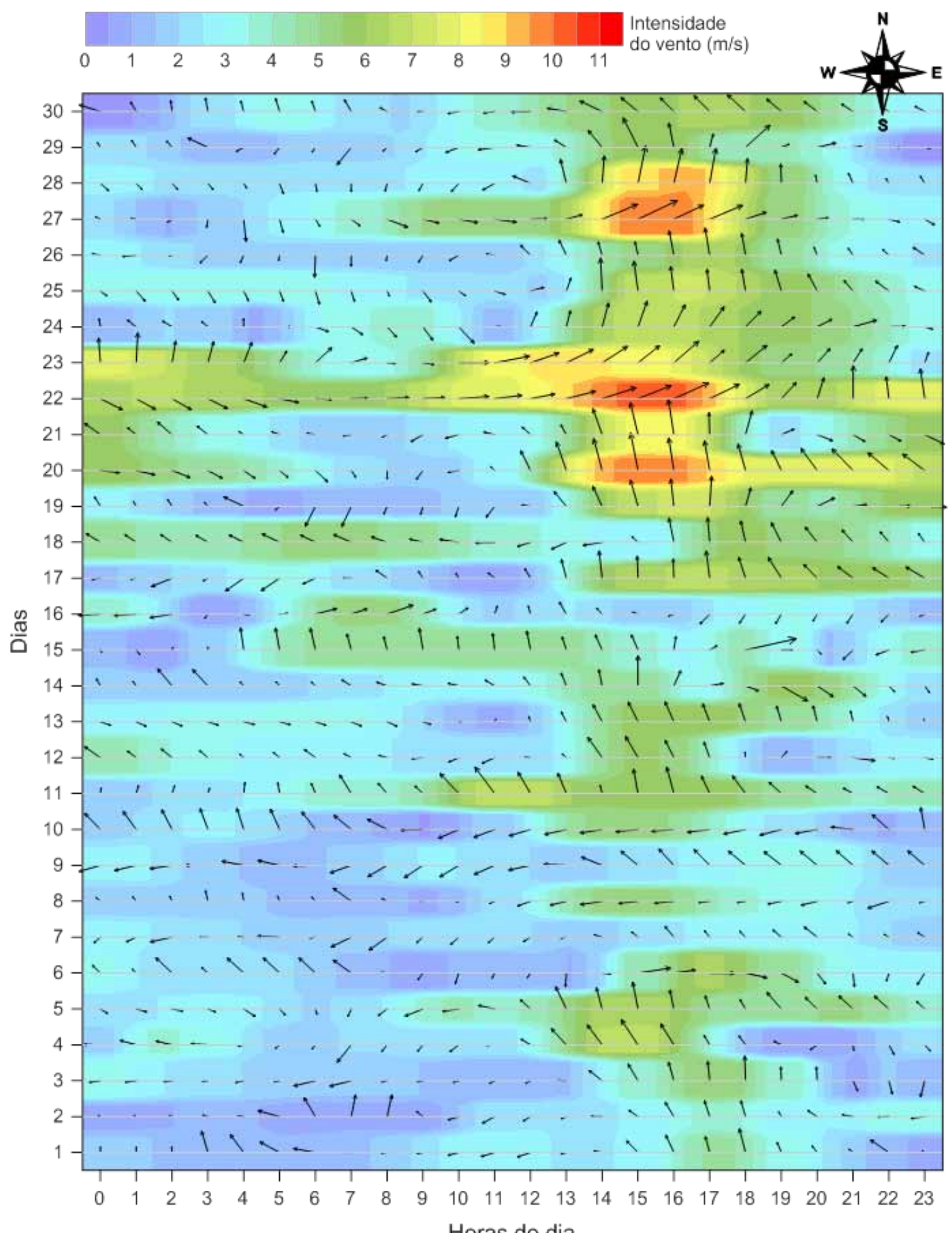

Figura 6. Os ventos utilizados representam situação típica da região com regime de brisa e uma passagem de frente fria entre os dias 20 e 23.

Figure 6. The adopted winds represent a typical local situation with a breeze regime and a cold front passage between days 20 and 23. 


\section{PROGNÓSTICOS DE HIDRODINÂMICA AMBIENTAL PARA A LRF}

Nesta seção são apresentados resultados de simulações computacionais com prognósticos de funcionamento da LRF, após a ligação permanente por dutos afogados, focando nos seguintes aspectos:

1. Variação de níveis de água e circulação hidrodinâmica.
2. Taxas de renovação de água.

3. Distribuição de salinidades médias na coluna de água.

\section{VARIAÇÃO DE NÍVEIS DE ÁGUA E CIRCULAÇÃO HIDRODINÂMICA}

De modo a permitir uma boa avaliação dos benefícios da situação projetada, esta seção apresenta

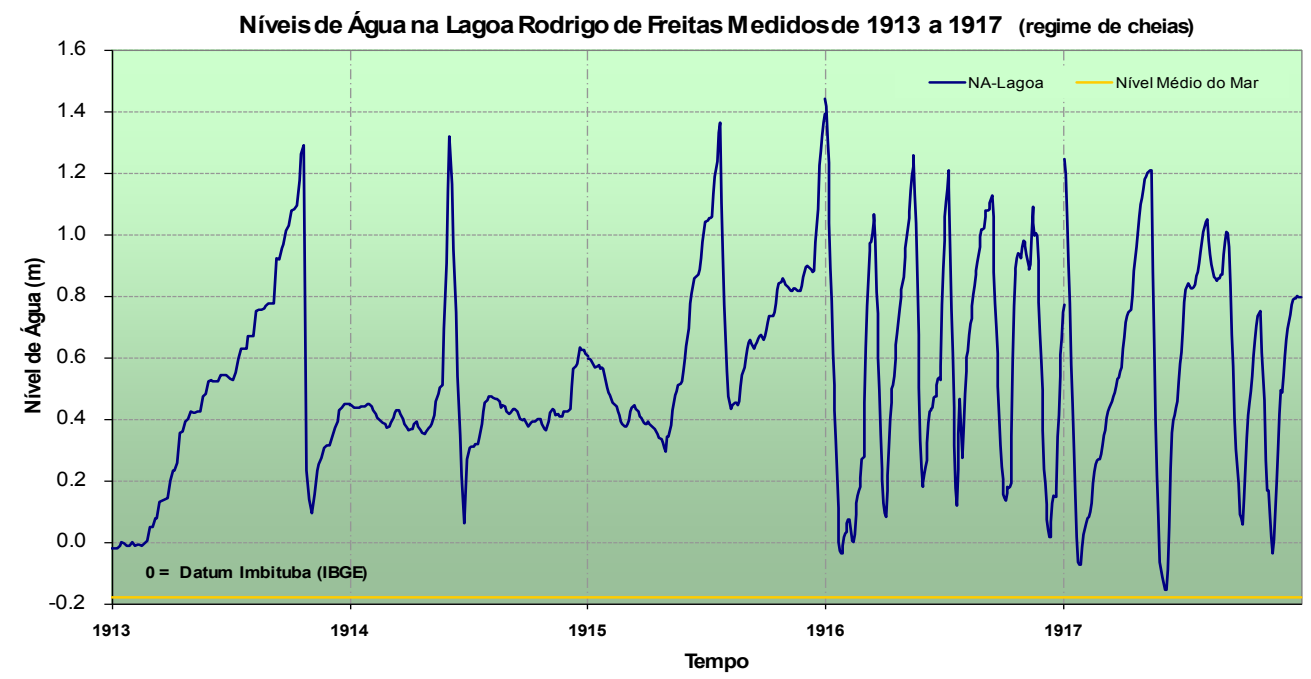

Figura 7. Níveis de água medidos na Lagoa Rodrigo de Freitas entre 1913 e 1917, antes da existência do canal do Jardim de Alah. Como a embocadura do canal natural existente ficava frequentemente bloqueada por areia, as aberturas só corriam em épocas de grandes chuvas, quando o nível de água na lagoa atingia cotas acima de 1,0m relativas ao datum Imbituba - IBGE. [Gráfico produzido pelo autor, com dados extraídos do Projeto do Canal do Jardim de Alah do Eng. Saturnino de Brito, 1920].

Figure 7. Water levels measured in Rodrigo de Freitas Lagoon between 1913 and 1917, before the existence of the Jardim de Alah canal. As a sand bar often blocked the mouth of the existing natural inlet, the openings only happened in times of strong rains, when the water level in the lagoon reached values above 1.0m, in respect to Datum Imbituba - IBGE. [Graph produced by the author, with data extracted from the Jardim de Alah Canal Project of Eng. Saturnino de Brito, 1920].

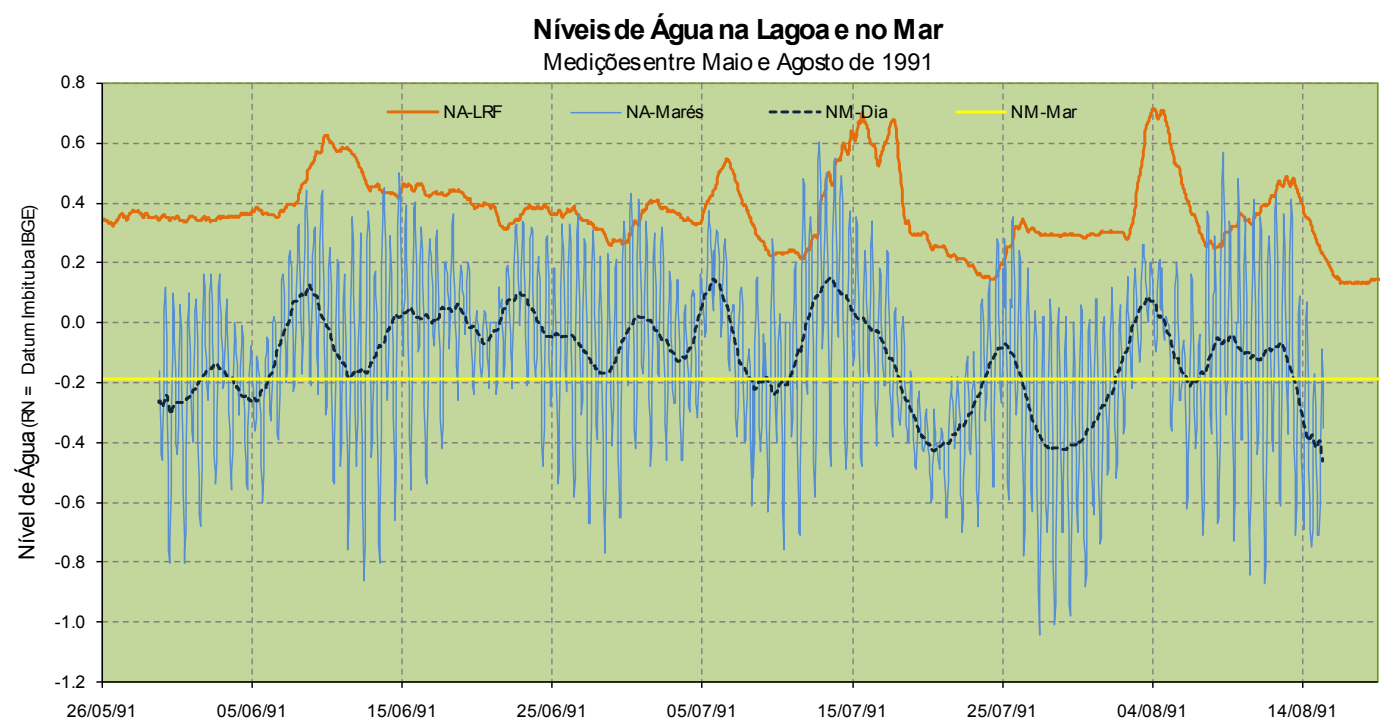

Figura 8. Níveis de água medidos na Lagoa Rodrigo de Freitas e no mar entre maio e agosto de 1991. Devido a operação da comporta do canal do Jardim de Alah e eventos de bloqueio por areia, o nível de água na lagoa permaneceu usualmente acima das cotas das preamares das marés na praia de Ipanema. [Gráfico produzido pelo autor no contexto do Projeto Coppetec ET-170173, 1992].

Figure 8. Water levels measured in the Rodrigo de Freitas Lagoon and at the sea between Mai and August of 1991. Due to operation of a water sluice and to sand bar blockages, the water levels in the lagoon usually stayed above the high-water tidal levels at the Ipanema beach. [Graph produced by the author in the context of Coppetec project ET-170173, 1992]. 
análises de situações passadas na LRF, além de situações projetadas com a ligação permanente por dutos afogados. Avaliações dos efeitos na lagoa de fortes chuvas e de elevação do nível médio do mar devido a mudanças climáticas também são consideradas.

\section{Níveis do passado na LRF para comparação com niveis projetados}

Como mostram os gráficos nas três figuras a seguir, os níveis médios de água da LRF têm sido mantidos em cotas que ficam perto de $0,5 \mathrm{~m}$ acima do nível médio do mar, NMM, na praia de Ipanema-Leblon. A persistência de níveis tão altos é devida aos bloqueios da embocadura do canal por areia e às operações da comporta. Ambos os motivos mantém a lagoa estagnada.

A Figura 9, além de mostrar os níveis de água, apresenta valores de salinidade medidos na boca do Canal do Jardim de Alah junto ao Clube Caiçaras, e valores de precipitação de chuva na bacia da Lagoa Rodrigo de Freitas. Analisando os gráficos da Figura 9, devem ser ressaltados os seguintes pontos:

- Ao longo dos mais de dois meses de medição, apenas durante cerca de 10 horas, ou em menos de $0,7 \%$ do tempo total, a salinidade na seção de medição apresentou valores equivalentes à da água do mar, ex.
$>$ 30ups. Isso indica que durante mais de dois meses o canal do Jardim de Alah praticamente só funcionou como canal de extravasamento, evidenciando que não ocorreu qualquer entrada significativa de água do mar na lagoa. Portanto, durante quase dois meses a renovação das águas da lagoa com água do mar foi praticamente nula, e as entradas de peixes e larvas do mar para a lagoa foram igualmente desprezíveis.

- Verifica-se que não há correlação entre os níveis da lagoa e o nível médio do mar. Isso é evidente, pois estando o nível de água (NA) da lagoa quase sempre acima do NA do mar, não haveria como entrar água do mar para a lagoa. Observa-se que as modificações de NA da lagoa decorrem basicamente de eventos de chuva na bacia e de operações de comporta no canal. Tais operações permitem o extravasamento das águas da lagoa para o mar, após dragagem do bloqueio de areia na embocadura.

- Note na Figura 9 que, de 6 a 12 de novembro de 1999, embora os níveis de preamar tenham estado acima dos níveis da lagoa, a água do mar só entrou no dia 6. De fato, a salinidade registrada na seção do canal junto ao Clube Caiçara permaneceu muito abaixo da salinidade da água do mar, exceto em um pico no dia 6/11, Portanto, a elevação de níveis da lagoa em tal período deveu-se às chuvas e não à entrada de água do mar.

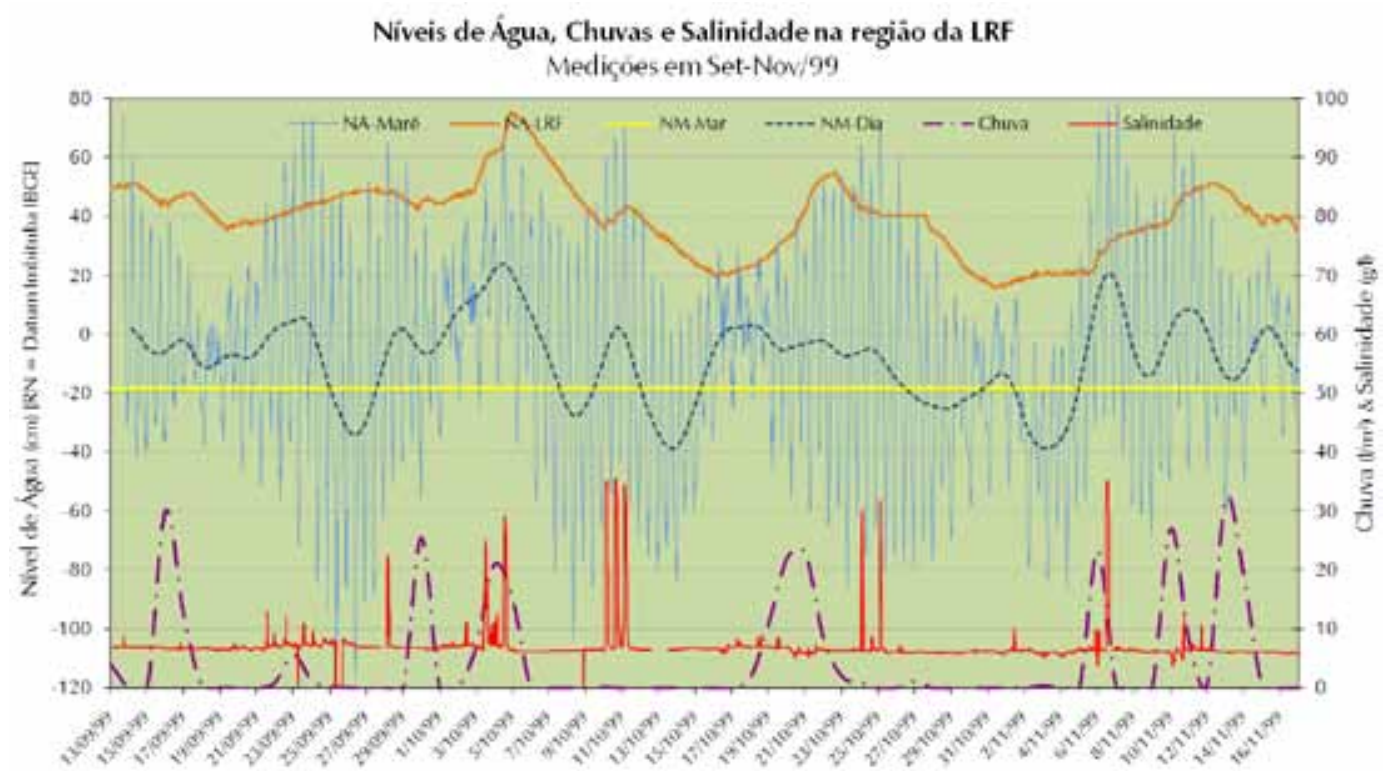

Figura 9. Níveis de água medidos na Lagoa Rodrigo de Freitas e no mar entre setembro e novembro de 1999. Como já ocorria em 1991, por conta de operação da comporta do canal do Jardim de Alah e eventos de bloqueio por areia, o nível de água na lagoa permaneceu usualmente acima das cotas das preamares das marés na praia de Ipanema. [Gráfico produzido pelo autor no âmbito do Projeto Coppetec PENO-467, 2000].

Figure 9. Water levels measured in the Rodrigo de Freitas Lagoon and at the sea between September and November of 1999. As occurred in 1991, due to operation of a water sluice in the Jardim de Alah Canal and to sand bar blockages, the water levels in the lagoon usually stayed above the high-water tidal levels at the Ipanema beach. [Graph produced by the author in the context of Coppetec project PENO-467, 2000]. 
- Em face da similaridade entre os níveis relativos da lagoa e do mar medidos em 1991 e em 1999, respectivamente apresentados na Figura 8 e na Figura 9, é plausível inferir que os pontos anteriores também se aplicam ao período de 1991.

\section{Niveis projetados na LRF com ligação por dutos afogados}

A Figura 10 apresenta prognósticos de níveis de água para a LRF para o caso de ligação lagoa-mar por um feixe de 4 dutos com diâmetro de $2,60 \mathrm{~m}$ e seção hidráulica de $21,24 \mathrm{~m}^{2}$. Na legenda da figura há explicações e análises.

Analisando a Figura 10, nota-se que o nível médio, $\mathrm{NM}$, diário da LRF estaria sempre correlacionado ao NM diário do mar, por estarem em equilíbrio dinâmico. As variações de NMs diários no mar e na LRF teriam amplitudes similares. Além das oscilações no NM diário evidenciam-se variações de nível de água na LRF seguindo as marés, porém com amplitudes bastante atenuadas.

Para ligação através de feixe de dutos com seção hidráulica de $21,24 \mathrm{~m}^{2}$, (Figura 10), a atenuação das amplitudes de maré seria da ordem de $80 \%$. Assim, uma maré com variação de nível de $1,0 \mathrm{~m}$ entre máximos e mínimos no mar, resultaria tipicamente numa variação equivalente de $0,20 \mathrm{~m}$ na LRF. Quanto aos níveis médios diários, verifica-se uma atenuação da ordem de $7 \%$ e uma defasagem da ordem de 12 horas entre os NM diários na LRF e no mar.

Comparando os níveis históricos na LRF, mostrados na Figura 8 e na Figura 9, com níveis projetados mostrados na Figura 10, constata-se: Os níveis do passado são dissociados dos níveis do mar e por isso o nível médio da LRF era artificialmente mantido acima do nível médio do mar em excessos da ordem de $0,5 \mathrm{~m}^{1}$. Já os níveis projetados estariam em equilíbrio dinâmico com o mar, com sobreelevações bem inferiores às artificialmente mantidas no passado. Note que, embora haja uma pequena diminuição do volume total da lagoa, efetivamente

\footnotetext{
${ }^{1}$ Depois da última inundação devido às grandes chuvas de 06/04/2010, os gestores ambientais do poder público do Rio de Janeiro, estado e município, decidiram rebaixar consideravelmente o nível da lagoa de modo a aumentar sua capacidade de retenção de águas de chuva. Desde abril de 2010 o nível da lagoa tem sido mantido próximo do nível zero do IBGE, que está cerca de $0,2 \mathrm{~m}$ acima no nível médio estático do mar em Ipanema e Leblon . Portanto, com a ligação por dutos, a diminuição do NA na lagoa seria pequena em relação ao NA que tem sido mantido desde $04 / 2010$
}

haverá um aumento muito grande do volume útil. De fato, atualmente, apenas a camada superficial com cerca de um metro de espessura mantém concentrações de oxigênio dissolvido adequadas, na camada abaixo de $1,5 \mathrm{~m}$ são frequentes concentrações de oxigênio dissolvido inferiores a $1 \mathrm{mg} / \ell$, ou mesmo anoxia (Ambiental 2001, Maciel 2007). Mesmo na camada superior, por conta das condições de eutrofização, as concentrações de OD variam de enormes superávits no final da tarde para déficits dramáticos na madrugada, em resposta aos ciclos de fotossíntese e respiração dos fitoplâncton e trocas atmosféricas.

\section{Niveis projetados na LRF com ligação por dutos afogados e cheia de 1996}

Considerando o histórico de inundações marginais em épocas de grandes chuvas, mostra-se uma análise de níveis na LRF conectada ao mar por feixe de 4 dutos com diâmetro de $2,60 \mathrm{~m}^{2}$, e área hidráulica de $21,24 \mathrm{~m}^{2}$, sob a influência da enorme cheia de 1996. Naquela ocasião, o nível de água na LRF atingiu a cota $1,60 \mathrm{~m}$ IBGE.

O histograma de vazões adotado mostrado na Figura 11, impõe vazões afluentes à LRF muito acima dos valores usuais previstos em estudos hidrológicos considerando apenas a afluência dos Rios Macacos e Cabeças, com tempo de retorno de 20 anos. Como se vê nos resultados apresentados na Figura 12, mesmo forçando a ocorrência das chuvas em dia de nível médio com forte sobre-elevação meteorológica na LRF, fica evidente que os dutos dariam passagem à onda de cheia sem maiores dificuldades, e que a lagoa não transbordaria, pois atingiria níveis máximos da ordem de $0,6 \mathrm{~m}$ IBGE.

\section{Niveis projetados na LRF com ligação por dutos afogados e Nivel Médio do Mar em 2100}

Para avaliar os efeitos de possível elevação do nível médio do mar, NMM, devido a mudanças climáticas, nos níveis de água na LRF, foi realizada uma simulação supondo sobre-elevação de $0,5 \mathrm{~m}$ no NMM em 2100. As condições de níveis de água impostas ao modelo podem ser vistas na Figura 5. A situação lagoa-mar simulada corresponde a da ligação com feixe de quatro dutos afogados com diâmetro de $2,60 \mathrm{~m}$ e área hidráulica de $21,24 \mathrm{~m}^{2}$. 


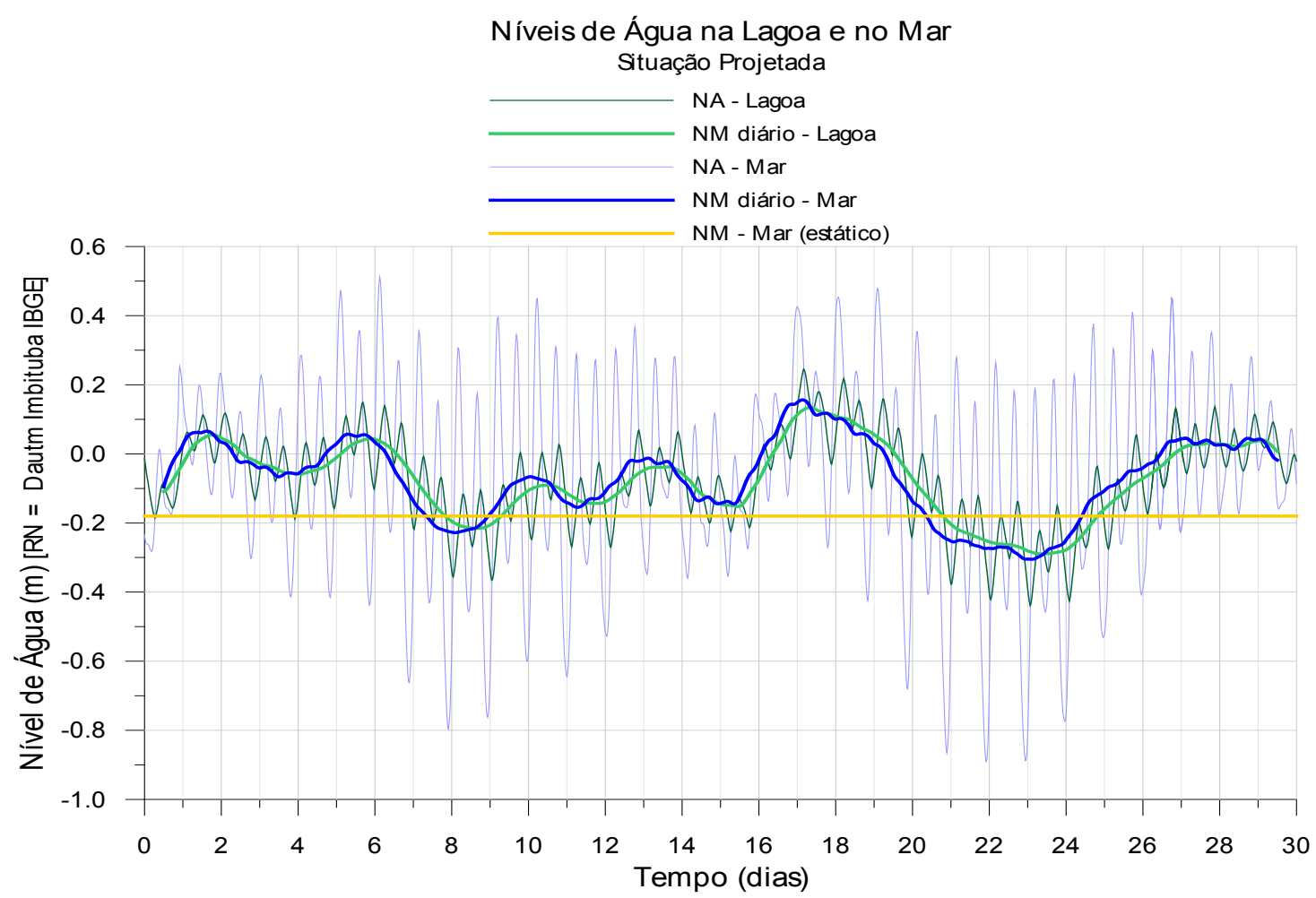

Figura 10. Prognóstico de níveis de água na Lagoa Rodrigo de Freitas em função de variações do nível do mar, supondo ligação através de feixe de 4 dutos com diâmetro de 2,60m, totalizando uma seção hidráulica de $21,24 \mathrm{~m}^{2}$. Adotou-se para todo o canal do Jardim de Alah uma seção hidráulica relativa ao NMM de no mínimo $21,24 \mathrm{~m}^{2}$. Nota-se que o nível médio diário da LRF ficaria em equilíbrio dinâmico com o nível médio diário do mar, e que haveria atenuação da ordem de $80 \%$ nas oscilações de nível na lagoa seguindo as marés.

Figure 10. Prognostic of water levels in the Rodrigo de Freitas lagoon as a function of sea level variations, assuming a connection through a group of 4 ducts with a diameter of $2.6 \mathrm{~m}$, totalizing a hydraulic section of $21.24 \mathrm{~m}^{2}$. It was assumed a hydraulic section in respect to the MSL of at least $21.24 \mathrm{~m}^{2}$ along the Jardim de Alah Canal. Note that that the daily mean water level in the lagoon would stay in dynamic equilibrium with the daily mean sea level, and that there would be an attenuation of about $80 \%$ in the water level oscillations in the lagoon following the tides.

niceograma sintecico - cneia de revereiro de iyyo

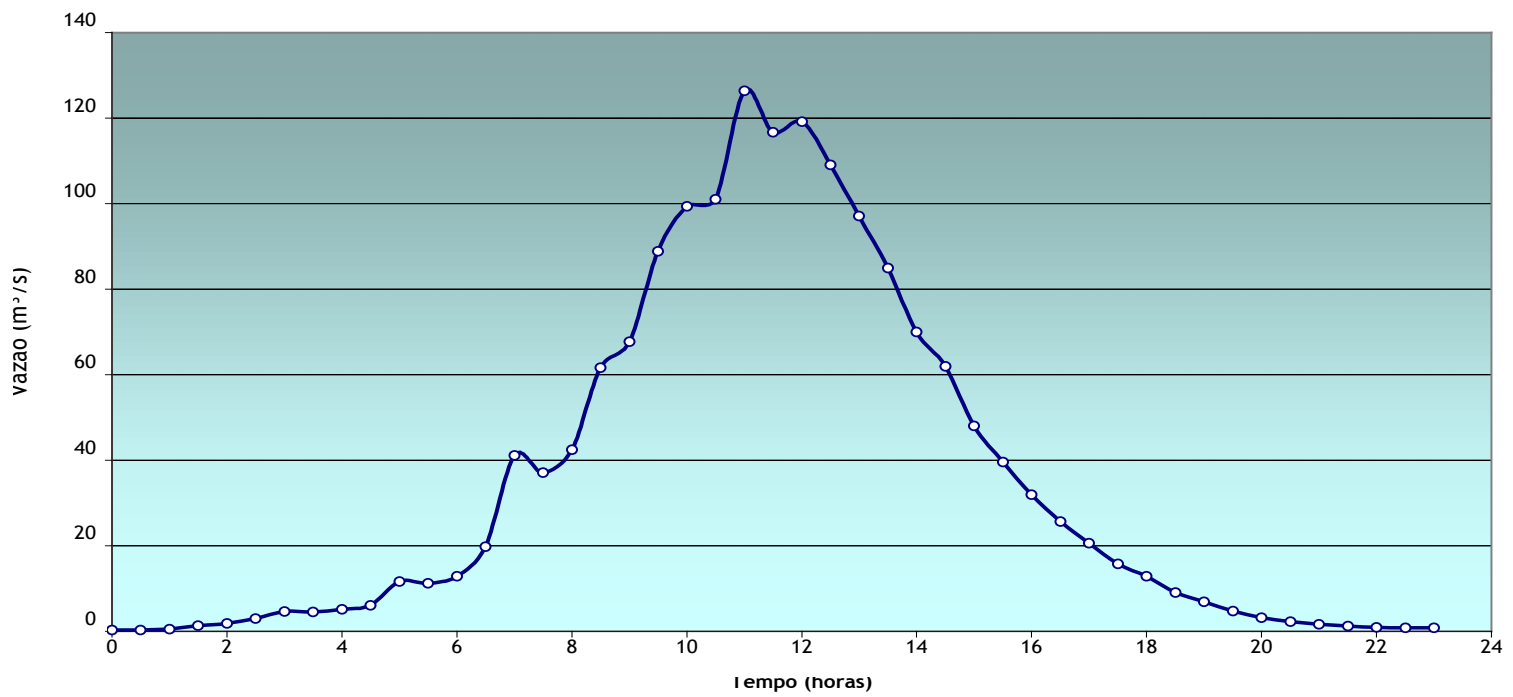

Figura 11. Hidrograma sintético afluente à LRF correspondente às chuvas entre 12 e 13/02/1996. Este hidrograma representa uma distribuição temporal do volume acumulado na lagoa, e atinge picos de vazão afluente à LRF muito acima das estimativas de vazões máximas com período de retorno de 20 anos.

Figure 11. Synthetic hydrograph of inflow into the LRF corresponding to the rainfall between the $12^{\text {th }}$ and the $13^{\text {th }}$ of February, 1996.This hydrograph is just a temporal distribution of the volume accumulated in the Lagoon, and reaches peak values well above the estimated maximum discharges with a return period of 20 years. 


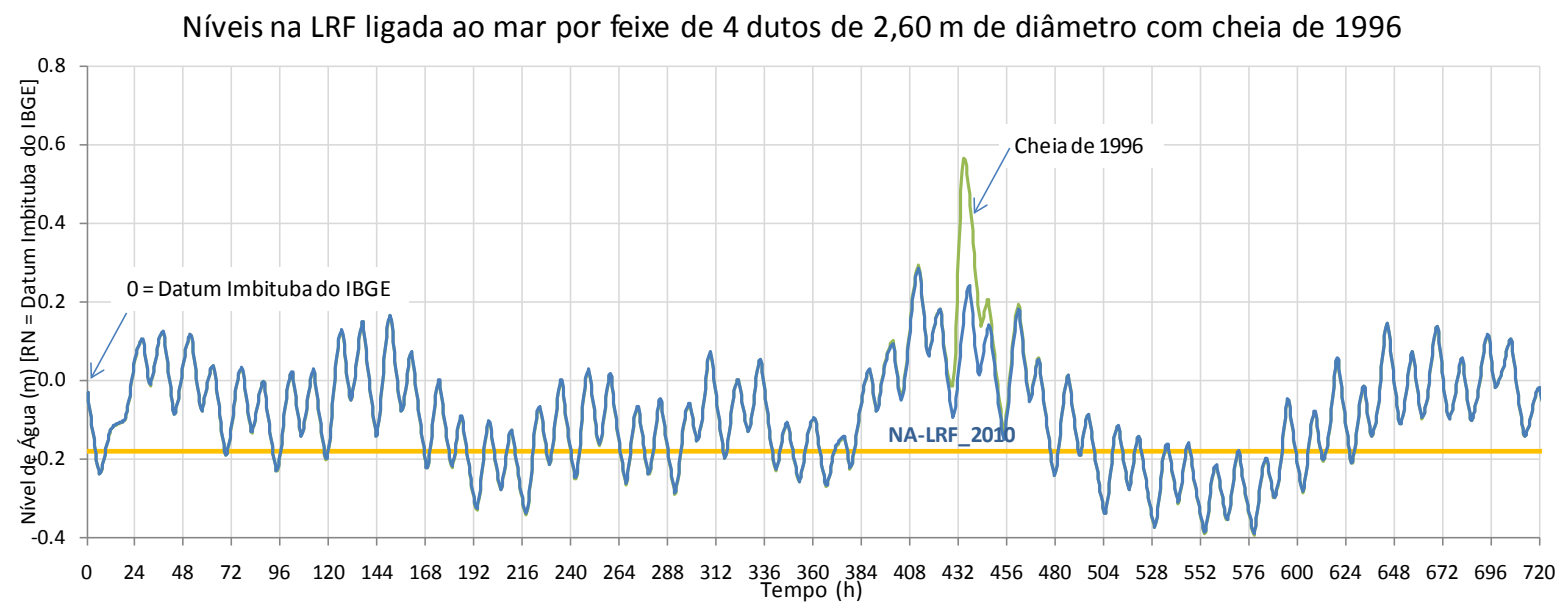

Figura 12. Níveis previstos na LRF sujeita a vazões da cheia de 1996. Verifica-se que a lagoa não transbordaria.

Figure 12. Forecasted water levels in the LRF with the flooding discharges of 1996. One can see that the lagoon would not overspill.

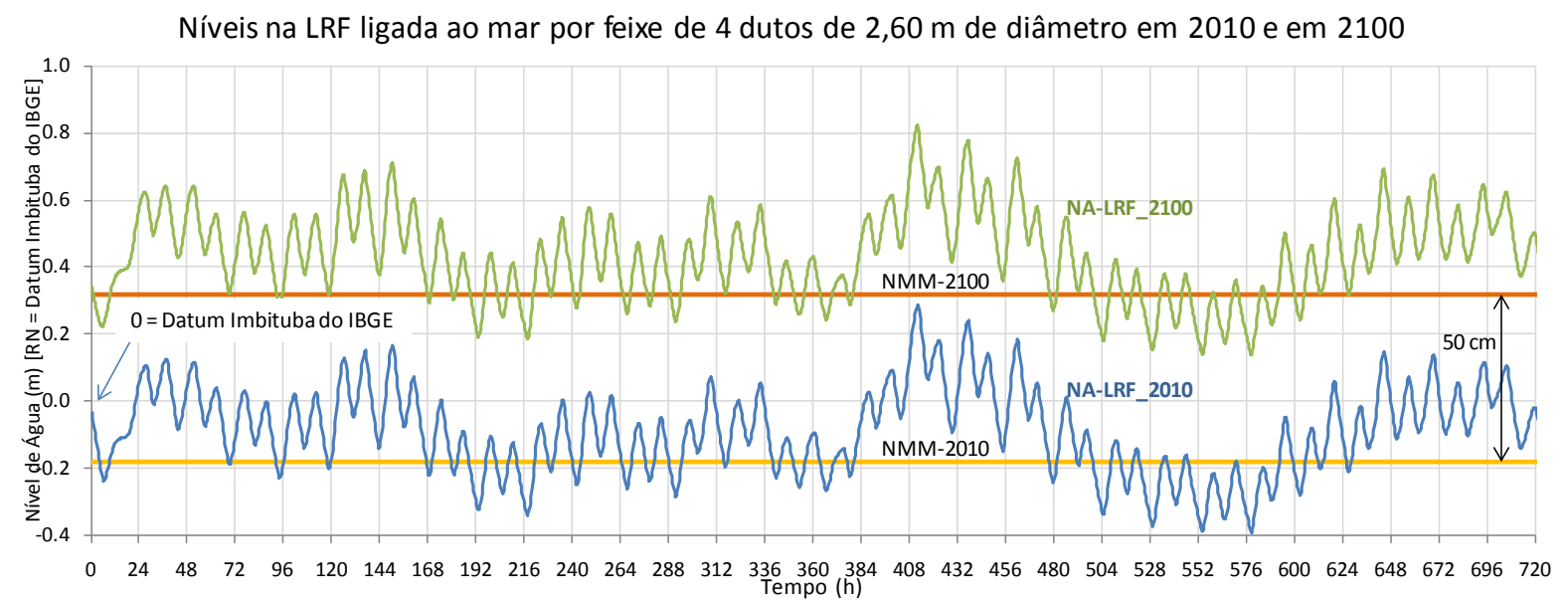

Figura 13. Prognóstico de variações de níveis de água na LRF, considerando a situação projetada em 2010 e elevação de $0,5 \mathrm{~m}$ no NMM em 2100 , devido a mudanças climáticas. Note que a resposta dinâmica do sistema gera um sobre-elevação na LRF superior em cerca de $3 \mathrm{~cm}$ à subida do NMM, e que as amplitudes de maré na LRF em 2100 seriam um pouco maiores que em 2010. Considerando os níveis observados em 1991 e em 1999 (Figura 8 e Figura 9), verifica-se que os máximos níveis de água na LRF previstos para 2100 seriam similares.

Figure 13. Prognostic of water level variations in the LRF, considering the projected situation in 2010 and, due to climate changes, a mean sea level rise of $0.5 \mathrm{~m}$ in 2100. Note that the dynamic system response causes an extra rise of about $3 \mathrm{~cm}$ in the LRF above the mean sea level rise, and that the tidal ranges in the lagoon would be slightly higher in 2100 than in the projected situation in 2010. Considering at the observed water levels in 1991 and 1999 (Figure 8 and Figure 9), one sees that the maximum forecasted water levels in 2100 would be similar.

A Figura 13 apresenta os resultados obtidos para prognósticos de variação de níveis de água na LRF na situação projetada em 2010 e na situação considerando sobre-elevação no NMM de $0,5 \mathrm{~m}$ devido a mudanças climáticas. Analisando os gráficos, nota-se que a resposta dinâmica do sistema gera um sobre-elevação na LRF superior em cerca de $3 \mathrm{~cm}$ à subida do NMM. Tal resultado é natural, uma vez que uma sobre-elevação do NMM aumenta a área hidráulica ao longo do Canal do Jardim de Alah, diminuindo as perdas de carga. Consequentemente, as amplitudes de maré na LRF em 2100 seriam um pouco maiores que as previstas para 2010, Este efeito implica em maior troca de volumes de água entre a LRF e o mar.

Comparando com os níveis observados em 1991 e em 1999, apresentados na Figura 8 e na Figura 9, com os simulados para 2100 , verifica-se que os níveis máximos previstos para 2100 seriam semelhantes aos que ocorreram em 1991 e 1999. Portanto, uma possível elevação de $0,5 \mathrm{~m}$ no $\mathrm{NMM}$ devido a mudanças climáticas não causaria problemas na orla da LRF. 


\section{Circulação hidrodinâmica na LRF}

O foco das análises sobre circulação hidrodinâmica nesta seção está na opção de ligação lagoa-mar através de feixe de 4 dutos com diâmetro de $2,60 \mathrm{~m}$ e área hidráulica de $21,24 \mathrm{~m}^{2}$, por ser a opção de maior viabilidade construtiva. Entretanto, objetivando dar uma ideia da relevância das demais opções são apresentados gráficos de vazões no Canal do Jardim de Alah para cada caso na Figura 14, Figura 15 e Figura 16. As legendas das figuras contêm análises para cada caso, que podem ser resumidas na Tabela 2.

Os volumes por dia que entrariam e sairiam da LRF a cada dia não devem ser entendidos como trocas de massas de água, pois parte da água no volume que sai estava no volume que entrou. Análises sobre trocas efetivas de água e taxas de renovação são apresentadas adiante.

Tabela 2. Resumo de vazões médias e volumes de água diários médios que entrariam e sairiam da LRF para cada opção de feixe de dutos Table 2. Summary of average discharges and average daily water volumes that would inflow and outflow the LRF for each option of group of ducts

\begin{tabular}{|c|c|c|c|c|c|}
\hline \multicolumn{2}{|c|}{ Feixe de Dutos } & \multicolumn{2}{|c|}{ Marés de Sizígia } & \multicolumn{2}{|c|}{ Marés de Quadratura } \\
\hline Diâmetro & Área Hidráulica & Vazão Média & Volume/dia & Vazão Média & Volume/dia \\
\hline $3 \mathrm{com} Q_{3,05 \mathrm{~m}}$ & $21,8 \mathrm{~m}^{2}$ & $17,0 \mathrm{~m}^{3} / \mathrm{s}$ & $750,000 \mathrm{~m}^{3} / \mathrm{d}$ & $11,0 \mathrm{~m}^{3} / \mathrm{s}$ & $490,000 \mathrm{~m}^{3} / \mathrm{d}$ \\
\hline $4 \mathrm{com} \bigcirc 2,60 \mathrm{~m}$ & $21,2 \mathrm{~m}^{2}$ & $16,0 \mathrm{~m}^{3} / \mathrm{s}$ & $710,000 \mathrm{~m}^{3} / \mathrm{d}$ & $10,5 \mathrm{~m}^{3} / \mathrm{s}$ & $465.000 \mathrm{~m}^{3} / \mathrm{d}$ \\
\hline $9_{\text {com }} \bigcirc 1,60 \mathrm{~m}$ & $18,1 \mathrm{~m}^{2}$ & $13,0 \mathrm{~m}^{3} / \mathrm{s}$ & $590,000 \mathrm{~m}^{3} / \mathrm{d}$ & $8,0 \mathrm{~m}^{3} / \mathrm{s}$ & $350,000 \mathrm{~m}^{3} / \mathrm{d}$ \\
\hline
\end{tabular}

Vazões no Canal do Jardim de Alah Ligação com 3 Dutos com diâmetro de 3,05 m

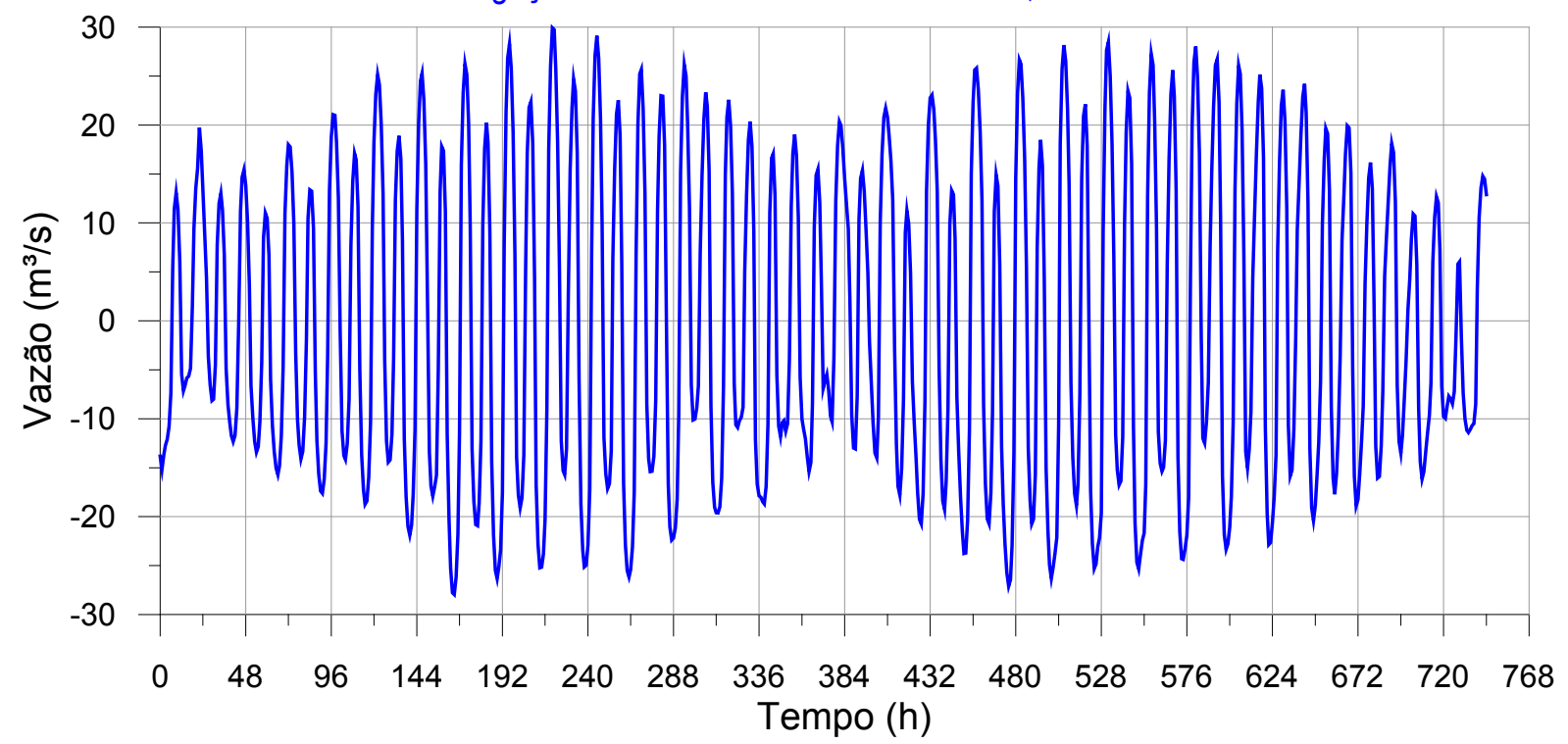

Figura 14. Vazões no Canal do Jardim de Alah com ligação lagoa-mar por 3 dutos com diâmetro de $3,05 \mathrm{~m}$ e área hidráulica de $21,8 \mathrm{~m}^{2}$. As vazões médias são próximas de $17 \mathrm{~m}^{3} / \mathrm{s}$ em marés de sizígia e de $11 \mathrm{~m}^{3} / \mathrm{s}$ em marés de quadratura, correspondendo a prismas de maré respectivamente de $375.000 \mathrm{~m}^{3}$ e $245.000 \mathrm{~m}^{3}$. Tipicamente, entrariam e sairiam da LRF volumes no entorno de $750.000 \mathrm{~m}^{3}$ em dias de marés de sizígia e de $490.000 \mathrm{~m}^{3}$ em dias de marés de quadratura.

Figure 14. Discharges in the Jardim de Alah Canal with a connection Lagoon-Sea through 3 ducts with a diameter of $3.05 m$ and hydraulic area of $21.8 \mathrm{~m}^{2}$. Average discharges are about $17 \mathrm{~m}^{3} / \mathrm{s}$ during spring tides and $11 \mathrm{~m}^{3} / \mathrm{s}$ in neap tides, corresponding to tidal prisms respectively of $375,000 \mathrm{~m}^{3}$ and $245,000 \mathrm{~m}^{3}$. Typically, the inflow and outflow volumes of water in the LRF would be about 750,000m ${ }^{3}$ in days of spring tides and $490,000 \mathrm{~m}^{3}$ in days of neap tides 


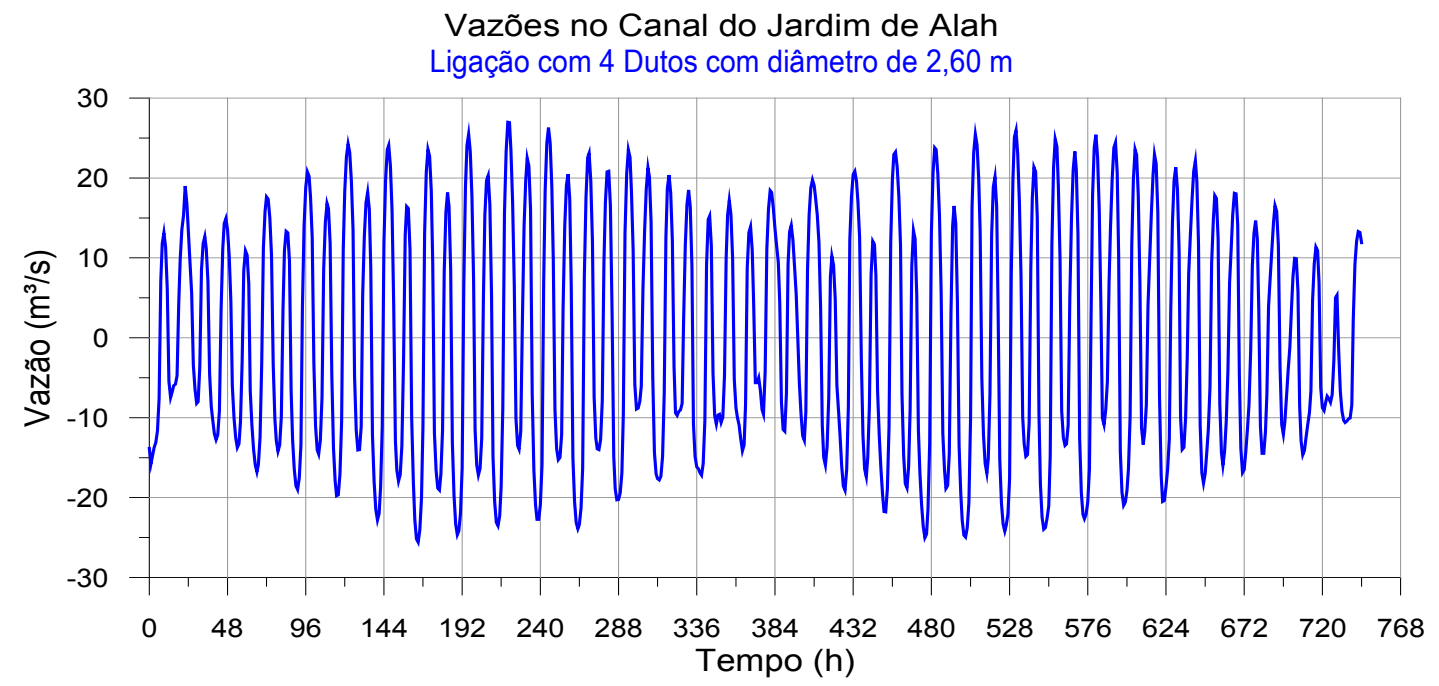

Figura 15. Vazões no Canal do Jardim de Alah com ligação lagoa-Mar por 4 dutos com diâmetro de 2,60m e área hidráulica de $21,2 \mathrm{~m}^{2}$. As vazões médias são próximas de $16 \mathrm{~m}^{3} / \mathrm{s}$ em marés de sizígia e de $10,5 \mathrm{~m}^{3} / \mathrm{s}$ em marés de quadratura, correspondendo a prismas de maré respectivamente de $355.000 \mathrm{~m}^{3} \mathrm{e} 233.000 \mathrm{~m}^{3}$. Tipicamente, entrariam e sairiam da LRF volumes no entorno de $710.000 \mathrm{~m}^{3} \mathrm{em}$ dias de marés de sizígia e de $466.000 \mathrm{~m}^{3} \mathrm{em}$ dias de marés de quadratura.

Figure 15. Discharges in the Jardim de Alah Canal with a connection Lagoon-Sea through 4 ducts with a diameter of 2.60m and hydraulic area of $21.2 \mathrm{~m}^{2}$. Average discharges are about $16 \mathrm{~m}^{3} / \mathrm{s}$ during spring tides and $10.5 \mathrm{~m}^{3} / \mathrm{s}$ in neap tides, corresponding to tidal prisms respectively of $355,000 \mathrm{~m}^{3}$ and $233,000 \mathrm{~m}^{3}$. Typically, the inflow and outflow volumes of water in the LRF would be about $760,000 \mathrm{~m}^{3}$ in days of spring tides and $466,000 \mathrm{~m}^{3}$ in days of neap tides

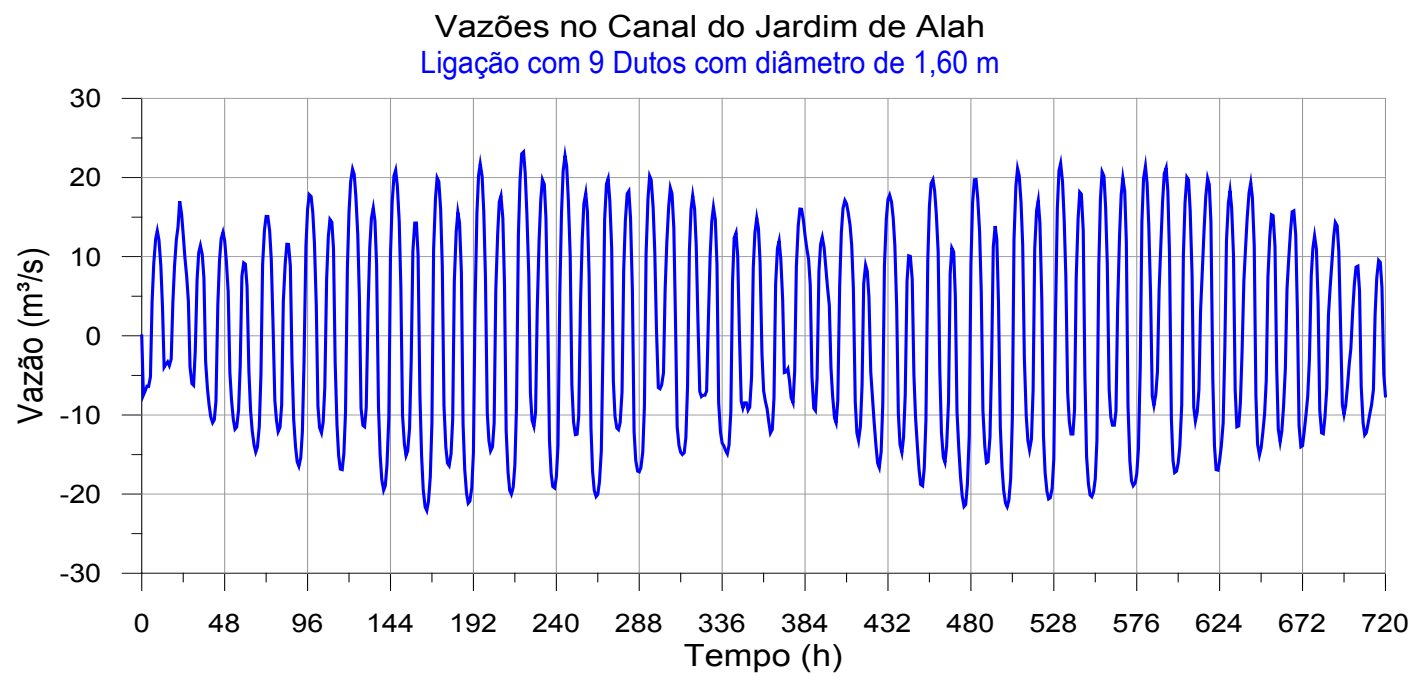

Figura 16. Vazões no Canal do Jardim de Alah com ligação lagoa-Mar por 9 dutos com diâmetro de 1,60m e área hidráulica de $18,1 \mathrm{~m}^{2}$. As vazões médias são próximas de $13 \mathrm{~m}^{3} / \mathrm{s}$ em marés de sizígia e de $8 \mathrm{~m}^{3} / \mathrm{s}$ em marés de quadratura, correspondendo a prismas de maré respectivamente de $295.000 \mathrm{~m}^{3}$ e $175.000 \mathrm{~m}^{3}$. Tipicamente, entrariam e sairiam da LRF volumes no entorno de $590.000 \mathrm{~m}^{3} \mathrm{em}$ dias de marés de sizígia e de $350.000 \mathrm{~m}^{3} \mathrm{em}$ dias de marés de quadratura.

Figure 16. Discharges in the Jardim de Alah Canal with a connection Lagoon-Sea through 9 ducts with a diameter of 1.60m and hydraulic area of $18.1 \mathrm{~m}^{2}$. Average discharges are about $13 \mathrm{~m}^{3} / \mathrm{s}$ during spring tides and $8 \mathrm{~m}^{3} / \mathrm{s}$ in neap tides, corresponding to tidal prisms respectively of $295,000 \mathrm{~m}^{3}$ and $175,000 \mathrm{~m}^{3}$. Typically, the inflow and outflow volumes of water in the LRF would be about 590,000 $\mathrm{m}^{3}$ in days of spring tides and $350,000 \mathrm{~m}^{3}$ in days of neap tides

Considerando que visualmente os padrões de circulação hidrodinâmica nos três casos de feixe de dutos são muito semelhantes, os resultados ilustrativos apresentados a seguir são apenas para ligação lagoamar por feixe com 4 dutos de 2,60m de diâmetro. Como mencionado, tal feixe é o mais viável em termos construtivos. As seguintes figuras ilustram aspectos de circulação hidrodinâmica:

- A Figura 17 mostra um exemplo de padrão de circulação hidrodinâmica média na coluna de água em situação de enchente de maré de sizígia, correspondendo à hora 531 no gráfico de vazões da Figura 15. 

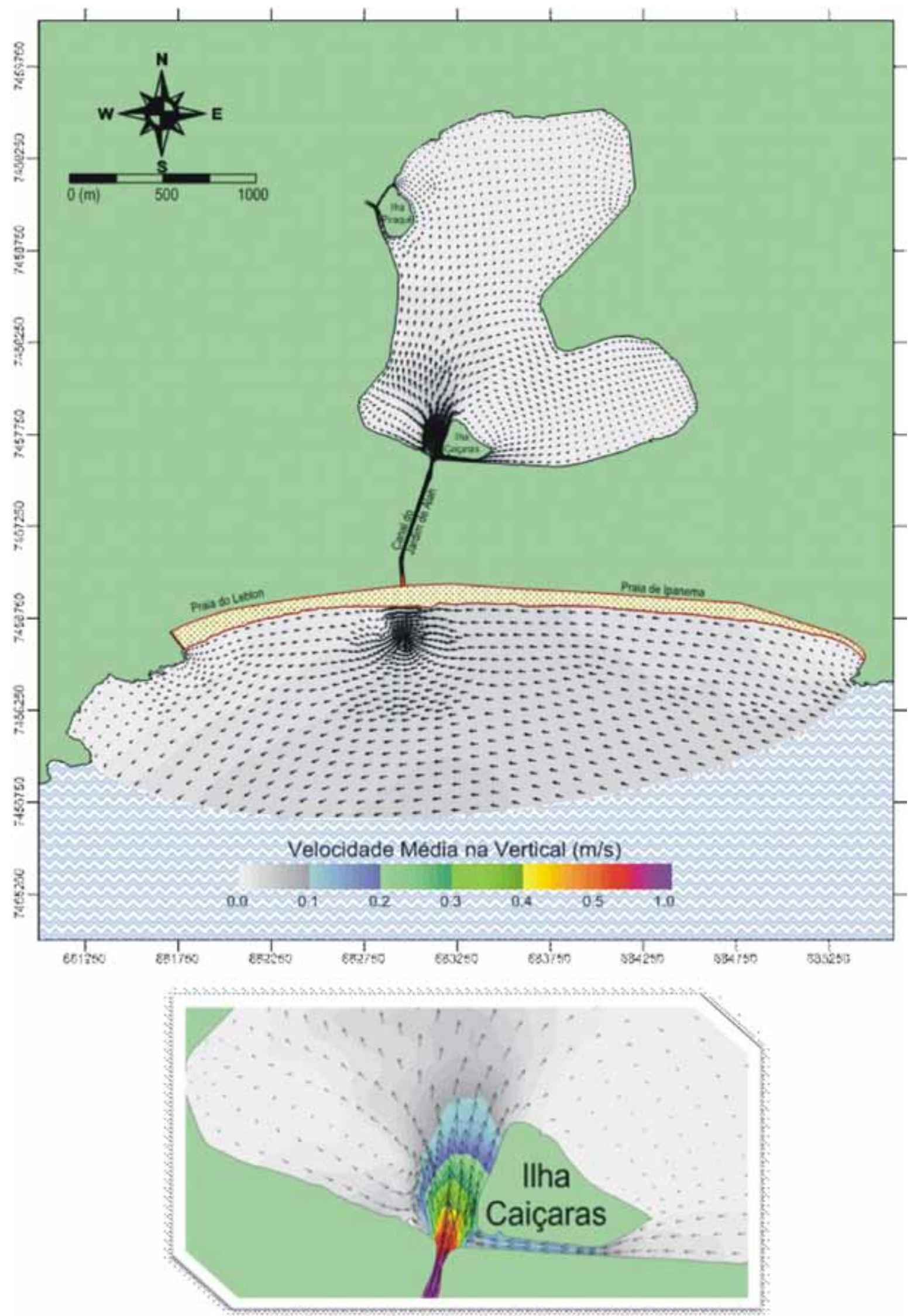

Figura 17. Exemplo de padrão de circulação hidrodinâmica média na coluna de água em situação de enchente de maré de sizígia, (hora 531 no gráfico de vazões da Figura 15).

Figure 17. Example of depth averaged hydrodynamic circulation pattern in a situation of flooding spring tide(. hour 532 in the discharge graph of Figure 15). 

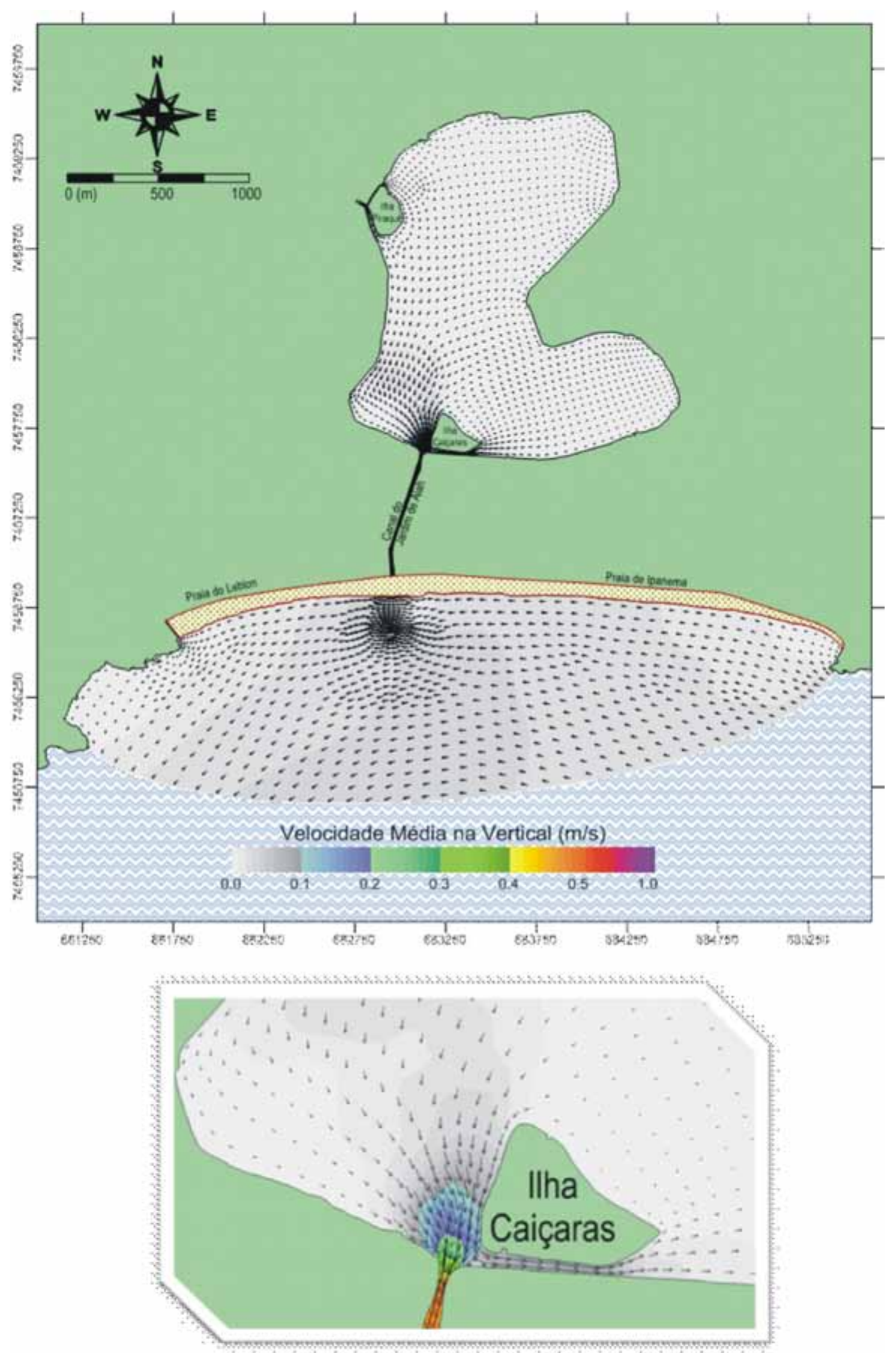

Figura 18. Exemplo de padrão de circulação hidrodinâmica média na coluna de água em situação de vazante de maré de sizígia (hora 537 no gráfico de vazões da Figura 15)

Figure 18. Example of depth averaged hydrodynamic circulation pattern in a situation of ebbing spring tide (hour 537 in the discharge graph of Figure $15)$. 


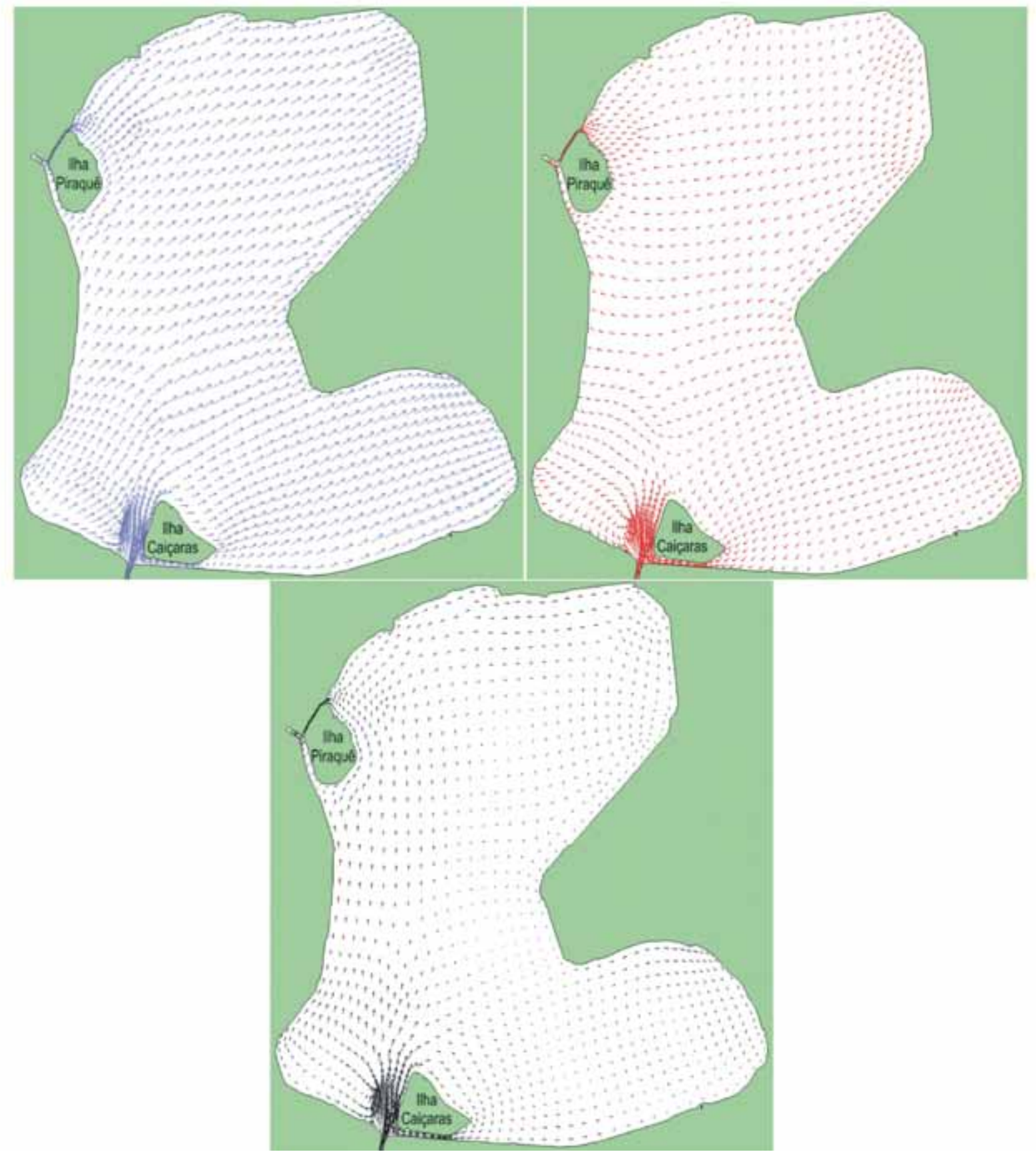

Figura 19. Visualização dos efeitos causados por ventos de SE no padrão de correntes na LRF, em situação de maré enchente. As correntes próximas da superfície livre, setas azuis, tendem a ser mais alinhadas com o vento e mostram o arraste exercido pelo vento nas águas superficiais. As setas vermelhas mostram que a circulação próxima ao fundo compensa o arraste superficial, pois nas camadas do fundo e da superfície as correntes têm sentidos opostos. As setas pretas representam as correntes médias na coluna de água.

Figure 19. Visualization of the SE winds effects on the current pattern in LRF during a flooding tide situation. The currents near the free surface, blue arrows, tend to be more aligned with the prevailing wind, and show the entrainment exerted by the wind on surface waters. The red arrows show that the circulation near to the bottom compensates the surface entrainment, since bottom and surface layers present flows in opposite directions. The black arrows represent depth averaged currents.

- A Figura 18 mostra um exemplo de padrão de circulação hidrodinâmica média na coluna de água em situação de vazante de maré de sizígia, correspondendo à hora 537 no gráfico de vazões da Figura 15.
- Objetivando mostrar a complexidade dos padrões de correntes na lagoa, a Figura 23 contém visualizações dos efeitos de vento Sudoeste no padrão de correntes na LRF em situação de maré enchente. O mapa com correntes próximas da superfície livre, 
em setas azuis, mostra que estas tendem a seguir o vento representando o arraste exercido pelo vento nas águas superficiais. As setas vermelhas mostram que a circulação próxima ao fundo compensa o arraste superficial, com correntes em sentidos opostos aos verificados na camada superficial. As setas pretas representam as correntes médias na coluna de água. Similarmente, a Figura 20 mostra os padrões de circulação para ventos de Noroeste.
Os exemplos representam uma pequeníssima parte dos resultados disponíveis nos casos simulados. Para cada caso, podem ser produzidos mapas e gráficos retratando valores horários ao longo dos 30 dias de simulação.

Os resultados agregados dos padrões de circulação são mais bem refletidos nas análises de renovação de águas da LRF devido a trocas efetivas de massas de água entre a lagoa e o mar, como discutido adiante.

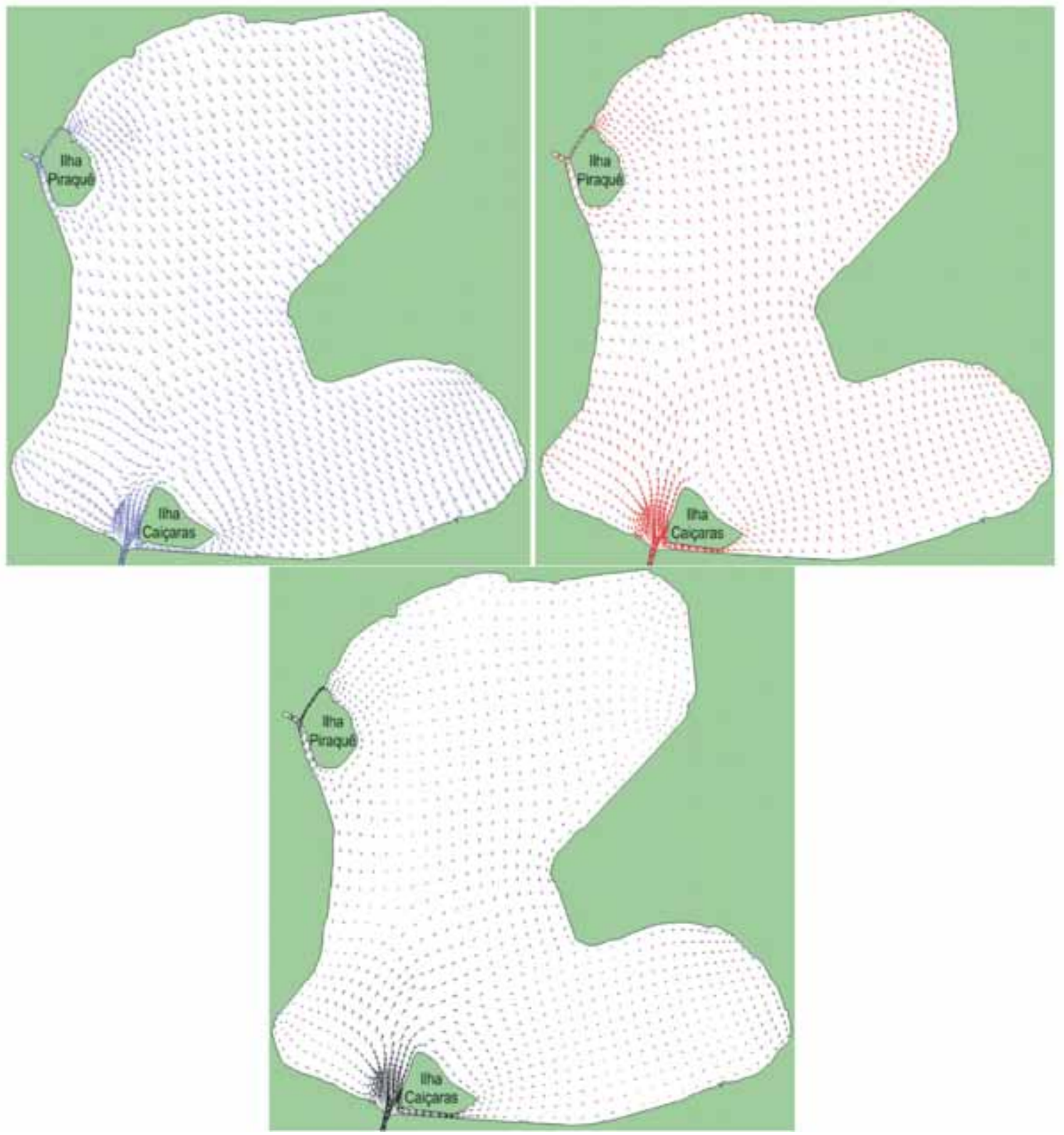

Figura 20. Visualização dos efeitos causados por ventos de NW no padrão de correntes na LRF em situação de maré enchente. As correntes próximas da superfície livre, setas azuis, tendem a ser mais alinhadas com o vento e mostram o arraste exercido pelo vento nas águas superficiais. As setas vermelhas mostram que a circulação próxima ao fundo compensa o arraste superficial, pois nas camadas do fundo e da superfície as correntes têm sentidos opostos. As setas pretas representam as correntes médias na coluna de água.

Figure 20. Visualization of the NW winds effects on the current pattern in LRF during a flooding tide situation. The currents near the free surface, blue arrows, tend to be more aligned with the prevailing wind, and show the entrainment exerted by the wind on surface waters. The red arrows show that the circulation near to the bottom compensates the surface entrainment, since bottom and surface layers present flows in opposite directions. The black 


\section{RENOVAÇÃO DE ÁGUAS NA LRF E EFEITOS NAS ÁGUAS COSTEIRAS}

Nesta seção são discutidos aspectos relacionados às trocas de massas de água entre a LRF e o mar, às taxas de renovação de águas na lagoa e efeitos da saída de águas da lagoa na linha de costa adjacente. A Figura 21 apresenta os nomes e respectivas posições de estações que são mencionadas em gráficos e tabelas apresentados nesta seção.
Os mapas apresentados nesta seção são da ligação lagoa mar através de feixe de 4 dutos com diâmetro de $2,60 \mathrm{~m}$ e área hidráulica de $21,2 \mathrm{~m}^{2}$. Esta é a opção de maior viabilidade construtiva segundo outros estudos contratados pela empresa EBX.

A seguir, nas Figura 22, Figura 23 e Figura 24 são apresentados gráficos mostrando taxas de renovação de águas na LRF em diferentes estações, para ligação via cada uma das três opções consideradas de feixe de dutos. Os cruzamentos de cada curva com as

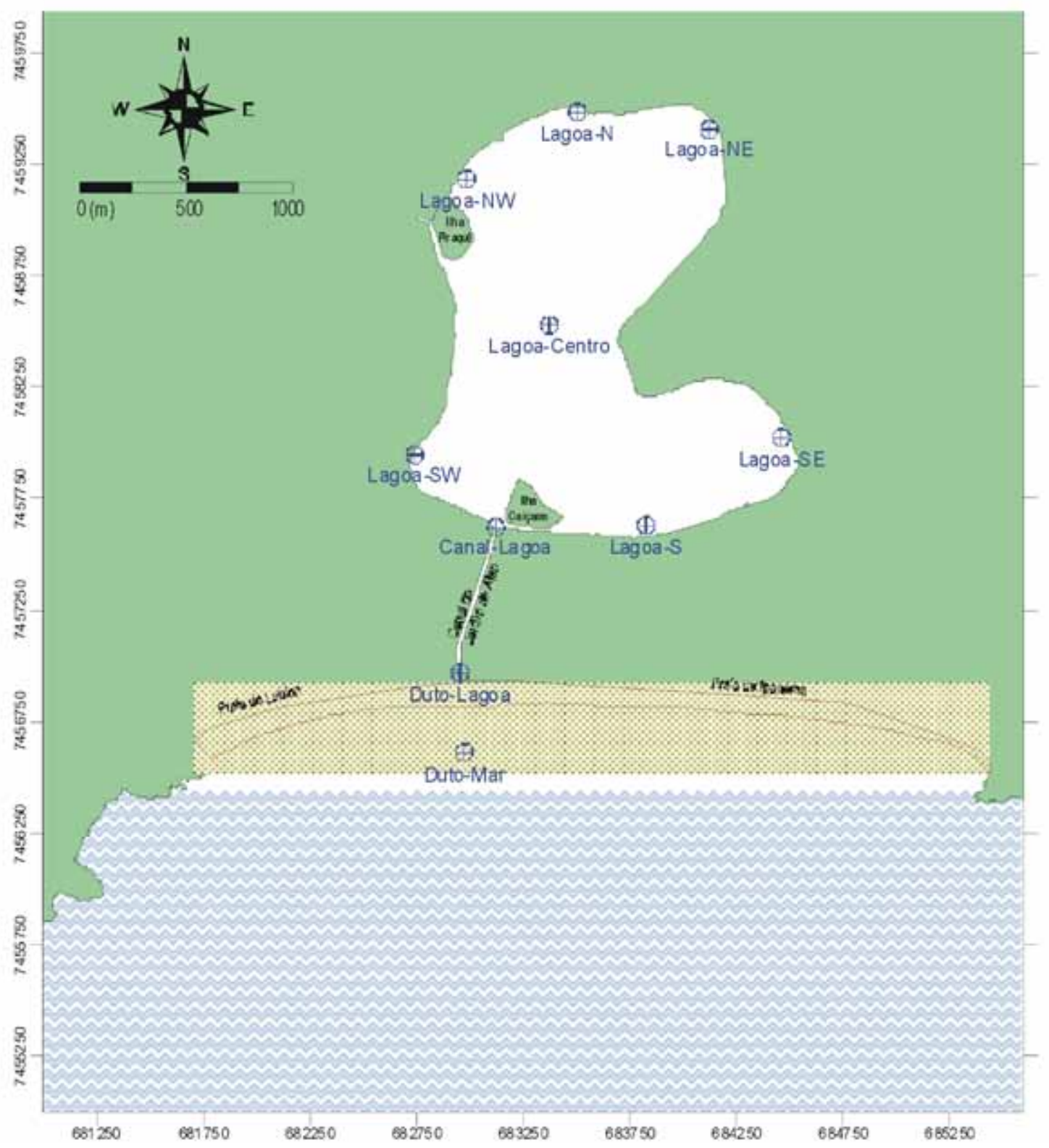

Figura 21. Posição e nomes de estações mencionadas em gráficos e tabelas nesta seção. Figure 21. Positioning and names of the stations mentioned in graphs and tables in this section. 
linhas indicadas $\mathrm{T}_{20}, \mathrm{~T}_{50}$ e $\mathrm{T}_{90}$ representam os tempos transcorridos para renovação de $20 \%, 50 \%$ e $90 \%$ das águas na respectiva estação. Como se pode ver nos gráficos, exceto para as regiões mais próximas do Canal do Jardim de Alah, ex. estação lagoa-SW, as taxas de renovação de água pelo escoamento médio na coluna de água são bastante similares.

Para o caso mais provável de ser construído, feixe de 4 dutos de 2,60m, a Figura 23 mostra que o tempo pata renovação de $50 \%$ das águas da LRF nas diferentes estações varia de 3 a 12 dias, sendo mais rápido na região próxima do Canal do Jardim de Alah e mais lento na extremidade NE da LRF. Mostra também que após cerca de 30 dias quase $90 \%$ das águas da LRF foram renovadas, em todos os pontos.

Para instantes selecionados pertinentes aos valores mostrados no gráfico da Figura 23, da Figura 25 à Figura 29 são apresentados mapas de isolinhas de trocas de massas de água entre a Lagoa Rodrigo de Freitas e o mar, e efeitos da saída das águas da lagoa no mar, correspondendo à ligação lagoa-mar com feixe de 4 dutos de $2,60 \mathrm{~m}$, respectivamente para os seguintes instantes:

- Figura 25: uma hora após a abertura da ligação lagoa-mar, em maré vazante.

- Figura 26: 05 dias após a abertura da ligação lagoa-mar, em maré enchente.

- Figura 27: 10 dias após a abertura da ligação lagoa-mar, em maré vazante.

- Figura 28: 20 dias após a abertura da ligação lagoa-mar, em maré enchente.

- Figura 29: 30 dias após a abertura da ligação lagoa-mar, em maré vazante.

Analisando os mapas juntamente com o gráfico da Figura 23 obtêm-se uma boa ideia da efetividade da renovação das águas da LRF propiciada pela ligação lagoa-mar. Também nos mapas, percebe-se que as interferências da saída das águas da LRF no mar tornam-se imperceptíveis após cerca de 20 dias.

Como ilustrado na Figura 30 e na Figura 31, ressalta-se que, levando em conta efeitos tridimensionais, e o fato da água do mar ser mais fria e salgada que as águas da lagoa, a renovação real seria mais rápida. Isso ocorreria, porque águas mais frias e salgadas nas marés enchentes iriam para o fundo, e nas vazantes as águas que sairiam seriam águas misturadas, menos salgadas e mais quentes da lagoa. Portanto haveria trocas mais efetivas devido à circulação residual por diferença de densidade que, pelo fundo ocorreria no sentido do interior da Lagoa e pelas camadas mais superficiais no sentido do Canal do Jardim de Alah.

\section{PROGNÓSTICOS DE SALINIDADES MÉDIAS NA $L R F$}

Como se mostra nesta seção, com a efetivação da ligação lagoa-mar, a LRF irá recuperar seus valores históricos de salinidade. Porém, isso ocorrerá de modo muito mais benéfico ao ambiente da LRF, pois ocorrerá sem a estratificação estagnada de então.

\section{Salinidades históricas na LRF}

Dados de salinidades na LRF medidos nas décadas de 60,70 e 80 mostram, frequentemente, um padrão de estratificação salina bem definida, com salinidades variando entre 15 e 23 ups numa camada superficial de aproximadamente $1,5 \mathrm{~m}$, e valores entre 19 e 31 ups na camada abaixo até o fundo (Ambiental 2001). A título de comparação, considera-se um corpo de água salgado se a salinidade for maior que 30ups, a salinidade do mar em Ipanema fica por volta de 34ups. Portanto, a LRF tem sido um corpo de águas salobras, chegando a ter águas salinas no fundo em décadas atrás.

Em fevereiro de 1996 houve uma súbita mudança no padrão de salinidades da LRF que persistiu pelo menos até 2000, pelas seguintes razões:

1. No final de 1995 e início de 1996 foi feito um engordamento de $370 \mathrm{mil} \mathrm{m}^{3}$ de areia na praia do Leblon. Tal engordamento foi executado de modo inadequado, resultando em uma praia relativamente baixa e excessivamente larga. Por conta disto, a embocadura do Canal do Jardim de Alah passou a ser fortemente assoreada, e desenvolveu-se uma verdadeira barra de areia em sua frente. Desde então o canal passou a funcionar como canal extravasor, permitindo a água do mar entrar muito raramente.

2. Como mostra a Figura 9, medições feitas em Set-Nov/99 comprovam que o canal do Jardim 
de Alah passou a se comportar como um canal extravasor. Ao longo de mais de dois meses de medições, ou aproximadamente 1500 horas, só durante cerca de 10 horas entrou água do mar na lagoa. Em termos percentuais, em 99,3\% do tempo ou o canal funcionou como extravasor ou estava obstruído, já que em apenas $0,7 \%$ do tempo entrou água salgada na lagoa.

3. Na noite de 12 para 13 de Fevereiro de 1996, uma chuva excepcionalmente forte levou para a lagoa quase 3 milhões de $\mathrm{m}^{3}$ de água doce. Tal volume é quase metade do volume usual da lagoa. A inundação que se seguiu chegou à cota $+1,6 \mathrm{~m}$ IBGE. E, evidentemente, houve enorme diluição do sal existente na lagoa, levando-a a uma salinidade média muito abaixo dos usuais valores na casa de 20ups.

Salinidades medidas na LRF desde 2002 têm mostrado variações de salinidades médias entre $8 \mathrm{e}$ 20ups, com épocas em que as águas da LRF ficam praticamente homogêneas e épocas em que a camada inferior chega a salinidades superiores a $20 \mathrm{ups}$, com significativa estratificação (Maciel 2007).

A seguir são mostrados prognósticos de salinidades médias na LRF resultantes da ligação lagoa-mar por dutos afogados.

\section{Salinidades com a ligação lagoa-mar por dutos afogados}

Focando na opção de ligação lagoa-mar com 4 dutos com diâmetro de $2,60 \mathrm{~m}$, nesta seção se mostra prognósticos de distribuições de salinidade na LRF. Destaca-se que os mapas e gráficos de prognóstico apresentados são de valores de salinidade médios na coluna de água. Porém, como mostram Martins \& Rosman 1999, devido a efeitos tridimensionais causados por diferenças de densidade, a situação real será mais complexa, com salinidades menores nas camadas superficiais e maiores no fundo, como ilustrado na Figura 30 e na Figura 31.

Enfatiza-se que a estratificação salina que se vê na Figura 30 e na Figura $31 \mathrm{em}$ nada se parece com a maligna estratificação estagnada do presente e passado, que tanto mal causam à lagoa. Trata-se de uma situação bastante dinâmica, na qual cerca de $600 \mathrm{mil} \mathrm{m}^{3} /$ dia entrariam e sairiam da LRF. Portanto, as águas mais salinas e frias do mar fluiriam para a camada do fundo da LRF propiciando duas vezes por dia renovação com águas saturadas de oxigênio dissolvido.

A Figura 32 mostra a evolução da variação e salinidades ao longo de 60 dias, indicando que o processo de alteração das salinidades tende ao equilíbrio. De fato, confrontando com os gráficos de renovação de água nas mesmas estações (Figura 23), é de se esperar que após 45 dias as salinidades tendam ao equilíbrio, visto que mais de $95 \%$ do volume de água original da LRF teria sido trocado. Note na Figura 32 que na condição do dia inicial, toda a LRF foi colocada com salinidade média igual a 8ups, um valor bem baixo.

Para 60 dias após a ligação lagoa-mar, a Figura 33 e a Figura 34 mostram mapas de isolinhas de salinidade na LRF em situações de maré vazante e de maré enchente. Nos mapas vê-se a gradação de salinidades crescentes em direção ao Canal do Jardim de Alah e decrescentes em direção à afluência dos rios Macacos e Cabeças junto da Ilha Piraquê. A gradação de salinidades, típica de sistemas estuarinos, favorece a diversidade biológica.

\section{SOBRE DRAGAGENS E NÍVEIS DE ÁGUA}

Esta seção discute variações de níveis de água, apresenta mapas de batimetria, além de recomendações sobre dragagens para recuperação ambiental de espaços aquáticos perdidos pelo assoreamento e manutenção de pleno espelho de água da Lagoa Rodrigo de Freitas, LRF.

\section{JUSTIFICATIVAS PARA A DRAGAGEM}

A ligação permanente da LRF ao mar fará com que os níveis de água da lagoa fiquem em equilíbrio dinâmico com os níveis de água no mar pelo princípio de vasos comunicantes. Como discutido, por décadas, os níveis de água da LRF têm sido mantidos artificialmente em cotas que, em média, até abril de 2010 ficavam cerca de $0,5 \mathrm{~m}$ acima do nível médio do mar, NMM, na praia de Ipanema-Leblon e, frequentemente, chegam a ficar até acima dos níveis usuais de preamar na praia de Ipanema-Leblon. Destaca-se que após as cheias de abril de 2010, por determinação dos órgãos ambientais da Prefeitura e do Estado do Rio de Janeiro, o NA da lagoa tem sido 


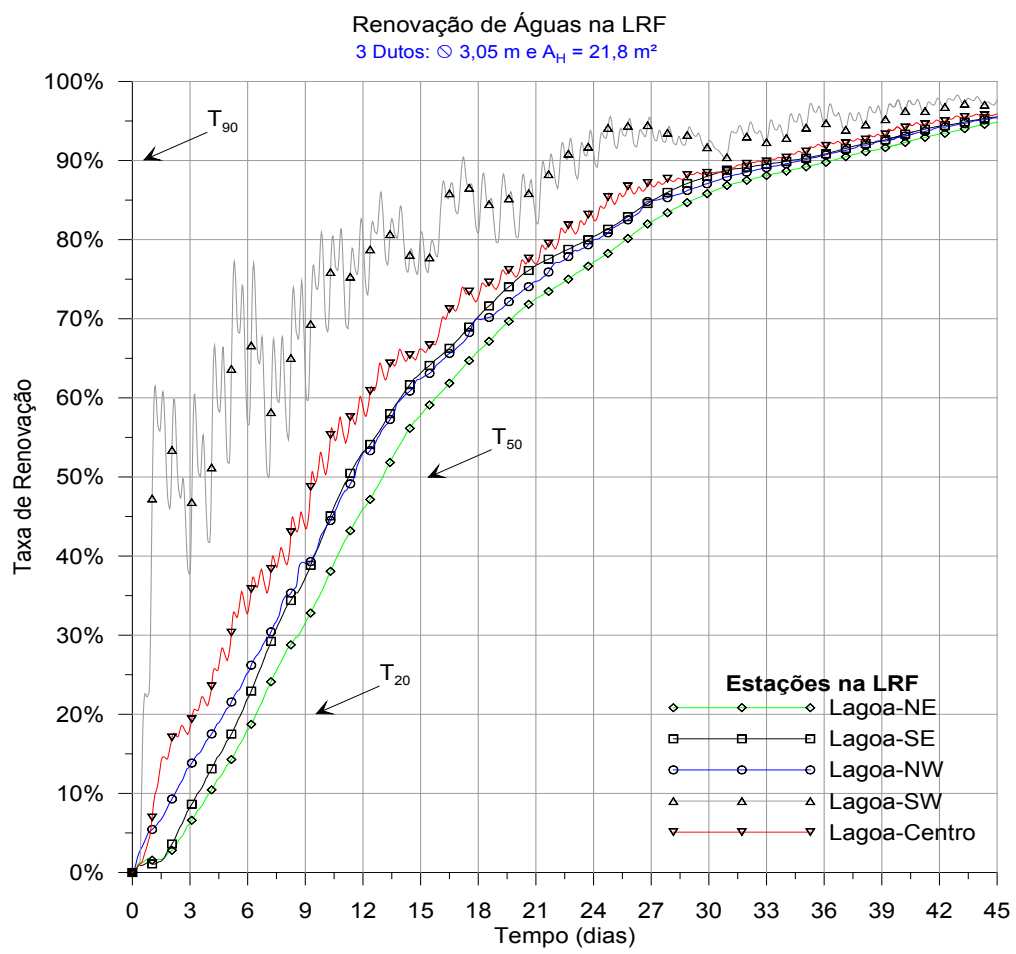

Figura 22. Tempos de renovação efetiva das águas em diferentes setores da LRF, considerando ligação por feixe de 3 dutos com diâmetro de $3,05 \mathrm{~m}$. Os cruzamentos de cada curva com as linhas indicadas $\mathrm{T}_{20}, \mathrm{~T}_{50}$ e $\mathrm{T}_{90}$ representam os tempos transcorridos para uma renovação de $20 \%, 50 \%$ e $90 \%$ das águas na respectiva estação. Comparando com os gráficos para os outros feixes de duto, nota-se que os tempos são semelhantes nas três opções.

Figure 22. Effective renewal times of the waters in different sectors of $L R F$, considering a connection with a group of 3 ducts with diameter of $3.05 m$. The crossings of each curve with the lines indicating $T_{20}, T_{50}$ and $T_{90}$ represent the passing time for a renewal of $20 \%, 50 \%$, and $90 \%$ of the waters in a respective station. Comparing with the graphs for the other groups of ducts, one sees that the renewal times are similar.

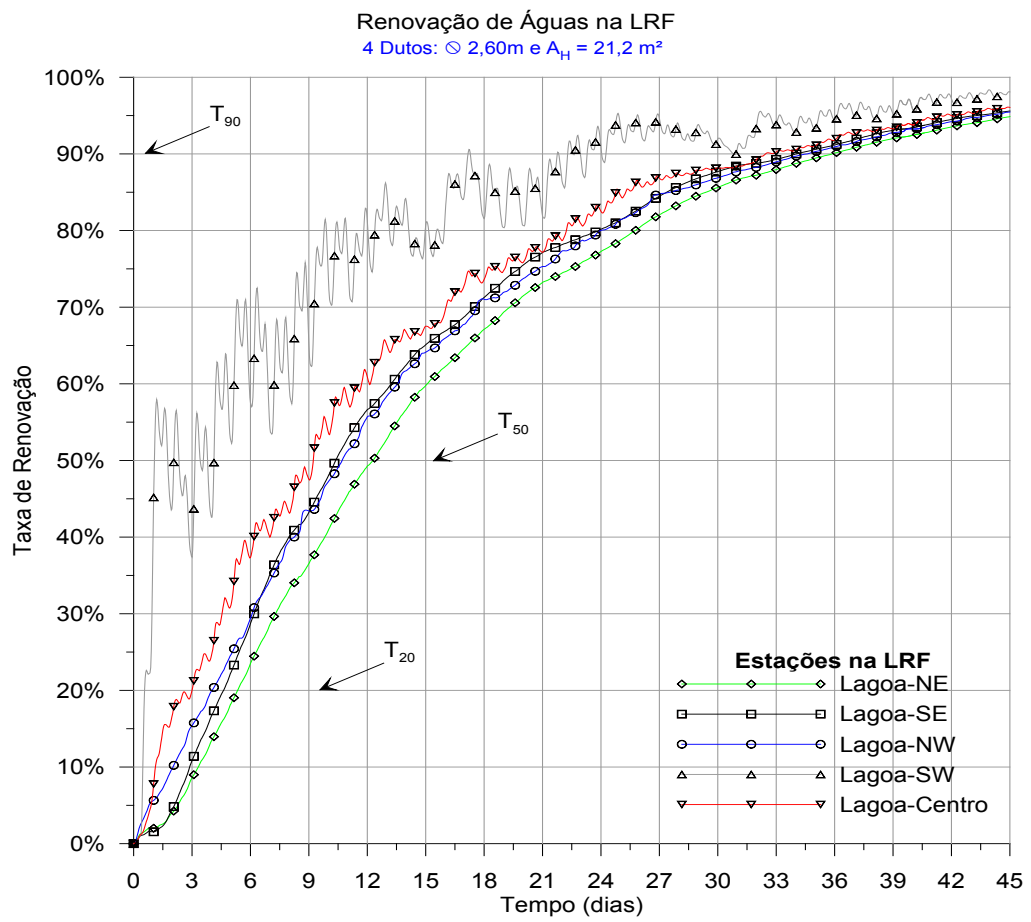

Figura 23. Tempos de renovação efetiva das águas em diferentes setores da LRF, considerando ligação por feixe de 3 dutos com diâmetro de $2,60 \mathrm{~m}$. Os cruzamentos de cada curva com as linhas indicadas $\mathrm{T}_{20}, \mathrm{~T}_{50}$ e $\mathrm{T}_{90}$ representam os tempos transcorridos para uma renovação de $20 \%, 50 \%$ e $90 \%$ das águas na respectiva estação. Comparando com os gráficos para os outros feixes de duto, nota-se que os tempos são semelhantes nas três opções.

Figure 23. Effective renewal times of the waters in different sectors of LRF, considering a connection with a group of 4 ducts with diameter of $2.60 \mathrm{~m}$. The crossings of each curve with the lines indicating $T_{20}, T_{50}$, and $T_{90}$ represent the passing time for a renewal of $20 \%, 50 \%$, and $90 \%$ of the waters in a respective station. Comparing with the graphs for the other groups of ducts, one sees that the renewal times are similar. 


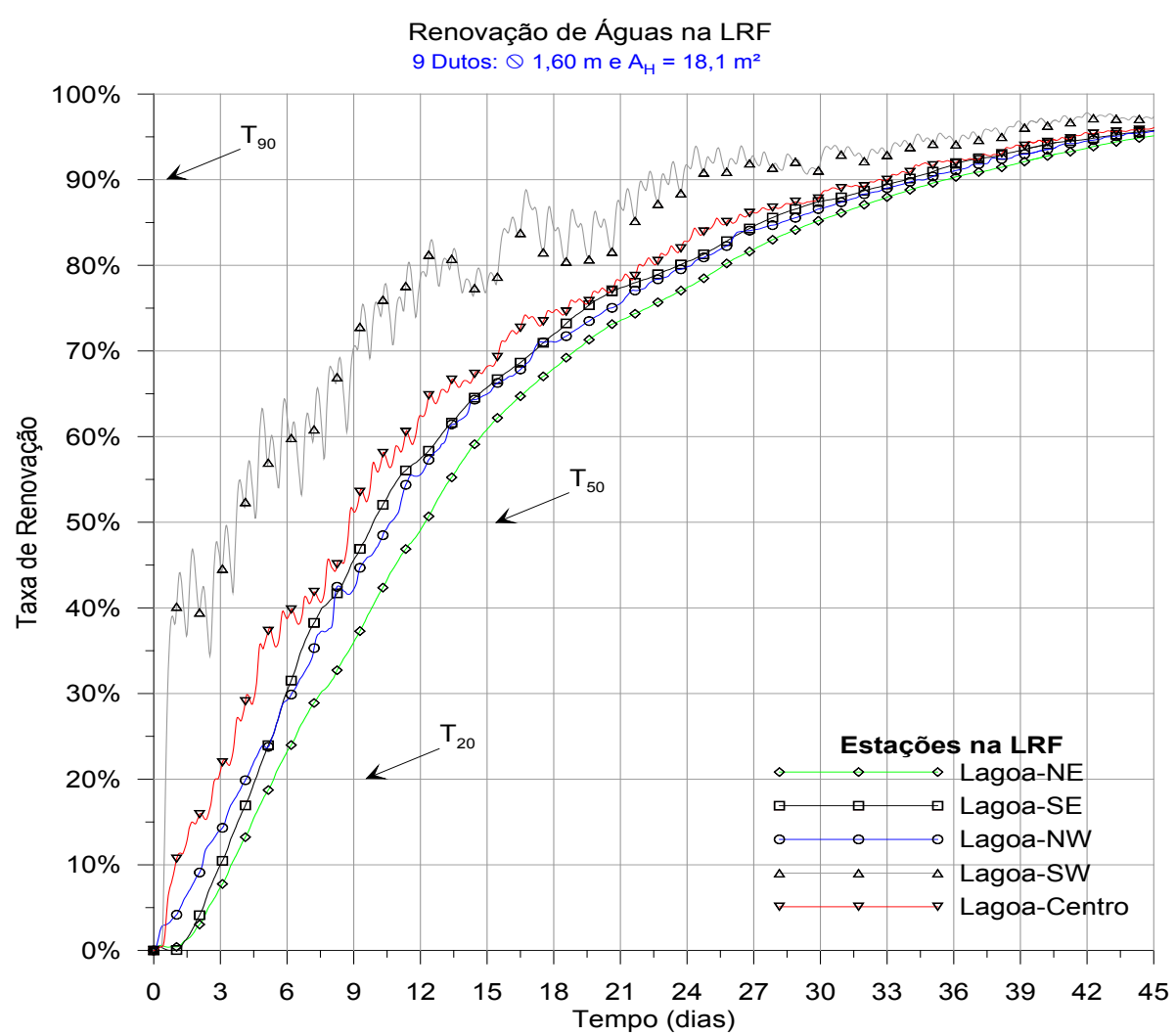

Figura 24. Tempos de renovação efetiva das águas em diferentes setores da LRF, considerando ligação por feixe de 9 dutos com diâmetro de 1,60m. Os cruzamentos de cada curva com as linhas indicadas $\mathrm{T}_{20}, \mathrm{~T}_{50}$ e $\mathrm{T}_{90}$ representam os tempos transcorridos para uma renovação de $20 \%, 50 \% \mathrm{e} 90 \%$ das águas na respectiva estação. Comparando com os gráficos para os outros feixes de duto, nota-se que os tempos são semelhantes nas três opções.

Figure 24. Effective renewal times of the waters in different sectors of LRF, considering a connection with a group of 9 ducts with diameter of $1.60 \mathrm{~m}$. The crossings of each curve with the lines indicating $T_{20^{\circ}} T_{50^{\circ}}$ and $T_{90}$ represent the passing time for a renewal of $20 \%, 50 \%$, and $90 \%$ of the waters in a respective station. Comparing with the graphs for the other groups of ducts, one sees that the renewal times are similar.

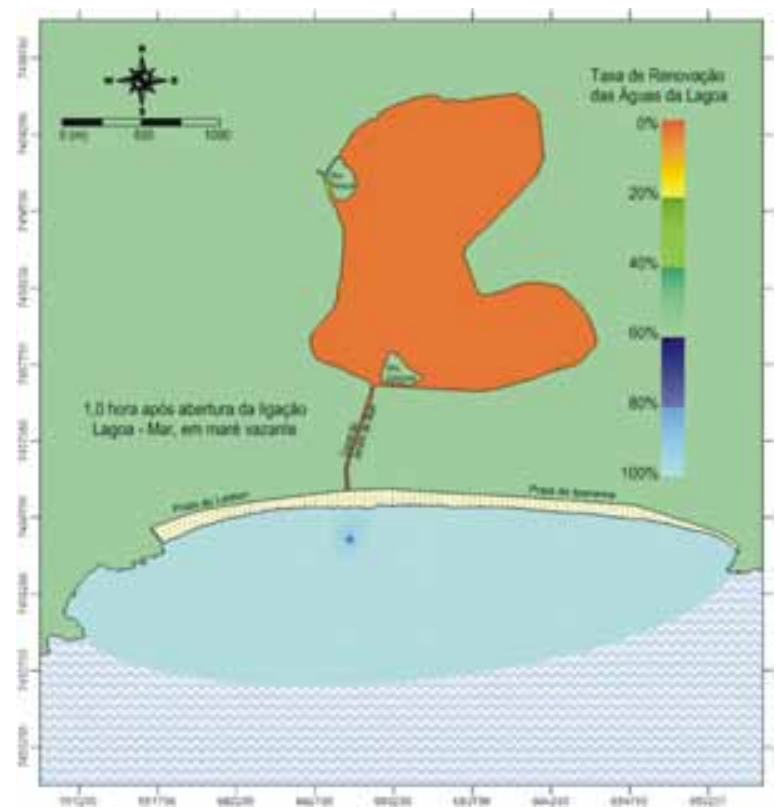

Figura 25. Mapa de isolinhas de taxas de trocas de águas da LRF com o mar mostrando taxas de renovação de águas na lagoa e efeitos da saída das águas da lagoa no mar, 1,0 hora após abertura da ligação com feixe de 4 dutos de diâmetro de 2,60m. Vê-se que a LRF apresenta águas ainda sem renovação, e que há uma mancha azul mais escuro no ponto de saída dos dutos no mar. Retrata-se a situação de máxima interferência das águas da LRF no mar na vazante dos dutos.

Figure 25. Map of isolines of rate of water exchange between the $L R F$ and the sea showing water renewal rates in the LRF, and the effects of the outflow of lagoon waters into the sea, 1.0 hour after the opening of connection with a group of 4 ducts with a diameter of 2.60m. One sees that the LRF still presents waters without renewal, and that the dark blue spot over the ducts points of discharge into the sea. The map shows the situation of maximum interference of the lagoon waters into the sea, while outflowing from the ducts. 


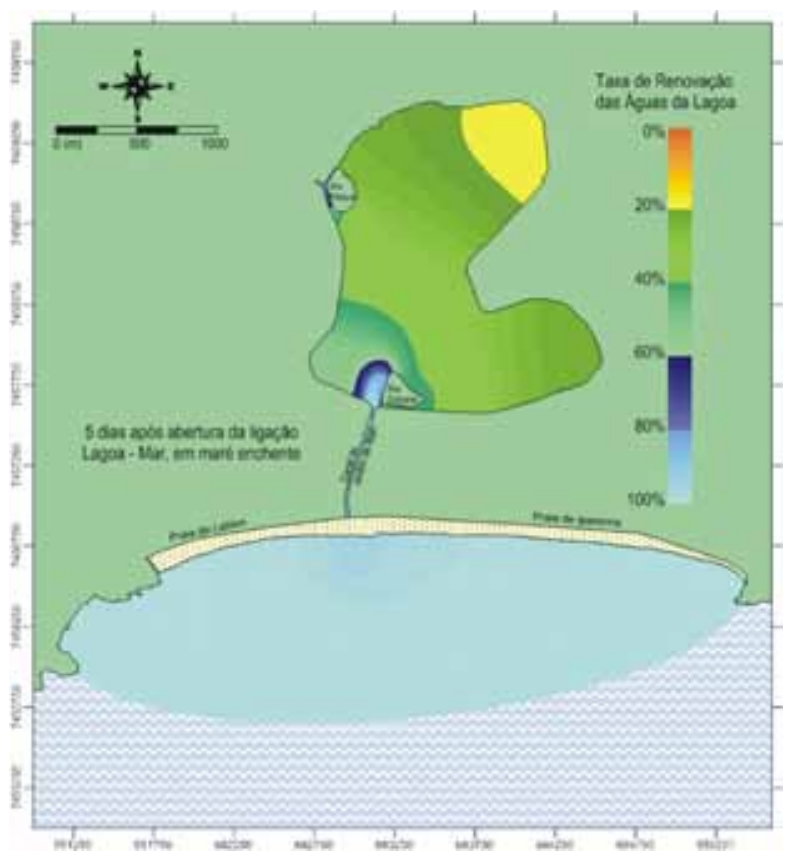

Figura 26. Mapa de isolinhas de taxas de trocas de águas da LRF com o mar, mostrando taxas de renovação de águas na LRF e efeitos da saída das águas da lagoa no mar, 5 dias após abertura da ligação com feixe de 4 dutos de diâmetro de 2,60m. Vê-se que, após apenas 5 dias, a LRF já apresenta relevante renovação em suas águas, e que a mancha azul mais escuro indicando a interferência das águas da LRF no mar é mais ampla, porém muito diluída para causar impactos relevantes na balneabilidade. Veja valores em pontos selecionados da LRF no gráfico da Figura 23.

Figure 26. Map of isolines of rate of water exchange between the LRF and the sea showing water renewal rates in the LRF, and the effects of the outflow of lagoon waters into the sea, 5 days after the opening of connection with a group of 4 ducts with a diameter of 2.60m. One sees that, after just 5 days, the LRF already presents a relevant water renewal. The darker blue area showing the interference of lagoon waters in the sea has spread, but it is too diluted to cause significant impacts in the bathing conditions along the beach. See values in selected points within LRF in the graph of Figure 23.

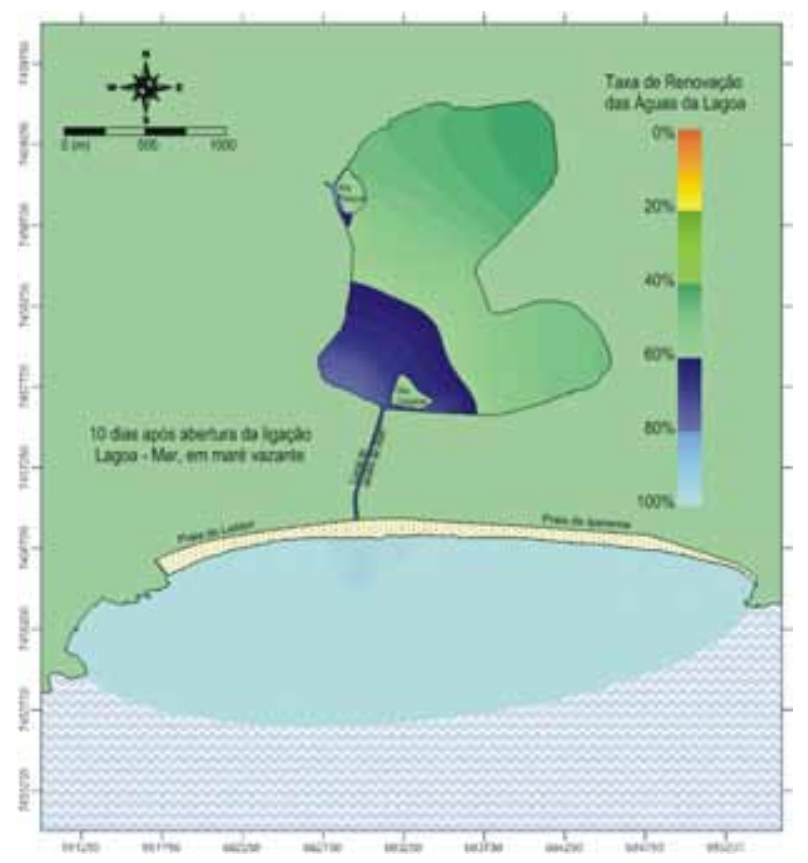

Figura 27. Isolinhas de taxas de trocas de águas da LRF com o mar, mostrando taxas de renovação de águas na LRF e efeitos da saída das águas da lagoa no mar, 10 dias após abertura da ligação com feixe de 4 dutos de diâmetro de 2,60m Vê-se que após 10 dias a LRF já apresenta renovação média de 50\% em suas águas. A mancha azul mais escuro indicando a interferência das águas da LRF no mar está muito diluída para causar impactos relevantes na balneabilidade, apesar de ser maré vazante nos dutos. Veja valores em pontos selecionados da LRF no gráfico da Figura 23.

Figure 27. Map of isolines of rate of water exchange between the $L R F$ and the sea showing water renewal rates in the LRF, and the effects of the outflow of lagoon waters into the sea, 10 days after the opening of connection with a group of 4 ducts with a diameter of $2.60 \mathrm{~m}$. One sees that after 10 days, the $L R F$ already presents an average water renewal of about $50 \%$. The darker blue area showing the interference of lagoon waters in the sea is too weak to cause significant impacts in the bathing conditions along the beach. See values in selected points within LRF in the graph of Figure 23. 


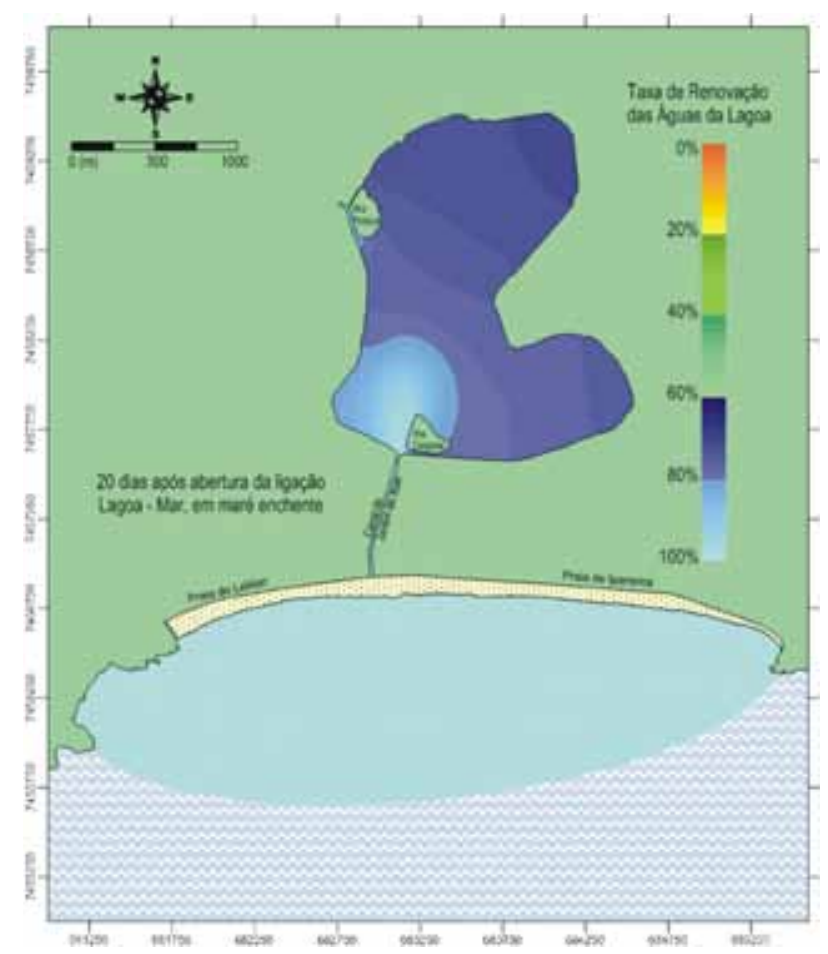

Figura 28. Isolinhas de taxas de trocas de águas da LRF com o mar, mostrando taxas de renovação de águas na LRF e efeitos da saída das águas da lagoa no mar, 20 dias após abertura da ligação com feixe de 4 dutos de diâmetro de 2,60 m. Vê-se que após 20 dias a LRF já apresenta renovação média de $70 \%$ em suas águas, e que a interferência das águas da LRF no mar está tão diluída que não se percebe. Veja valores em pontos selecionados da LRF no gráfico da Figura 23.

Figure 28. Map of isolines of rate of water exchange between the LRF and the sea showing water renewal rates in the LRF, and the effects of the outflow of lagoon waters into the sea, 20 days after the opening of connection with a group of 4 ducts with a diameter of $2.60 m$. One sees that after 20 days, the $L R F$ already presents an average water renewal of about $70 \%$. The darker blue area showing the interference of lagoon waters in the sea is so weak, that it is almost imperceptible. See values in selected points within LRF in the graph of Figure 23.

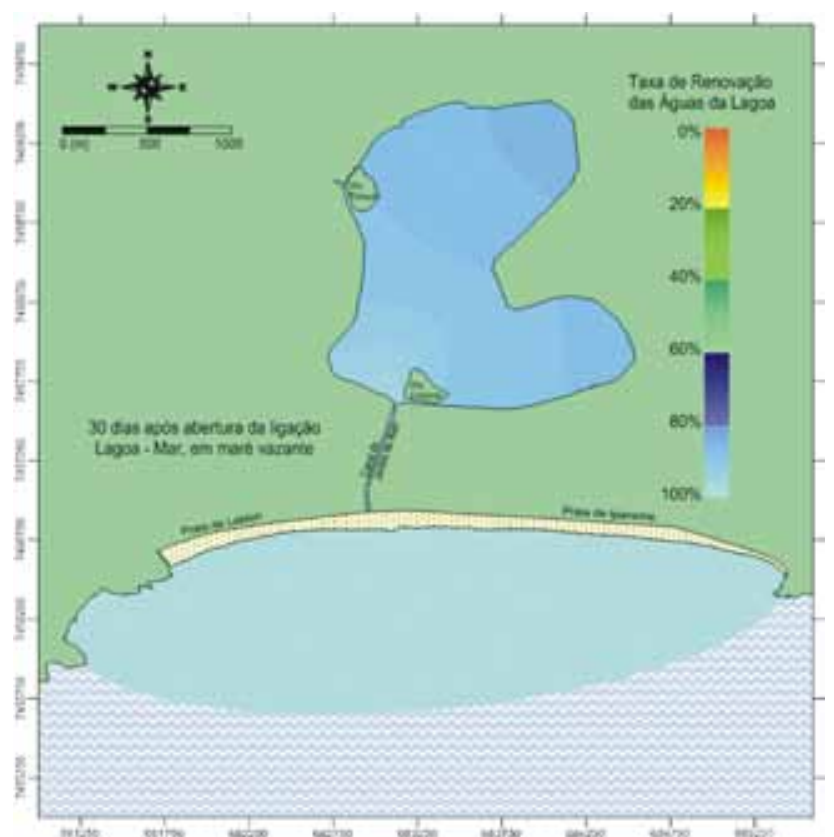

Figura 29. Isolinhas de taxas de trocas de águas da LRF com o mar, mostrando taxas de renovação de águas na LRF e efeitos da saída das águas da lagoa no mar, 30 dias após abertura da ligação com feixe de 4 dutos de diâmetro de 2,60 m. Vê-se que após 30 dias a LRF já apresenta renovação média próxima de $90 \%$ em suas águas, e que a interferência das águas da LRF no mar está tão diluída que não se percebe, mesmo em maré vazante nos dutos. Veja valores em pontos selecionados da LRF no gráfico da Figura 23.

Figure 29. Map of isolines of rate of water exchange between the LRF and the sea showing water renewal rates in the LRF, and the effects of the outflow of lagoon waters into the sea, 30 days after the opening of connection with a group of 4 ducts with a diameter of 2.60m. One sees that after 30 days, the LRF already presents an average water renewal of about $90 \%$. The interference of lagoon waters in the sea is so weak, that it is imperceptible even during ebbing tides. See values in selected points within LRF in the graph of Figure 23. 


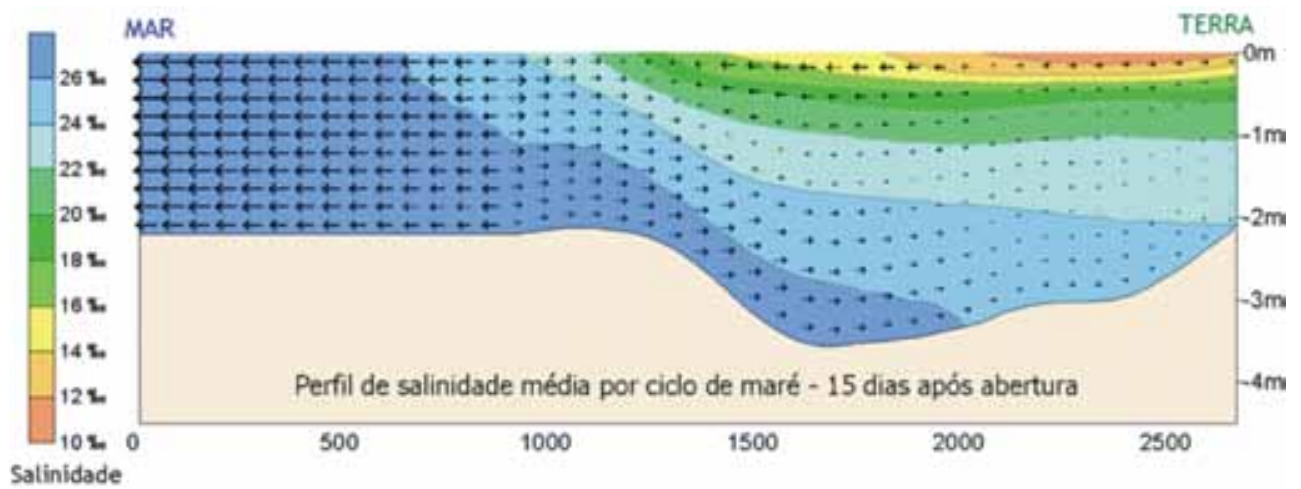

Figura 30. Seções transversais de valores médios por ciclo de maré, de correntes e salinidade, em um plano vertical que vai da embocadura do Canal do Jardim de Alah até a margem norte, próximo da Ilha do Piraquê. A Figura retrata a situação 15 dias após a abertura do Canal do Jardim de Alah, como projetado em Rosman et al. (1992), em simulação dinâmica com marés astronômicas e vazão fluvial de $1,0 \mathrm{~m}^{3} / \mathrm{s}$, não se considerou vento nem marés meteorológicas (Martins \& Rosman 1999).

Figure 30. Transversal section of values averaged over a tidal cycle, of currents and salinity, in a vertical plane from the mouth of the Jardim de Alah Canal up to the North shore, near the Piraque Island. The picture shows a situation 15 days after the opening of the canal do the sea, as designed in Rosman et al. (1992), in a dynamic simulation with astronomical tides and river flow of $1.0 \mathrm{~m}^{3} / \mathrm{s}$, winds and storm surges were not considered. (Martins \& Rosman 1999).

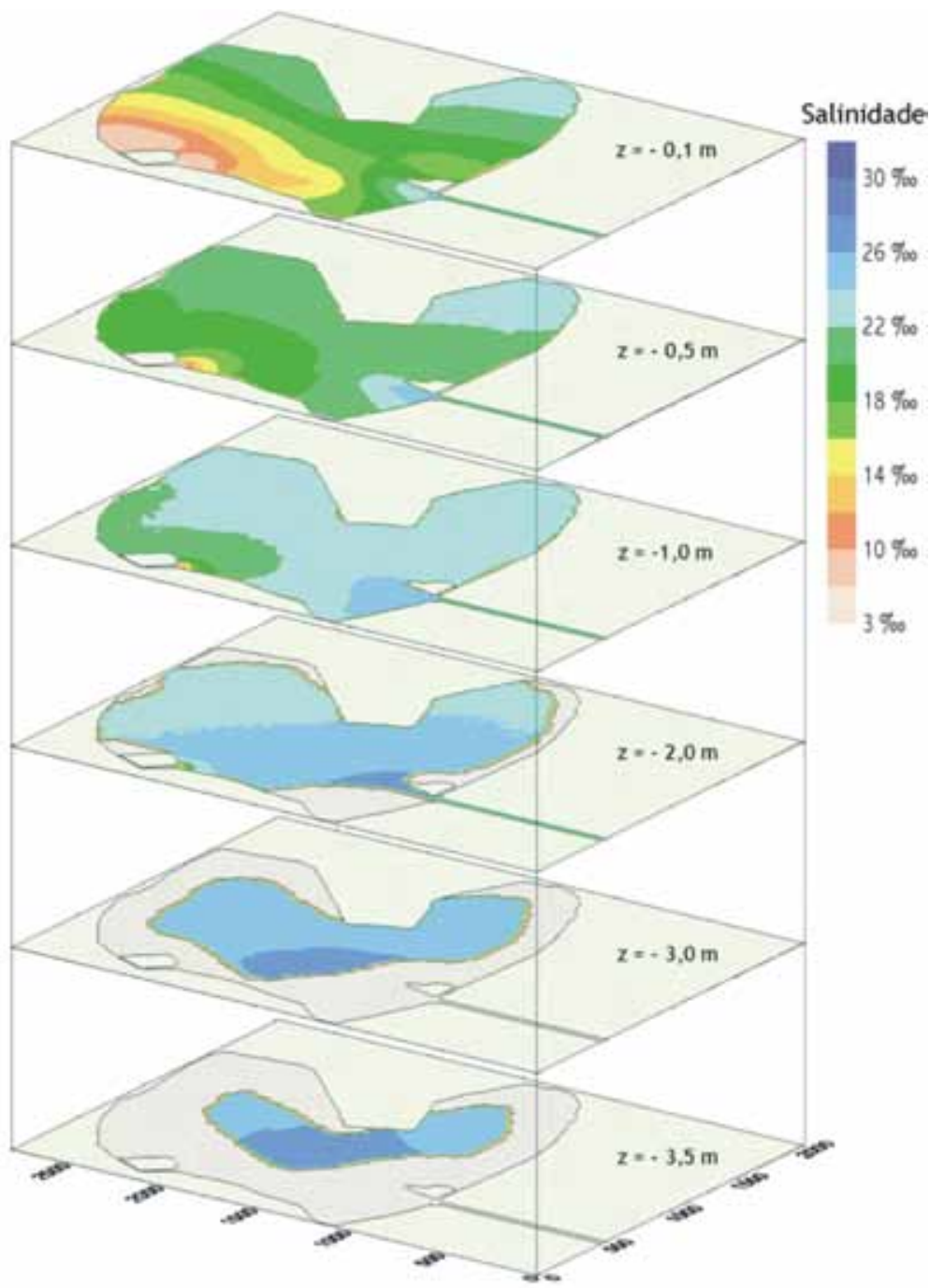

Figura 31. Isolinhas de salinidades médias por ciclo de maré em seis planos horizontais: $\mathrm{z}=-0,1 \mathrm{~m} ; \mathrm{z}=-0,5 \mathrm{~m} ; \mathrm{z}=-1,0 \mathrm{~m} ; \mathrm{z}=-2,0 \mathrm{~m} ; \mathrm{z}=-3,0 \mathrm{~m}$ e $\mathrm{z}=$ $-3,5 \mathrm{~m}$. A Figura retrata a situação 15 dias após a abertura do Canal do Jardim de Alah, como projetado em Rosman et al. (1992), em simulação dinâmica com marés astronômicas e vazão fluvial de $1,0 \mathrm{~m}^{3} / \mathrm{s}$, não se considerou vento nem marés meteorológicas. (Martins \& Rosman 1999).

Figure 31. Salinity isolines averaged over a tidal cycle in six horizontal planes: $z=-0.1 \mathrm{~m} ; z=-0.5 \mathrm{~m} ; z=-1.0 \mathrm{~m} ; z=-2.0 \mathrm{~m} ; z=-3.0 \mathrm{~m}$ e $z=-3.5 \mathrm{~m}$. The picture shows a situation 15 days after the opening of the canal do the sea, as designed in Rosman et alii (1992), in a dynamic simulation with astronomical tides and river flow of $1.0 \mathrm{~m}^{3} / \mathrm{s}$, winds and storm surges were not considered. (Martins \& Rosman 1999). 


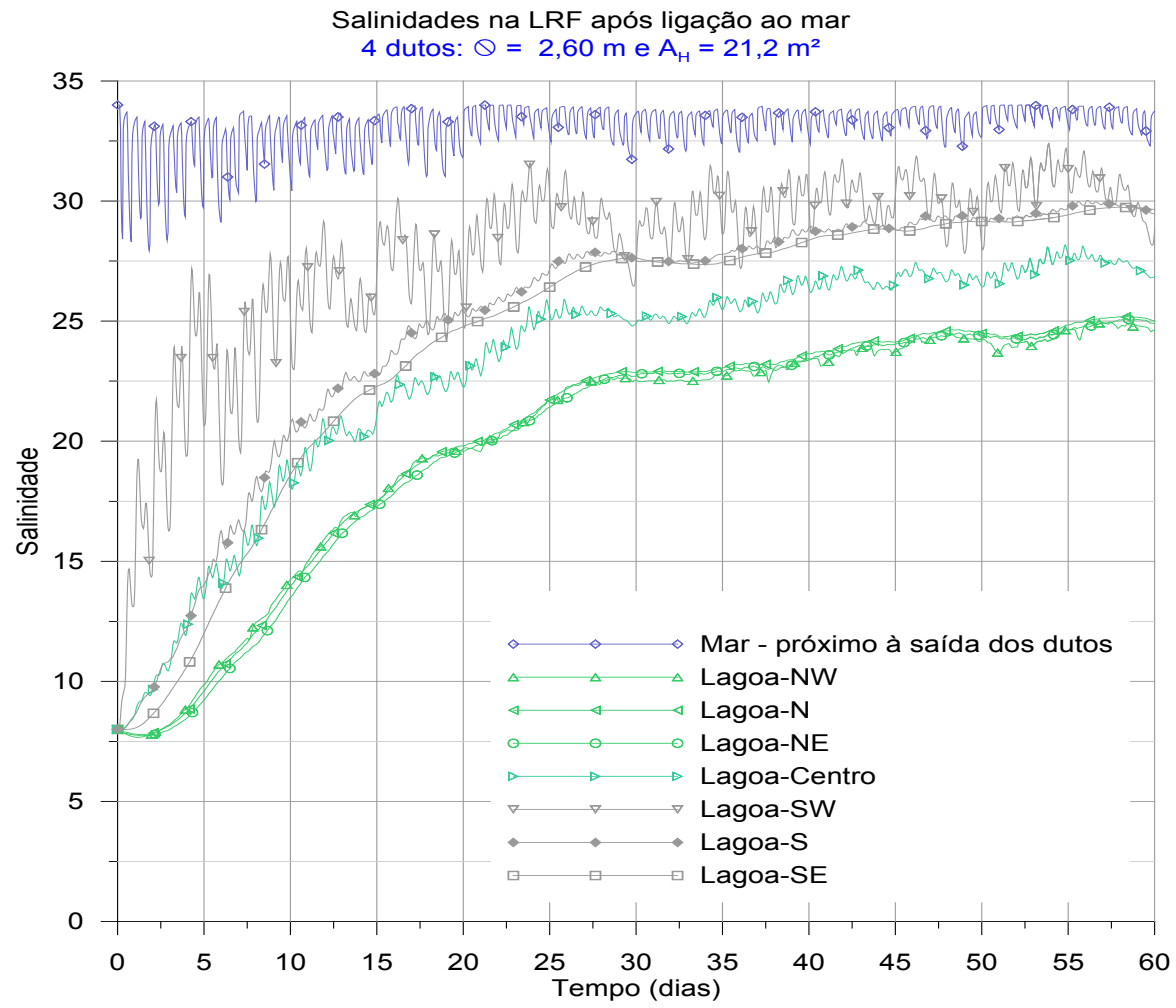

Figura 32. Salinidades na LRF após ligação lagoa-mar com dutos afogados. Verifica-se que após 60 dias as curvas de salinidade tendem a valores assintóticos que variam para médias entre 25 e 30 nas diferentes estações. Veja mapas na figura a seguir.

Figure 32. Salinities in the LRF after connection lagoon-sea with drowned ducts. One sees that after 60 days the salinity curves tend to asymptotic values that vary to average values from 25 to 30 in the different stations. See maps in the pictures ahead.

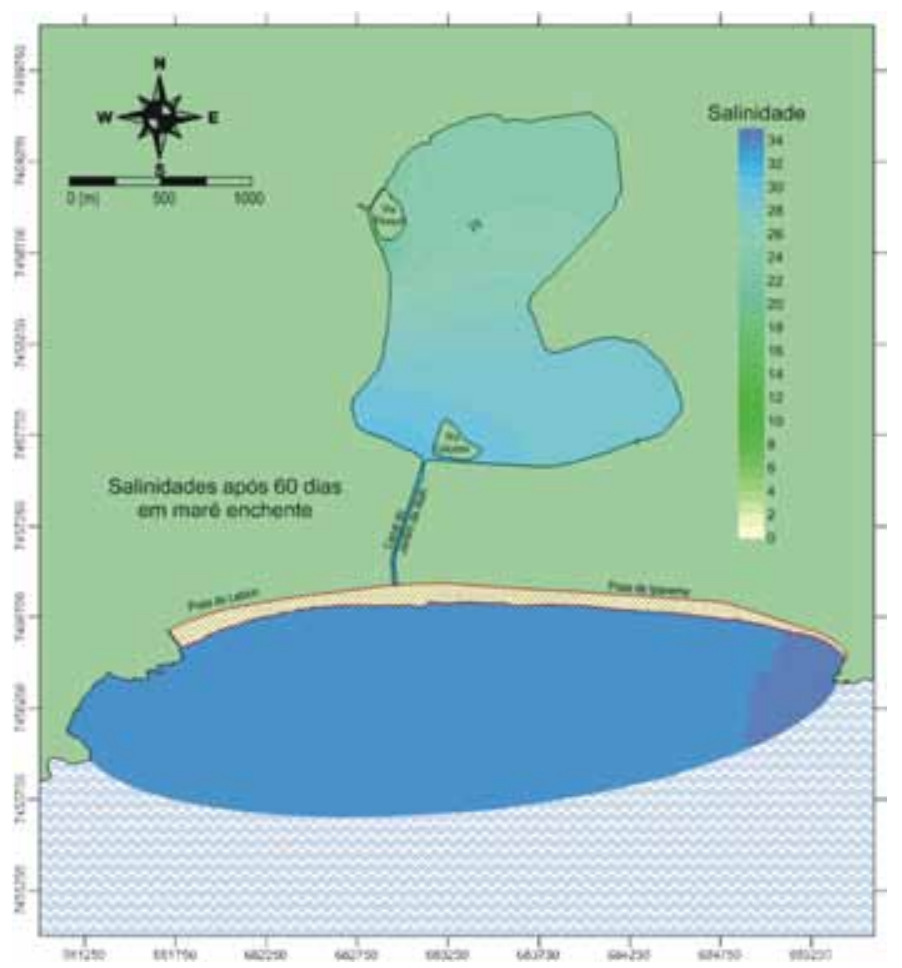

Figura 33. Mapas de isolinhas de salinidades em maré vazante, 60 dias após ligação da LRF ao mar com feixe de 4 dutos de 2,60m de diâmetro. Nota-se a gradação de salinidades crescentes em direção ao Canal do Jardim de Alah e decrescentes em direção à afluência dos rios Macacos e Cabeças junto da Ilha Piraquê. A gradação de salinidade, típica de sistemas estuarinos, favorece uma maior diversidade biológica.

Figure 33. Maps of salinity isolines in an ebbing tide, 60 days after the connection of LRF to the sea with a group of 4 ducts with diameter of $2.60 \mathrm{~m}$. One sees the salinity gradation growing towards the Jardim de Alah Canal and diminishing towards the entrance of Macacos and Cabeças rivers near Piraque Islands. The salinity gradation, typical of estuarine systems, favors a greater biological diversity. 


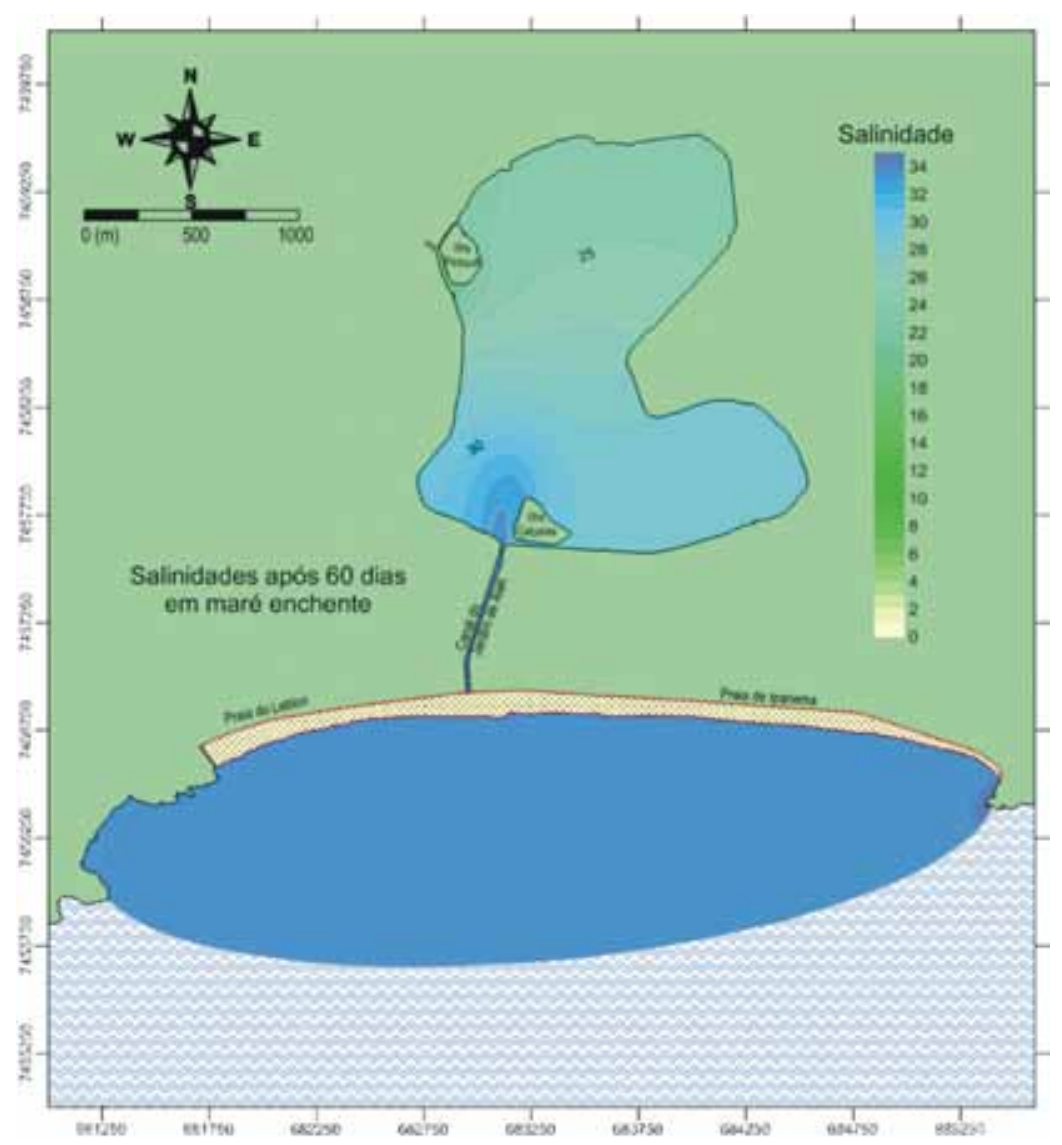

Figura 34. Mapas de isolinhas de salinidades em maré enchente 60 dias após ligação da LRF ao mar com feixe de 4 dutos de 2,60m de diâmetro. Notase a gradação de salinidades crescentes em direção ao Canal do Jardim de Alah e decrescentes em direção à afluência dos rios Macacos e Cabeças junto da Ilha Piraquê. A gradação de salinidades, típica de sistemas estuarinos, favorece a diversidade biológica.

Figure 34. Maps of salinity isolines in a flooding tide, 60 days after the connection of LRF to the sea with a group of 4 ducts with diameter of 2.60m. One sees the salinity gradation growing in the direction of the Jardim de Alah Canal and diminishing towards the entrance of Macacos and Cabeças river near Piraque Islands. The salinity gradation, typical of estuarine systems, favors a greater biological diversity.

mantido próximo do zero do IBGE, que fica cerca de $0,2 \mathrm{~m}$ acima do NMM do mar.

Portanto, ter níveis em equilíbrio dinâmico com o mar implicará em um pequeno rebaixamento nos níveis médios de água da LRF em relação aos níveis passados. O rebaixamento dos níveis de água na LRF, mantidos os fundos atuais, certamente acarretaria no afloramento de bancos de sedimentos em áreas atualmente muito rasas, com impactos estéticos e ambientais negativos. Portanto, a dragagem de tais áreas é altamente justificável e recomendável, pois permitirá:

- Recuperação de espaços aquáticos perdidos ao longo dos anos por naturais processos de assoreamento.

- Revitalização de áreas hoje muito degradadas por apresentarem bancos de sedimentos e profundidades muito baixas, frequentemente tomadas por algas macrófitas e vegetação nem sempre benéfica ao ambiente, pois acumulam lixo e deixam um aspecto de sujeira.

- Enchimento, com sedimentos da própria lagoa, de enormes e profundas cavas de dragagens feitas nos anos 70, para extração de areia para realização dos aterros do Parque dos Patins, junto ao Jockey Club, e do Parque do Cantagalo. Há décadas tais cavas funcionam como biodigestores anaeróbicos produzindo, entre outros, gases metano e sulfídrico, que são altamente deletérios para o ambiente da lagoa e cercanias. Além do mau cheiro, tais gases são muito tóxicos, prejudicando a qualidade da água e do ar nas cercanias.

- Manutenção do espelho de água da lagoa com mínima variação de área sob qualquer situação de nível de água, sem afloramento de bancos de sedimentos em áreas mais rasas.

Vale frisar que os benefícios listados acima, por si só, justificam e recomendam a dragagem, com ou 
sem ligação permanente da lagoa ao mar. A seguir, são discutidas em pormenor as questões de níveis de água na LRF, áreas de dragagem e cavas a serem preenchidas.

\section{SOBRE NÍVEIS DE ÁGUA E DRAGAGENS NA LAGOA RODRIGO DE FREITAS}

Como mostram os gráficos apresentados na Figura 8 e na Figura 9, os níveis de água da LRF têm sido mantidos artificialmente em cotas que, em média, ficam cerca de $0,5 \mathrm{~m}$ acima do nível médio do mar, NMM, na praia de Ipanema-Leblon. A persistência de níveis tão altos é devida a bloqueios da embocadura do canal por areia e a operações da comporta, ambos mantêm a lagoa estagnada.

Comparando os níveis históricos na LRF com níveis projetados mostrados Figura 10, conclui-se que haveria um rebaixamento do nível médio diário, visto que a lagoa passaria a funcionar em equilíbrio dinâmico com o mar.

\section{Vantagens e desvantagens da manutenção de níveis} elevados na LRF

Supostamente, as principais vantagens da manutenção artificial de altos níveis de água na LRF, através de operações da comporta do Canal do Jardim de Alah, além de bloqueios por areia na embocadura, são:

- Manter o espelho de água pleno, evitando o afloramento de bancos de sedimentos em áreas muito rasas. É indiscutível que tal efeito gera impacto estético positivo.

- $\quad$ Alega-se que níveis de água mais elevados aumentam a espessura da camada superior da coluna de água, que apresenta condições fóticas e concentrações de oxigênio dissolvido suficientes para manutenção de peixes. Isso é duvidoso, pois em um corpo de água hipertrófico com excesso de fitoplâncton como a LRF, a espessura da camada fótica depende fortemente da concentração de biomassa de fitoplâncton. Vale lembrar que as concentrações de OD na camada superficial da LRF também dependem desta biomassa e, por efeito de fotossíntese e respiração, variam da hipersaturação no final da tarde a grandes déficits no final da madrugada. Tal situação é ambientalmente insustentável e instável. Consequentemente, o que pode acontecer com a elevação dos níveis de água na LRF é simplesmente a elevação da camada superficial capaz de manter peixes sem efetivo aumento de sua espessura. Em contrapartida, ocorreria aumento da espessura da camada afótica e anaeróbica do fundo.

- Alega-se que níveis de água mais altos dificultariam a ressuspensão de lodo orgânico do fundo devido à ação de ondas de vento na lagoa. É fato que isso ocorre, porém, considerando que é da ordem de $0,5 \mathrm{~m}$ a diferença entre os níveis atuais da LRF e os níveis de equilíbrio com o mar, pode-se constatar que o efeito de proteção contra a ação de ondas é pouco relevante. A Figura 35 mostra mapas comparativos de isolinhas de tensões oscilatórias no fundo devido a ondas na LRF geradas por ventos de $8 \mathrm{~m} / \mathrm{s}$ vindos de SW, como é típico em entradas de frentes frias.

As principais desvantagens da manutenção artificial de altos níveis de água na LRF, através de operações da comporta do Canal do Jardim de Alah, além de bloqueios por areia na embocadura, são:

- Dificultar muito a entrada de água do mar, pois frequentemente os níveis de água na LRF ficam acima dos níveis de preamar na praia de IpanemaLeblon. Como já discutido, na prática, o canal do Jardim de Alah tem funcionado como um canal extravasor.

- Diminuir drasticamente as trocas biológicas entre o mar e a lagoa, reduzindo a diversidade biológica.

- Destruir a gradação de salinidades típica de sistemas estuarinos lagunares, favorecendo a estagnação, uniformização horizontal e estratificação vertical das águas da lagoa, contribuindo também para redução da diversidade biológica.

- Facilitar o transbordamento da lagoa em épocas de fortes chuvas.

\section{ÁREAS DE DRAGAGEM E DE ENCHIMENTO DE CAVAS}

A Figura 36 e a Figura 37 mostram mapas de batimetria feita na Lagoa Rodrigo de Freitas no ano de 2000, com cotas referidas ao mesmo Datum Imbituba - IBGE usado nos gráficos de níveis de água das figuras anteriores. As áreas a serem dragadas são 
as marcadas nas cores laranja claro e escuro, ou com profundidades inferiores a $1,0 \mathrm{~m}$. É fácil constatar que se trata de volume inferior a $200.000 \mathrm{~m}^{3}$.

As cavas a serem preenchidas com o material dragado são áreas marcadas com cores azuis mais escuras, apresentando profundidades superiores a $5 \mathrm{~m}$. As cavas seriam cheias até nivelar com as profundidades circunvizinhas. Portanto haveria um preenchimento de 4 a $5 \mathrm{~m}$ para uma área de cavas da ordem de $50.000 \mathrm{~m}^{2}$, ou seja, o volume disponível seria superior a $200.000 \mathrm{~m}^{3}$. Assim, todo o material dragado deverá ser jogado nas cavas, diminuindo muito os custos de dragagem.

O mapa da Figura 36 apresenta isolinhas de batimetria feita com ecobatímetro de alta frequência, e as cotas refletem o eco da superfície do lodo ou lama não consolidada no fundo. Por sua vez, o mapa da Figura 37 apresenta isolinhas de batimetria feita com ecobatímetro de baixa frequência, e as cotas refletem o eco da superfície do lodo já consolidado no fundo.

Portanto, a diferença entre as cotas de fundo das duas figuras representa uma estimativa da espessura de lodo fluido, ou lama não consolidada, no ano de 2000, Naquela ocasião o volume total calculado de lodo não consolidado era de cerca de $660.000 \mathrm{~m}^{3}$, como se vê na Figura 38.

Desde 2000 ocorreram pelo menos duas operações de dragagem na LRF. Na primeira realizada em $2002 / 2003$ teriam sido dragados cerca de $200,000 \mathrm{~m}^{3}$ de lodo fluido na região central da LRF. A segunda foi realizada nos preparativos dos jogos Pan-Americanos em 2006/2007, quando teriam sido dragados trechos mais rasos da faixa da raia de regata para obter as profundidades requeridas pela competição.

Por fim, vale destacar que, como mostra a Figura 38 , não há praticamente lama fluida nas áreas rasas a serem dragadas. Provavelmente, o material a ser dragado das áreas em laranja (Figura 36 e Figura 37), contém alto teor de areia, o que representa menores custos de dragagem e baixo risco de contaminação por metais pesados.

\section{DUTOS AFOGADOS OU GUIA-CORRENTES}

Esta seção aborda aspectos comparativos de modos de se viabilizar uma ligação permanente entre a Lagoa Rodrigo de Freitas e o mar através do Canal do Jardim de Alah, CJA. Duas opções são comparadas:
1. Guia-Correntes: Ligação canal-mar através de embocadura estabilizada com guia correntes, como proposto no estudo "Solução Conjunta dos Problemas de Erosão na Praia de Ipanema - Leblon e Qualidade de Água na Lagoa Rodrigo de Freitas" desenvolvido na COPPE em 1992. O projeto básico de engenharia para tal concepção foi realizado pelo LNEC em 2000 sob o título "SOLUÇÃO INTEGRADA DE REABILITAÇÃO AMBIENTAL DA LAGOA RODRIGO DE FREITAS, CANAL DO JARDIM DE ALAH E PRAIAS DO ARPOADOR, IPANEMA E LEBLON", cujo EIA - RIMA foi apresentado pela empresa Ambiental Engenharia e Consultoria Ltda., em 2001.

2. Dutos Afogados: Ligação canal-mar através de feixe de dutos afogados, conforme discutido anteriormente neste capítulo.

\section{PAISAGEM E LAZER}

Guia-Correntes: Sem dúvida a grande desvantagem desta alternativa está na definitiva divisão da praia de Ipanema e Leblon, com um par de estruturas em enrocamento se projetando cerca de $200 \mathrm{~m}$ mar adentro em relação à linha de praia atual. Embora seja uma questão subjetiva sujeita a gosto pessoal, em termos paisagísticos, os guia-correntes dificilmente podem ser considerados atraentes. Tal opção representa uma enorme alteração no alinhamento da orla hoje existente, podendo ser considerada por muitos como uma agressão paisagística.

Dutos Afogados: É no ganho paisagístico que estaria uma das maiores vantagens desta opção. Com o uso de dutos afogados, a praia poderia passar a ser contínua do Arpoador até o final do Leblon. Apesar do aspecto subjetivo, poucos discordariam do ganho paisagístico com uma praia única. Mesmo o pequeno trecho de canal hoje existente, que corta a praia, poderia ser suprimido dando continuidade efetiva ao novo arco praial.

Em termos de lazer pode-se considerar, por exemplo:

- Com os guias correntes seriam geradas ondas para surf.

- Os guias correntes também ofereceriam ótimos pontos de pesca.

- Por sua vez, os dutos afogados ampliam a faixa areia disponível ao lazer e não produziriam áreas 

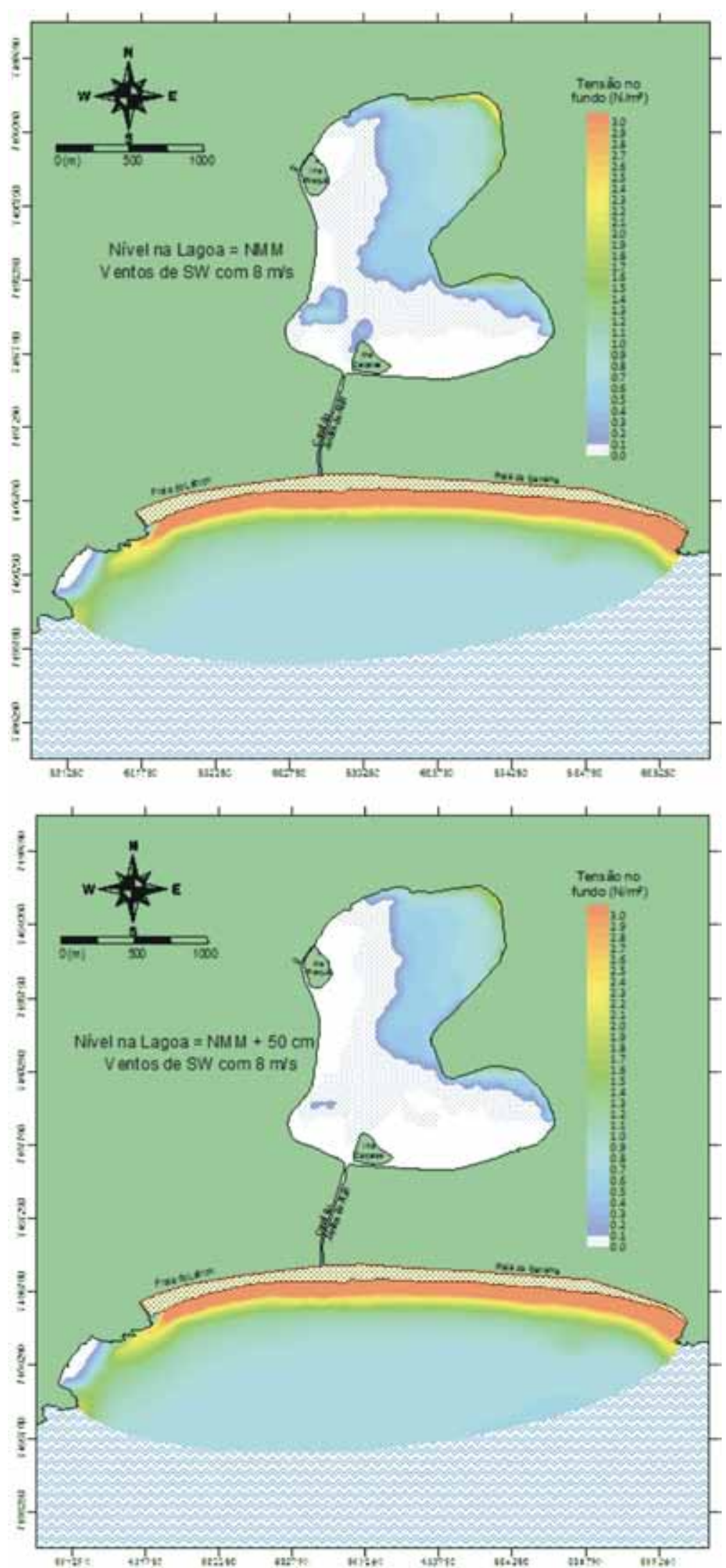

Figura 35. Exemplo do efeito de manter o nível médio da LRF 0,5m acima do NMM, na geração de tensões no fundo com capacidade de erodir e suspender lodo não consolidado. Para ressuspensão de lodos e lamas não consolidados é necessário uma tensão de pelo menos $0,1 \mathrm{~N} / \mathrm{m}^{2}$. Comparando os mapas, nota-se que o efeito de redução de tensões por elevação do NA é pouco relevante.

Figure 35. Example of the effect of keeping the mean water level in the LRF 0.5m above the MSL, in generating bottom stresses with capacity to erode and suspend unconsolidated mud. For erosion of unconsolidated mud it is necessary a bottom stress of at least $0.1 \mathrm{~N} / \mathrm{m}^{2}$. By comparing the maps, one sees that the effect of bottom stress reduction due to elevation of the water level is of little relevance. 
de risco, que certamente existiriam na vizinhança dos enrocamentos.

- Em ambos os casos, a natação no Canal do Jardim de Alah seria convidativa, e envolveria riscos inerentes à prática.

No dimensionamento do projeto básico desenvolvido pelo LNEC o CJA com guia-correntes permaneceria não navegável. No dimensionamento previsto no estudo da COPPE em 1992, o CJA seria navegável e poderia haver passagem de barcos entre o mar e a LRF. De fato, no estudo da
COPPE foi considerado que, se fosse para se pagar o preço paisagístico de dividir as praias, haveria de se propiciar ganhos muito compensatórios de outra natureza, provavelmente através de um projeto paisagístico arrojado. A LRF ligada ao mar via um canal navegável abriria opções muito interessantes. Porém, tal consideração não foi levada em conta no projeto básico do LNEC.

Convém destacar que a ligação por feixe de dutos não impede que, no futuro, se resolva ligar a LRF ao mar via canal navegável, em um arrojado

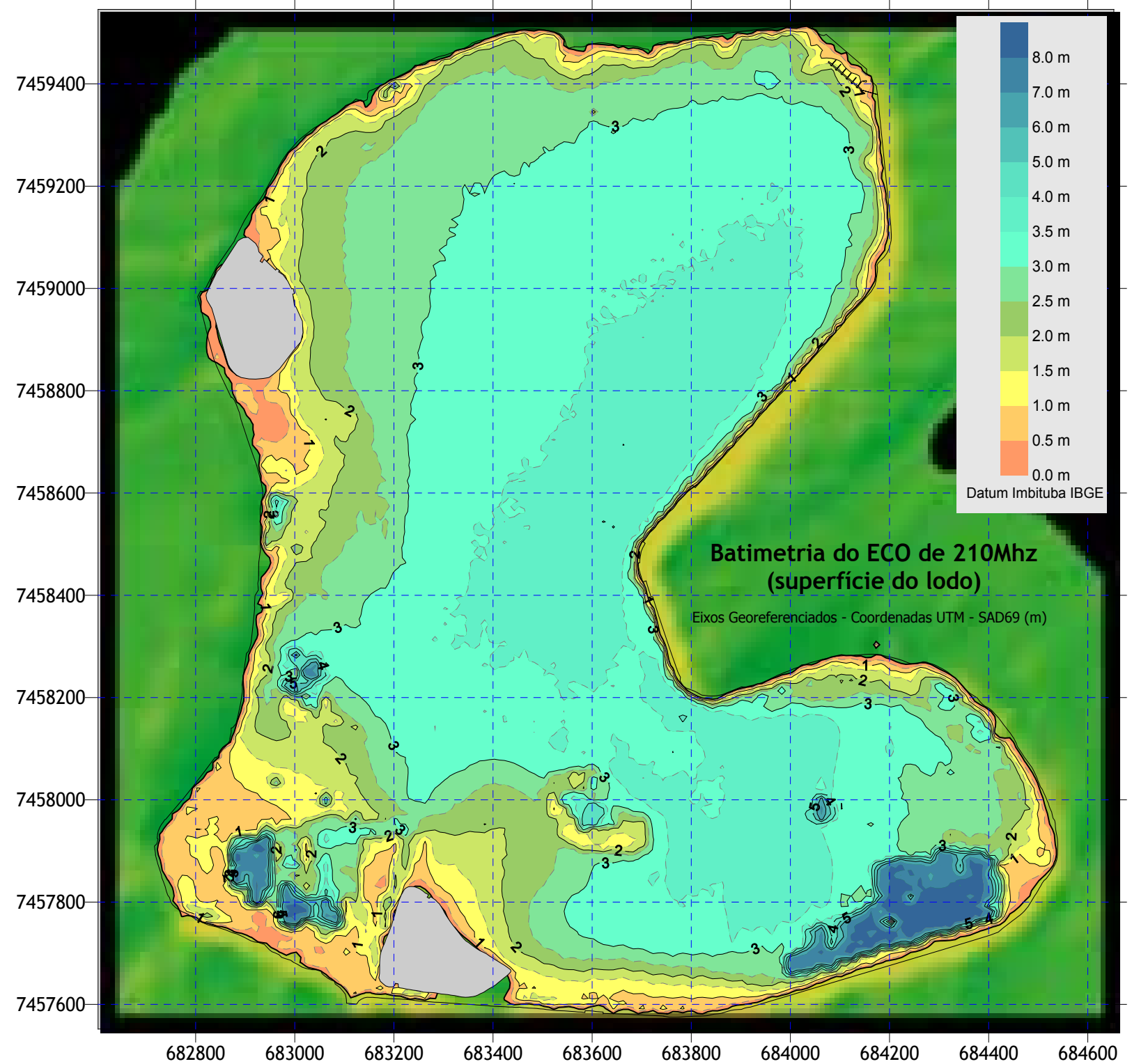

Figura 36. Batimetria da Lagoa Rodrigo de Freitas realizada em 2000 no âmbito do Projeto Coppetec PENO-467, para a Fundação Rio Águas da prefeitura do Rio de Janeiro. Como a batimetria foi feita com ecobatímetro de alta frequência, as cotas refletem o eco da superfície do lodo não consolidada no fundo. (Mapa produzido pelo autor).

Figure 36. Bathymetry of Rodrigo de Freitas lagoon surveyed in 2000 in the context of Project Coppetec PENO-467 for Rio-Aguas Foundation of the Rio de Janeiro City. Since this bathymetry was surveyed with a high frequency ecobathymeter, the levels reflect the top layer of the unconsolidated bottom mud. (Map produced by the author). 
projeto de paisagismo e lazer. Já com a opção de guia-correntes no dimensionamento do projeto do LNEC, as dificuldades seriam evidentes, pois seria necessário reposicionar pelo menos um dos lados do guia-correntes, o que não seria uma obra trivial.

\section{COMPORTAMENTO HIDRÁULICO}

No que segue, as cotas são referidas ao datum Imbituba - IBGE. O Nível Médio do Mar, NMM, tem cota $-0,18 \mathrm{~m}$. A seguir, o sinal ' $\sim$ ' antes de valores indica 'aproximadamente'.

- $\quad$ No caso da opção Guia-Correntes, conforme consta no Capítulo 2 do EIA-RIMA (Ambiental 2001), o Canal do Jardim de Alah, CJA, seria dragado para cota $-0,9 \mathrm{~m}$ na parte mais larga que tem $18 \mathrm{~m}$, e para $-1,50 \mathrm{~m}$ na parte mais estreita que chega a menos de $9 \mathrm{~m}$ sob a Avenida Vieira Souto. Desta forma, as áreas hidráulicas no CJA, em relação ao NMM, teriam valores de $\sim 13 \mathrm{~m}^{2}$.

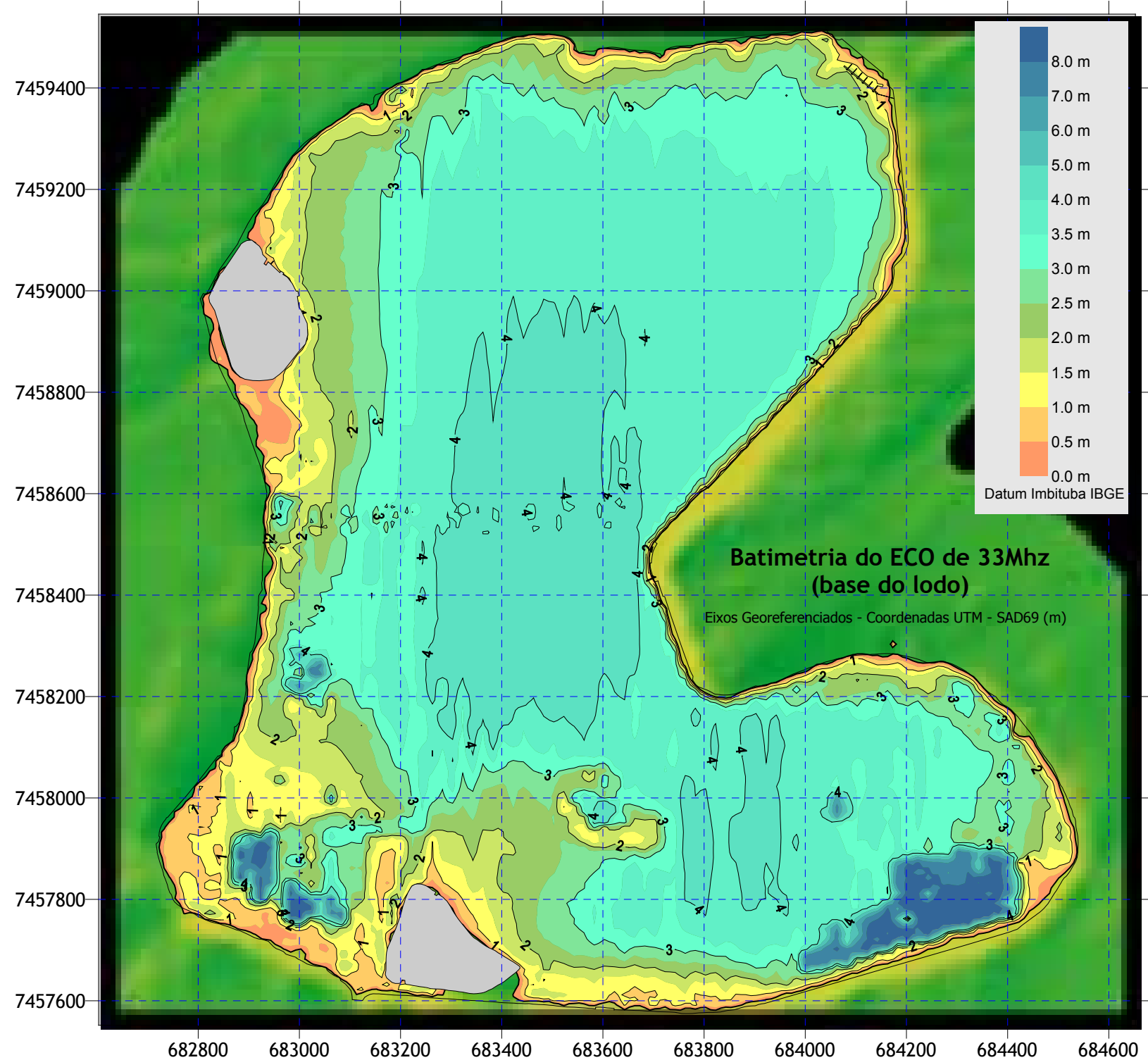

Figura 37. Batimetria da Lagoa Rodrigo de Freitas realizada em 2000 no âmbito do Projeto Coppetec PENO-467, para a Fundação Rio Águas da prefeitura do Rio de Janeiro. Neste mapa a batimetria foi feita com ecobatímetro de baixa frequência, que capta as cotas do eco que reflete na base do lodo não consolidado no fundo. A diferença entre as cotas deste mapa e as do anterior representam uma estimativa da espessura do lodo não consolidado existente em 2000 (Figura 38.) (Mapa produzido pelo autor).

Figure 37. Bathymetry of Rodrigo de Freitas lagoon surveyed in 2000 in the context of Project Coppetec PENO-467 for Rio-Águas Foundation of the Rio de Janeiro City. In this map, the bathymetry was surveyed with a low frequency ecobathymeter, therefore the levels reflect the lower layer of the unconsolidated bottom mud. The difference in the levels depicted in the former map and the above one represent the estimated thickness of the unconsolidated mud in 2000 (Figure 38). (Map produced by the author). 
- No caso da opção Dutos Afogados, a área hidráulica seria por volta de $\sim 21 \mathrm{~m}^{2}$ conforme discutido neste capítulo.

Nas duas opções, as oscilações de níveis de maré na LRF seriam visualmente iguais, com diferenças de poucos centímetros entre máximos e mínimos usuais. Efetivamente, diferenças de nível da ordem de 2 a $3 \mathrm{~cm}$ não seriam distinguíveis a olho. Entretanto, quando se multiplica tal diferença pela área de dois milhões e duzentos mil metros quadrados do espelho de água da LRF, as diferenças de volumes de água envolvidos são consideráveis, como se discute a seguir.

Como a seção hidráulica no CJA ligado por feixe de dutos seria maior, as amplitudes de maré seriam um pouco maiores. Por exemplo, para uma maré com variação de $\sim 1,0$ m entre preamar e baixamar, valor usual em condições de sizígia no mar em IpanemaLeblon, as respostas na LRF seriam:

- $\quad \mathrm{Na}$ opção de guia-correntes com o projeto do LNEC e seção hidráulica no CJA de $\sim 13 \mathrm{~m}^{2}$, as amplitudes de maré na LRF seriam de $\sim 0,04 \mathrm{~m}$, ex. as diferença de nível entre preamar e baixamar seriam de $\sim 0,08 \mathrm{~m}$. Isso propiciaria trocas de volumes de água de $\sim 355 \mathrm{mil} \mathrm{m}^{3} / \mathrm{dia}$, ou cerca da metade deste valor por ciclo de maré.

- $\quad \mathrm{Na}$ opção de dutos afogados com seção hidráulica no CJA de $\sim 21 \mathrm{~m}^{2}$, as amplitudes de maré na LRF seriam de $0,065 \mathrm{~m}$, ex. as diferenças de nível entre preamar e baixamar seriam de $\sim 0,13 \mathrm{~m}$. Isso propiciaria trocas de volumes de $\sim 600 \mathrm{mil} \mathrm{m}^{3} / \mathrm{dia}$, ou cerca da metade de tal valor por ciclo de maré.

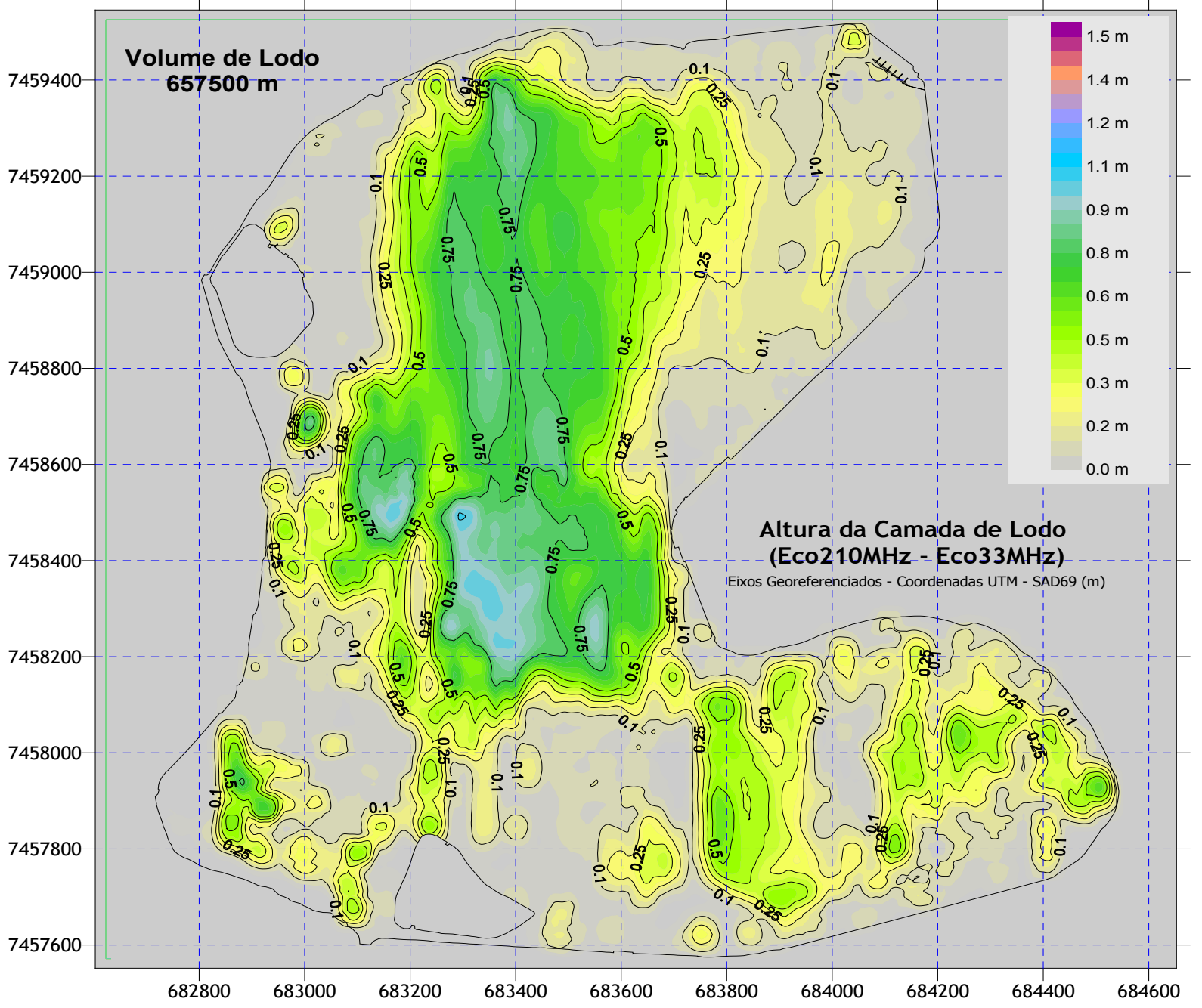

Figura 38. Estimativa da espessura do lodo não consolidado existente em 2000, resultando da diferença entre os ecos de baixa e alta frequencia (Figura 37 e Figura 36). Note que não há praticamente lodo nas regiões rasas, que são as marcadas em cor laranja nos mapas anteriores. Portanto, o material a ser dragado é principalmente composto por areia. (Mapa produzido pelo autor.)

Figure 38. Estimation of the thickness of the unconsolidated bottom mud layer in 2000, resulting from the difference in levels obtained from reflectance of low and high frequency ecobathymeters (Figure 37 and Figure 38). One can note that there is practically no mud in the shallow regions, that are the ones colored in orange in the former maps. Therefore, the material to be dredged is mainly composed of sand. (Map produced by the author.) 
- As variações de nível médio diário em resposta aos eventos meteorológicos, que alteram o nível médio do mar, seriam semelhantes em ambas as opções.

- Em ambos os casos, as correntes no CJA teriam velocidades médias próximas de $0,60 \mathrm{~m} / \mathrm{s}$ com valores máximos de até $1,2 \mathrm{~m} / \mathrm{s}$ nas marés de sizígia mais altas.

- As vazões médias no CJA seriam de $\sim 8,2 \mathrm{~m}^{3} / \mathrm{s}$ no caso do projeto do LNEC, e seriam de $\sim 13,8 \mathrm{~m}^{3} / \mathrm{s}$ no caso da ligação via feixe de dutos.

É evidente que com a ligação por dutos afogados e Canal do Jardim de Alah com seção de $\sim 21 \mathrm{~m}^{2}$ haveria maior renovação de águas na LRF.

\section{LIMPEZA E MANUTENÇÃO}

Pela concepção dos projetos, prevê-se que não seja necessário haver operações para manutenção da seção hidráulica útil no trecho de embocadura por guia-correntes ou por dutos afogados. Em ambos os casos, os projetos foram idealizados de modo a evitar a entrada de sedimentos e, consequentemente, impedir assoreamentos que acarretariam em diminuição da seção hidráulica útil. Em linhas gerais, isso é feito situando-se a embocadura no mar em profundidades superiores a $8 \mathrm{~m}$. Tal profundidade é definida como tendo um valor $150 \%$ maior que a altura de ondas de ressacas com tempo de recorrência superior a 10 anos. Tais profundidades são as requeridas para que haja pouca mobilidade de sedimentos por ação de ondas, ou seja, as embocaduras estariam fora da zona de processos litorâneos relevantes ${ }^{1}$. Ondas de ressacas na região de Ipanema Leblon raramente têm alturas acima de $3,0 \mathrm{~m}$. No projeto existente, a embocadura dos guia-correntes estaria a $8 \mathrm{~m}$ de profundidade média. O posicionamento da estrutura de embocadura dos dutos foi projetado a para local com cerca de $10 \mathrm{~m}$ de profundidade, o que garante pouca mobilidade de sedimentos.

No caso dos dutos afogados, convém destacar:

- Como esquematizado na Figura 39, as estruturas de embocadura são como terminações de cachimbo. Os dutos seguem enterrados até um local com cerca de $10 \mathrm{~m}$ de profundidade, onde são conectados, ainda enterrados, em uma parede vertical

${ }^{1}$ Para amplos detalhes técnicos, consulte o Coastal Engineering Manual, http://chl.erdc.usace.army.mil/cem (2012) de sua caixa de embocadura com o mar. As caixas têm cerca de $7 \mathrm{~m}$ de altura, sendo $4 \mathrm{~m}$ enterrados, onde os dutos são conectados, e $3 \mathrm{~m}$ acima do solo do mar. O fluxo de enchente e vazante das marés ocorre apenas pelo topo das caixas, as paredes verticais e o fundo são fechados. O projeto prevê grades de proteção no topo de cada caixa. As grades teriam espaçamento suficiente para permitir a fácil passagem de peixes, porém impediriam a passagem de pessoas, mesmo pequenas. Cada duto teria a sua própria caixa de embocadura independente. A seção hidráulica da entrada do fluxo no topo das caixas seria muito maior que a seção hidráulica dos dutos. Assim é projetado para que a velocidade das correntes seja baixa o suficiente para impedir que um eventual "aventureiro" fique colado à grade por efeito de sucção em condições de fluxo enchente.

- No interior dos dutos, bem como no canal do jardim de Alah, as velocidades seriam amplamente suficientes para impedir assoreamentos de areias ou sedimentos mais finos.

- De modo a evitar erosões no leito do canal, o projeto considera revestimento no fundo com uma camada com menos $15 \mathrm{~cm}$ de espessura de pequenas pedras com diâmetros de 2 a $3 \mathrm{~cm}$.

- As velocidades na lagoa são muito baixas para haver mobilização de sedimentos.

- Pode-se concluir que possibilidade de haver assoreamento nos dutos é muito baixa.

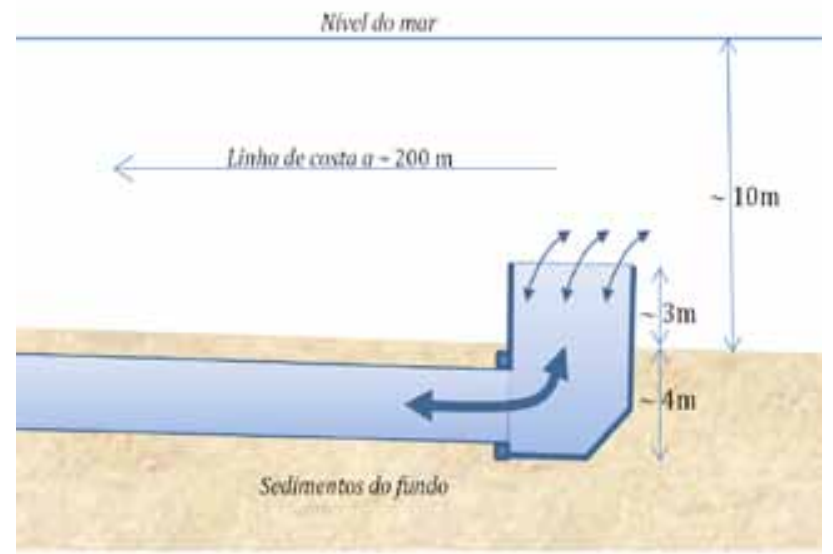

Figura 39. Esquema da caixa de embocadura dos dutos afogados no mar. Os fluxos de enchente e vazante ocorrem pela seção de topo da caixa, $3 \mathrm{~m}$ acima do fundo, evitando arraste de sedimentos.

Figure 39. Sketch of the inlet-outlet box for the drowned ducts in the sea. The flooding and ebbing fluxes occur through the top section of the box, $3 \mathrm{~m}$ above the sea floor to avoid sediment entrainment. 
Quanto a incrustações de mariscos, as perdas de carga associadas estão contabilizadas. Entretanto, outros tipos de manutenção e limpeza devem ser considerados, dentre os quais se destacam:

- No caso dos guia-correntes, por serem estruturas de enrocamento, certamente haverá necessidade de inspeção e eventual manutenção estrutural após episódios de fortes ressacas, pois é usual ocorrerem danos em estruturas de enrocamento em tais episódios. Basta lembrar o que já ocorreu algumas vezes no guia-correntes do canal da Joatinga e em outras estruturas de enrocamento ao longo da costa. Também servem de exemplo as usuais obras de manutenção em quebra-mares e molhes de proteção se zonas portuárias.

- No caso dos dutos afogados, por estarem enterrados e terem estrutura de saída a $10 \mathrm{~m}$ de profundidade não haveria danos em eventos de ressacas.

- Por serem estruturas com revestimento contendo grandes irregularidades, os guia-correntes de enrocamento acumulariam lixo flutuante, ou detritos trazidos pelos ventos nas areias, e serviriam de toca para ratos e outros animais. Portanto, haveria necessidade de limpeza permanente.

- No caso dos dutos afogados não haveria acúmulo de detritos e não se prevê necessidade de limpeza.

No caso excepcional de se julgar necessário inspecionar ou efetuar alguma operação no interior dos dutos afogados, seria necessário um tamponamento parcial do canal. O tamponamento poderia ser feito com colocação de blocos de concreto com alças para fácil posicionamento $\mathrm{e}$ retirada do canal, sem maiores dificuldades. Não haveria necessidade de tamponamento estanque, bastaria criar uma grande redução na seção hidráulica útil para diminuir a vazão e com isso ocorrer grande redução na velocidade das correntes nos dutos. Na eventualidade de tal necessidade, o cálculo hidráulico para definição do peso dos blocos de concreto para tamponamento parcial do CJA, bem como método de colocação e remoção, deverão ser criteriosos, para evitar represamentos com fortes correntes que possam causar erosões no canal ou tombamento de blocos.

\section{ESTABILIDADE MORFOLÓGICA DA PRAIA}

Neste quesito a alternativa dos guia-correntes seria positiva. Com os guia-correntes obtêm-se a divisão morfológica das praias de Ipanema e Leblon, o que contribuiria significativamente para aumentar a estabilidade das praias, especialmente para a praia do Leblon, como demonstrado em Rosman et al. (1992) e no projeto do LNEC de 2000, analisado no EIA-RIMA de tal projeto (Ambiental 2001). Porém, isso alteraria radicalmente o arco praial e a paisagem atual.

Por sua vez, com os dutos afogados o comportamento morfodinâmica permanecerá como o atual, já que a praia de Ipanema-Leblon já é morfologicamente contínua. Entretanto, deve ficar claro que, com o engordamento previsto tanto no estudo da COPPE, (Rosman et al.1992), quanto no projeto básico do LNEC de 2000 (Ambiental 2001), os problemas hoje existentes seriam sanados.

\section{TROCAS BIOLÓGICAS}

Como os fluxos de enchente e vazante entre a lagoa e o mar ocorreriam com correntes de intensidade similares nas duas opções, pode-se inferir que:

- Para larvas e plânctons, que são levados pelas correntes, é indiferente passar pela embocadura do canal entre guia-correntes ou por dutos afogados. $O$ fato da entrada dos dutos estar a cerca de sete metros de profundidade, não representaria prejuízo significativo.

- Intuitivamente, pode-se imaginar que entradas e saídas de peixes talvez fossem mais fáceis através da embocadura entre guia-correntes do que por dutos afogados. Porém, como peixes são atraídos para o interior da LRF por gradientes de constituintes da água, como sais e nutrientes, que seriam muito similares nas duas opções, é pouco provável que haja diferenças significativas.

- Convém destacar que os fluxos e correntes nos dutos seriam exclusivamente devido aos desníveis de maré, assim como ocorreria na embocadura por guia-correntes. Imaginar que peixes deixariam de transitar pelos dutos por ser escuro 
é semelhante a imaginar que peixes não passariam pelos guia-correntes à noite.

\section{CUSTOS E FACILIDADES CONSTRUTIVAS}

Neste caso, provavelmente, a opção via dutos afogados seria menos custosa, especialmente se levando em conta os custos indiretos de transtornos na cidade durante a fase construtiva. Para construção dos guia-correntes haveria um enorme tráfego de pesados caminhões com cargas de pedras e enormes blocos de concreto para a carapaça externa dos enrocamentos. Já para construção dos dutos afogados nada disso seria necessário. O canteiro de obras para construção dos dutos seria muito menor do que o necessário para construção dos guia-correntes.

\section{CONCLUSÕES E RECOMENDAÇÕES FINAIS}

As principais conclusões destes estudos de hidrodinâmica ambiental, para ligação da Lagoa Rodrigo de Freitas ao mar por dutos afogados, são que os objetivos propostos no início do artigo ficariam plenamente atendidos, a saber:

1. Garante-se plenas condições de renovação de águas permitindo resolver de modo definitivo os problemas de má qualidade de água, em função do excessivo estoque de nutrientes na LRF que se acumulam pelo fato do sistema atual não exportar em taxas suficientes os nutrientes que recebe. Como exposto, a LRF adquire boa capacidade de reequilibrar seus estoques de nutrientes em níveis adequados, pela enorme capacidade de exportação propiciada pela ligação permanente.

2. Ficam resolvidos os problemas de alagamentos marginais decorrentes de obstruções do canal do Jardim de Alah em épocas de fortes chuvas.

3. Cessam os gastos de manutenção da embocadura do Canal do Jardim de Alah devido ao contínuo processo de assoreamento e fica garantida a macrodrenagem da bacia da LRF. Recupera-se também a paisagem, pois acaba o estado de "canteiro de obras" que persiste há décadas na região da embocadura do Canal do Jardim de Alah.

4. Acabam os problemas atuais decorrentes da perda das características estuarinas em função da estagnação e uniformização das águas da LRF, acarretando em biodiversidade reduzida e má qualidade ambiental. A LRF interligada permanentemente ao mar voltaria a apresentar padrões de gradação de salinidade típicos de sistemas estuarinos, o que propiciaria significativo aumento de diversidade biológica. Nas condições vigentes o fundo da lagoa é anaeróbico e por isso, principalmente, contém bactérias anaeróbicas. Com a nova dinâmica, os fundos receberiam 2 vezes por dia entrada de águas saturadas de oxigênio do mar. Em questão de meses haveria uma mudança radical na fauna do fundo, que passaria a ter bons níveis de oxigênio dissolvido e deixaria de ser estéril.

Como recomendações finais destacam-se:

1. Necessidade de avaliar efeitos de erosão no Canal do Jardim de Alah, CJA, devido às correntes que passarão a existir. Pelas vazões previstas (Figura 15), pode-se estimar as velocidades médias máximas na calha sejam de até $1,2 \mathrm{~m} / \mathrm{s}$, presumindo que a área hidráulica mínima ao longo do canal em relação ao NMM, seria de $21,24 \mathrm{~m}^{2}$.

2. Há que se avaliar até que cota se poderia aprofundar os diferentes trechos do CJA sem por em risco os muros e pontes. Partindo do princípio que a seção mínima no canal deveria ser $21,24 \mathrm{~m}^{2}$ haverá necessidade de aprofundamento, especialmente no trecho entre a Av. Prudente de Moraes e o emboque nos dutos.

3. Uma vez aprofundado o CJA seu leito deve ser revestido com pedras tipo brita média, para criar um efeito de armadura de modo a evitar erosões. A seção mínima de $21,24 \mathrm{~m}^{2}$ deve ser medida acima deste revestimento.

\section{REFERÊNCIAS}

AMBIENTAL - Engenharia e Consultoria Ltda. 2001. EIARIMA pertinente ao projeto "Lagoa Rodrigo de Freitas e Praias de Leblon, Ipanema e Arpoador: Solução Integrada de Reabilitação Ambiental" desenvolvido pelo LNEC para Fundação Rio - Águas da Prefeitura da Cidade do Rio de Janeiro.

MACIEL, G.L.R. 2007. Análise de dados hidrodinâmicos e estratificação na lagoa Rodrigo de Freitas, RJ, relação com a concentração de oxigênio dissolvido. Dissertação de mestrado. Universidade Federal do Rio de Janeiro. Rio de Janeiro, RJ, Brasil. 78p. <http://www.oceanica.ufrj.br/intranet/modules/ PDdownloads/visit.php?cid=15\&lid=90>. $\quad$ (Acesso em 09/04/2012). 
MARTINS, R.P, \& ROSMAN, P.C.C. 1999. Modelo 3D para corpos de água com densidade variável via diferenças finitas. Pp 187-264. In: R.V. Silva (ed.). Métodos Numéricos em Recursos Hídricos IV, Associação Brasileira de Recursos Hídricos, <www. abrh.org.br>.

MORAES, A. 2007. Análise de alternativas hidrodinâmicas para o sistema lagunar da Baixada de Jacarepaguá. Dissertação de mestrado. Universidade Federal do Rio de Janeiro. Rio de Janeiro, RJ, Brasil. 146p. <http://www.oceanica.ufrj.br/intranet/modules/ pddownloads/viewcat.php?cid=15>. (Acesso em 09/04/2012).

NEVES, C.F.; MUEHE, D.E.; VALENTINI, E.M. \& ROSMAN, P.C.C. 2007. Estudo de vulnerabilidades no litoral do Estado do Rio de Janeiro devido às mudanças climáticas - Relatório Final. Relatório Técnico. Fundação Coppetec, ref. PENO-9501, <http:// www.coppetec.coppe.ufrj.br>. Estudo contratado pela Secretaria de Ambiente do Estado do Rio de Janeiro e coordenado por P.C.C. Rosman, 100 p.

ROSMAN, P.C.C. 1997. Subsídios para modelagem de sistemas estuarinos. Pp. 231-348. In: R.V. Silva (ed.). Métodos Numéricos em Recursos Hídricos III, Associação Brasileira de Recursos Hídricos, <www.abrh.org.br>.

ROSMAN, P.C.C. 2009. Estudos de hidrodinâmica ambiental para ligação da Lagoa Rodrigo de Freitas ao mar por dutos afogados, RJ. Relatório Técnico, Fundação Coppetec, ref. PENO11113, <http://www.coppetec.coppe.ufrj.br>. Estudo contratado pela empresa EBX e coordenado por P.C.C. Rosman. 70p.

ROSMAN, P.C.C. 2011. Referência Técnica do SisBaHiA ${ }^{\circledR}, 239$ p. <http://www.sisbahia.coppe.ufrj.br//SisBAHIA_RefTec_V85. pdf $>$. (Acesso em 09/04/2012).

ROSMAN, P.C.C., NEVES, C.F.\& MELLO, E.M. 1992. Solução Conjunta dos Problemas de Erosão na Praia de Ipanema - Leblon e Qualidade de Água na Lagoa Rodrigo de Freitas - Relatório Final. Relatório Técnico, Fundação Coppetec ET-170172. 353p.

ROSMAN, P.C.C.; NEVES, C.F.; MUEHE, D.C.E.H.; CARVALHO, J.L.B.; KLEIN, A.H.F. \& ARAUJO. M. 2009. Vulnerabilidades da zona costeira brasileira às mudanças climáticas. Relatório Técnico. Fundação Coppetec PENO-11896, $<$ http://www.coppetec.coppe.ufrj.br $>$. Estudo contratado pela Embaixada Britânica / Banco Mundial e coordenado por P.C.C. Rosman. 537p.

U.S. Army Corps of Engineers - CEM - Coastal Engineering Manual (2011), http://chl.erdc.usace.army.mil/cem 